\title{
WestVirginiaUniversity
}

THE RESEARCH REPOSITORY @ WVU

Graduate Theses, Dissertations, and Problem Reports

2002

\section{Appalachian diabetes patients' preferences for mental health treatment}

Sameep Dilip Maniar

West Virginia University

Follow this and additional works at: https://researchrepository.wvu.edu/etd

\section{Recommended Citation}

Maniar, Sameep Dilip, "Appalachian diabetes patients' preferences for mental health treatment" (2002). Graduate Theses, Dissertations, and Problem Reports. 1604.

https://researchrepository.wvu.edu/etd/1604

This Dissertation is protected by copyright and/or related rights. It has been brought to you by the The Research Repository @ WVU with permission from the rights-holder(s). You are free to use this Dissertation in any way that is permitted by the copyright and related rights legislation that applies to your use. For other uses you must obtain permission from the rights-holder(s) directly, unless additional rights are indicated by a Creative Commons license in the record and/ or on the work itself. This Dissertation has been accepted for inclusion in WVU Graduate Theses, Dissertations, and Problem Reports collection by an authorized administrator of The Research Repository @ WVU.

For more information, please contact researchrepository@mail.wvu.edu. 
Appalachian Diabetes Patients' Preferences for Mental Health Treatment

Sameep D. Maniar

\author{
Dissertation submitted to the \\ College of Human Resources and Education \\ at West Virginia University \\ in partial fulfillment of the requirements \\ for the degree of
}

Doctor of Philosophy
in
Counseling Psychology

Cynthia R. Kalodner, Ph.D., Chair

Frank M. Perna, Ed.D., Ph.D.

W. Guyton Hornsby, Jr., Ph.D.

Roy H. Tunick, Ed.D.

L. Sherilyn Cormier, Ph.D.

Geri A. Dino, Ph.D.

Department of Counseling, Rehabilitation Counseling, and Counseling Psychology

\author{
Morgantown, West Virginia \\ 2002
}

Keywords: Diabetes, Treatment Acceptability, Stigma of Psychologists Copyright 2002 Sameep D. Maniar 


\title{
ABSTRACT \\ Appalachian Diabetes Patients' Preferences for Mental Health Treatment
}

\author{
Sameep D. Maniar
}

\begin{abstract}
Although psychologists are beginning to be employed in medical settings, little is known about medical patients' preferences when encountering mental health problems. One population that could be better served by this type of research is diabetes mellitus because of the poor adherence rates and high depression associated with the disease. The current study aimed to identify diabetes patients' preferences for treatments and helpers when encountering emotional difficulties. Data were collected on 80 patients from an Appalachian region of the United States who had previously been diagnosed with either type 1 or type 2 diabetes. Results indicated that diabetes patients were less willing to seek out the help of psychological professionals as compared to medical professionals. Psychological professionals were also rated as less effective at treating emotional problems than medical professionals. Patients were willing to use a variety of treatments, but psychological treatments were rated as less effective than non-psychological treatments. Additionally, satisfaction regarding one's treatment, impact of diabetes, gender, and hope were related to willingness to use treatments and seek out the help of psychologists. Discussion focuses on the collaboration between medical and psychological professionals, message framing/making referrals, consumer education, and the need for treatment acceptability research in the area of health psychology.
\end{abstract}




\section{Dedication}

To all of my math and stats teachers/professors over the years.

None of this would have been possible without you. 


\section{Acknowledgements}

I would like to express my deepest appreciation to my chair and advisor, Dr. Cynthia Kalodner and committee members Dr. Frank Perna, Dr. Guy Hornsby, Dr. Roy Tunick, Dr. Sherry Cormier, and Dr. Geri Dino. Cyndee, thank you for your continued support, reading and revising draft after draft, and taking on a dissertation topic that was outside of your area of interest. None of this would have been possible without you. Frank, thank you for encouraging me to pursue the current research, helping me develop the study, and continuing to serve on the committee after leaving WVU. Guy, thank you for your expertise in the area of diabetes and helping me get the study going. Roy, thank you for your feedback with respect to design and validity, as well as your willingness to be a part of this committee. Sherry, thank you for all of your support and your willingness to take on a dissertation at the last moment. Thank you also for teaching me so much about counseling. Geri, listen up because it may be the last time you ever hear a compliment from me! Thank you for teaching me more about research, providing a fun environment to work, and being willing to serve on this committee.

I would also like to thank the doctors, nurses, diabetes educators, and staff at the WVU Physician Office Center and Family Medicine Clinics. Thank you for permitting me to use participants in your offices and for your assistance in collecting the current study's data.

Thank you to my family and Theresa for your love, support, and belief in me. I love you. And, thank you to Dr. Sam "Mitch" Zizzi for his assistance in jumping through the hoops. 


\section{TABLE OF CONTENTS}

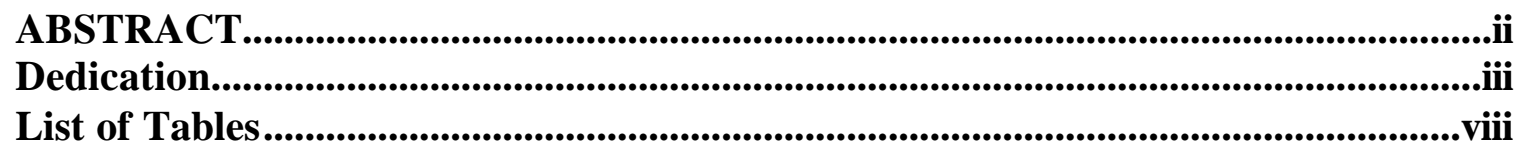

Chapter 1: Introduction ...................................................................................................................1

Barriers to Psychological and Medical Collaboration ...............................................

Perception of Psychologists ...................................................................................5

Utilization Rates of Mental Health Services ..............................................................

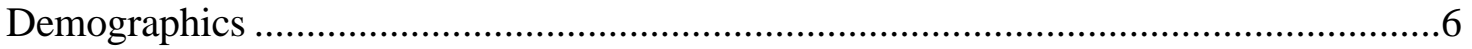

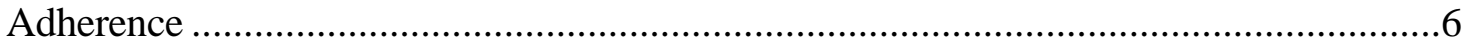

Treatment Acceptability .................................................................................... 7

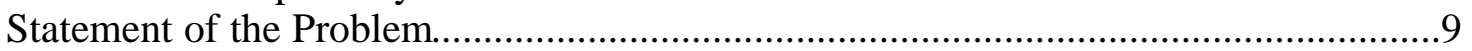

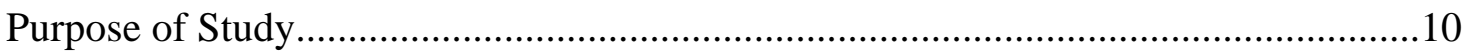

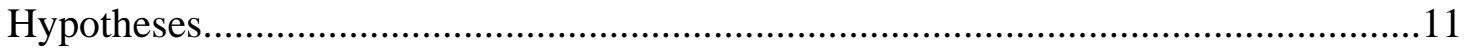

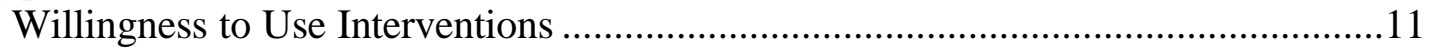

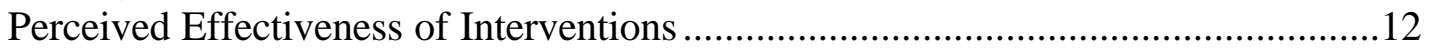

Willingness to Seek Help from Various Individuals ............................................ 12

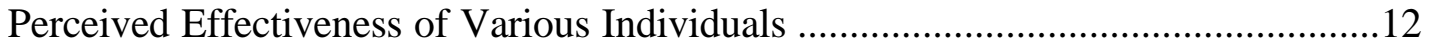

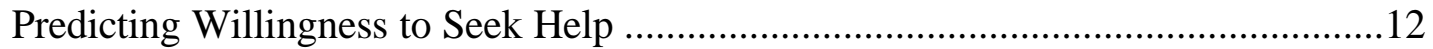

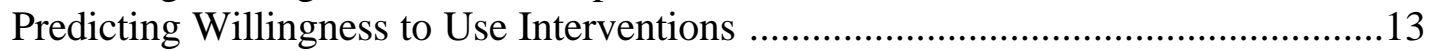

Gender Preferences for Seeking Help...............................................................13

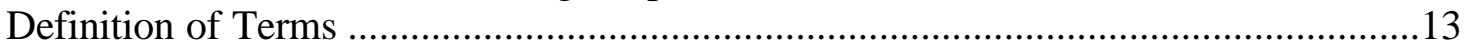

Chapter 2: Literature Review.......................................................................................................16

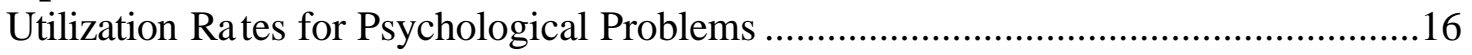

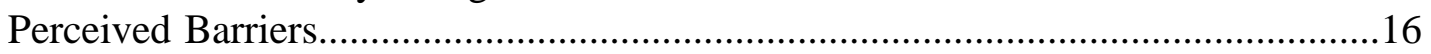

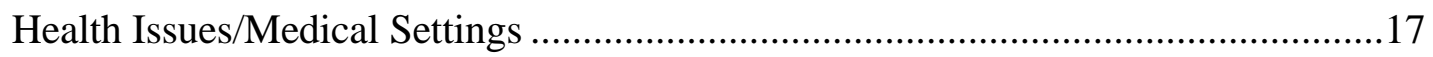

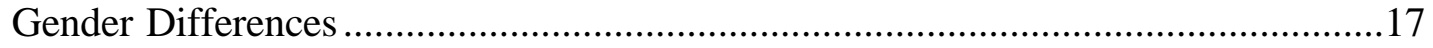

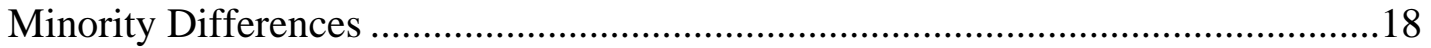

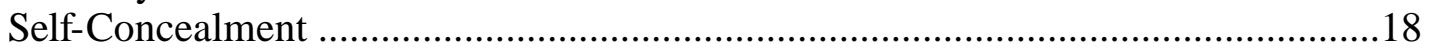

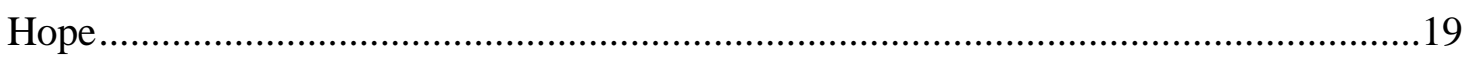

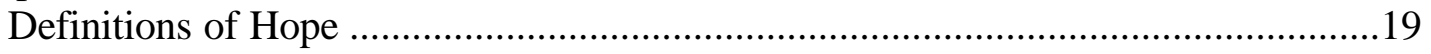

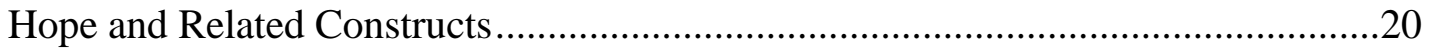

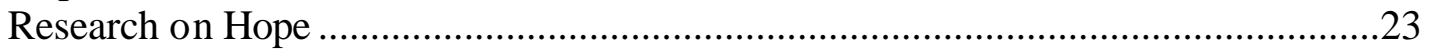

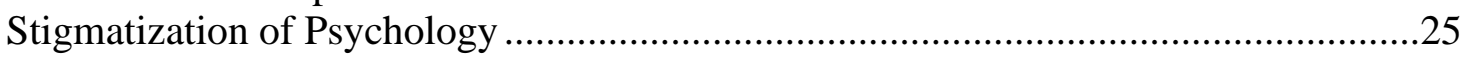

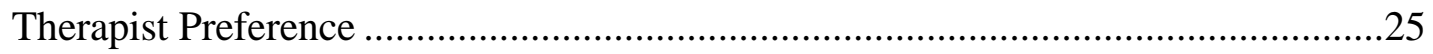

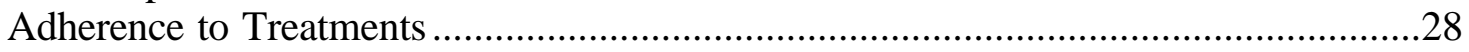

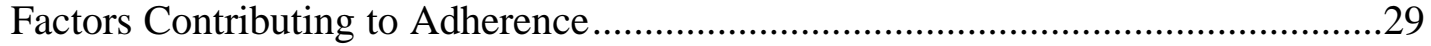

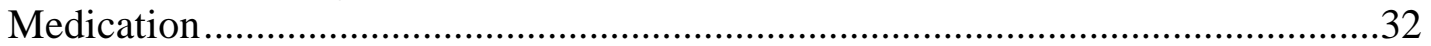

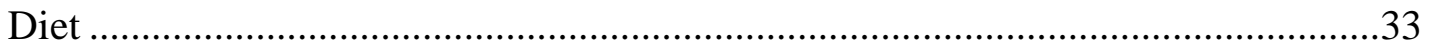

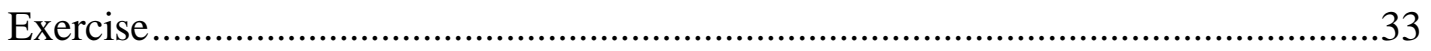

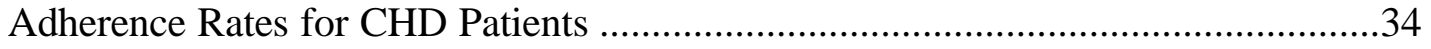

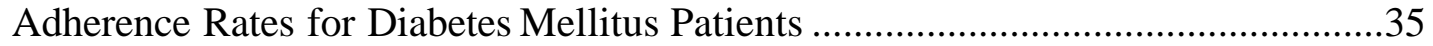

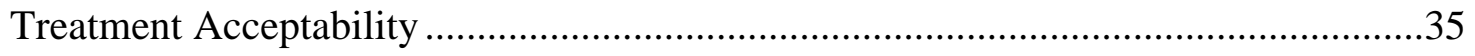




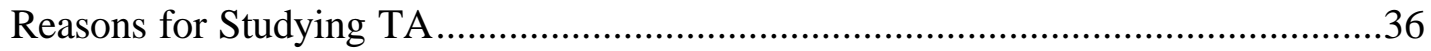

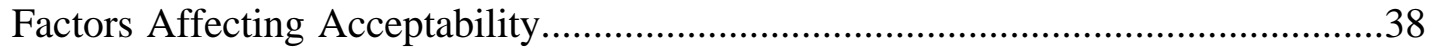

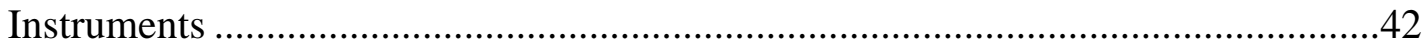

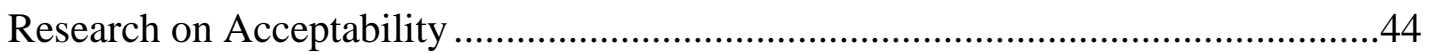

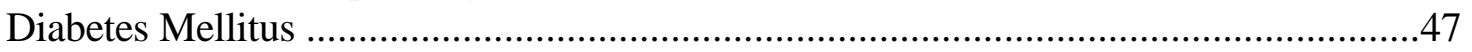

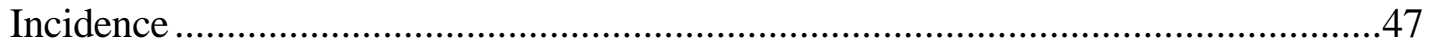

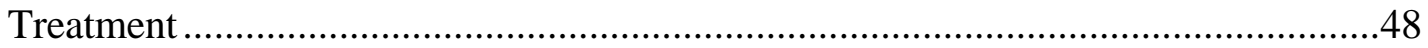

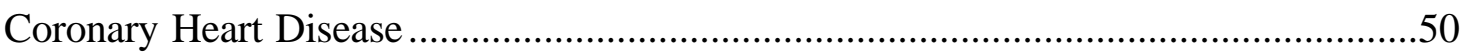

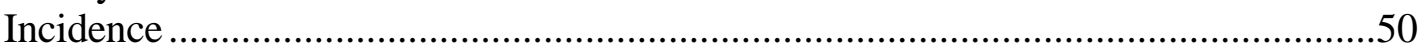

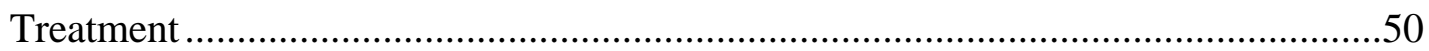

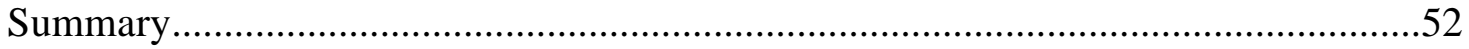

Chapter 3: Methods ...........................................................................................................................54

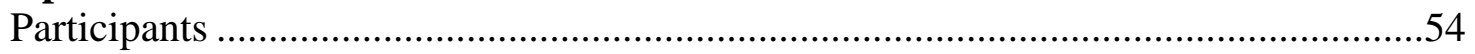

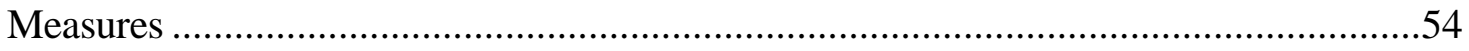

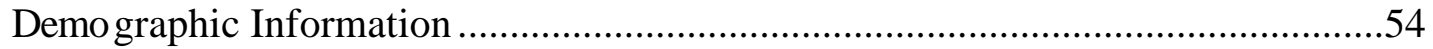

Health Preferences Questionnaire......................................................................54

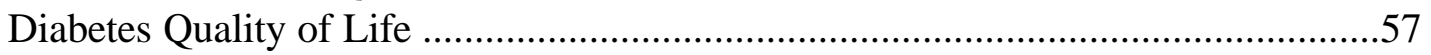

Dispositional Hope Scale ................................................................................6

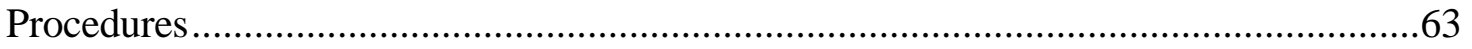

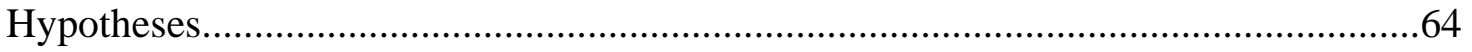

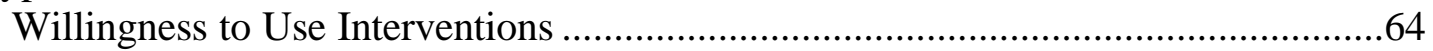

Perceived Effectiveness of Interventions ..................................................................64

Willingness to Seek Help from Various Individuals .................................................64

Perceived Effectiveness of Various Individuals ........................................................64

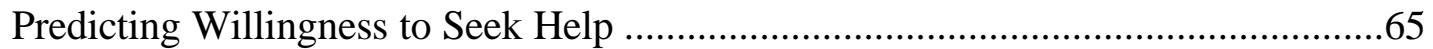

Predicting Willingness to Use Interventions ......................................................65

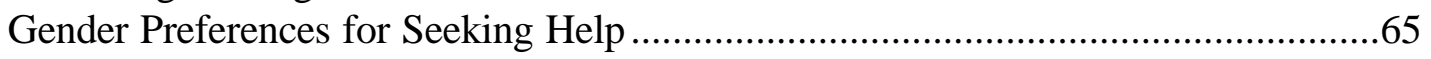

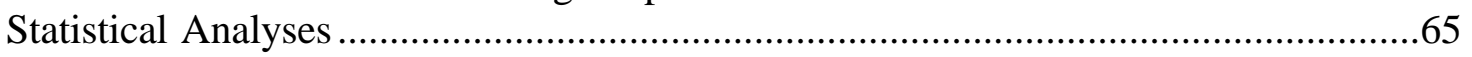

Chapter 4: Results ...........................................................................................................................69

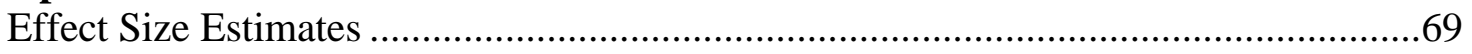

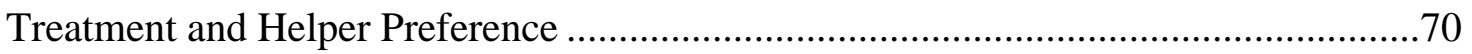

Willingness to Use Treatments ...............................................................................71

Perceived Effectiveness of Treatments..................................................................72

Willingness to Seek Help from Various Individuals .................................................74

Perceived Effectiveness of Various Individuals ........................................................77

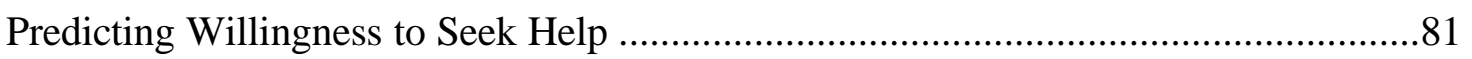

Willingness to Seek Help in General.....................................................................

Willingness to Seek Help from a Psychologist...........................................................84

Willingness to Use Interventions as a Function of Hope Pathways ...........................86

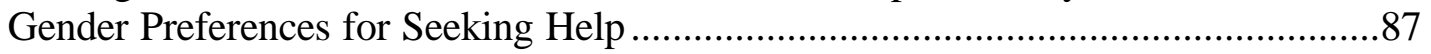

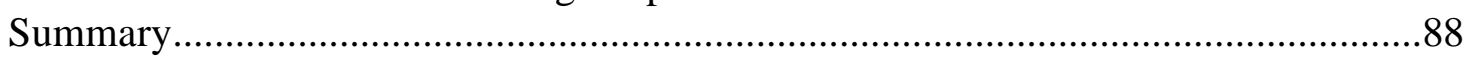

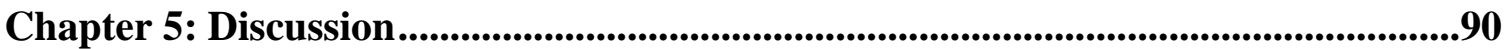

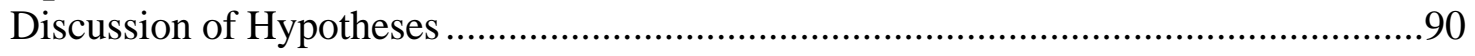




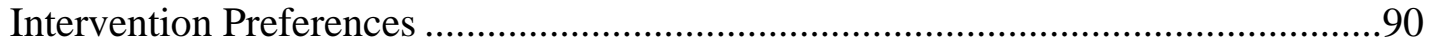

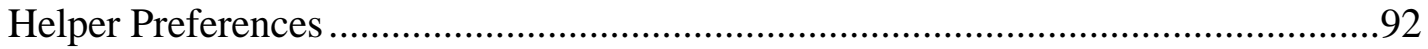

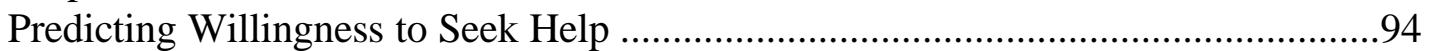

Predicting Willingness to Use Interventions ........................................................96

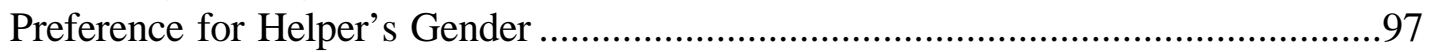

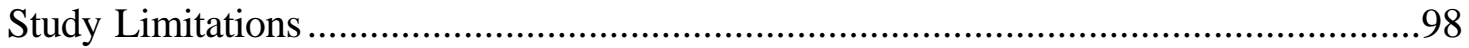

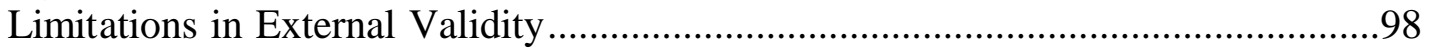

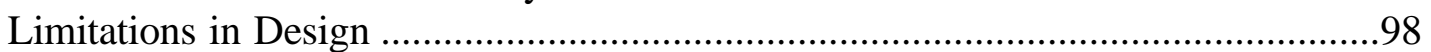

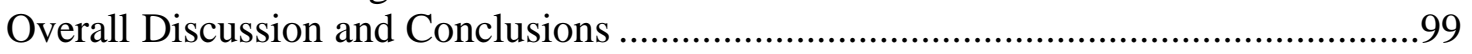

Collaboration between Medicine and Psychology ................................................99

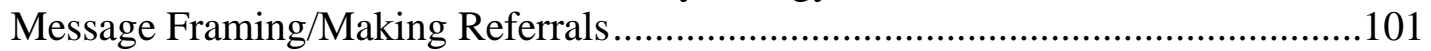

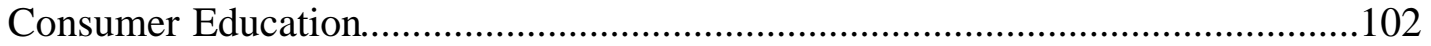

The Need for Additional Treatment Acceptability Research ...............................105

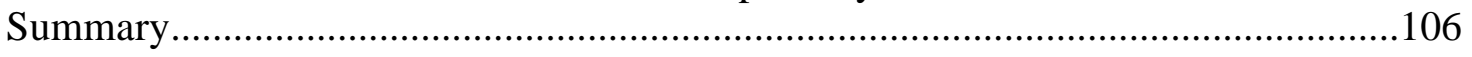

References.................................................................................................................................108

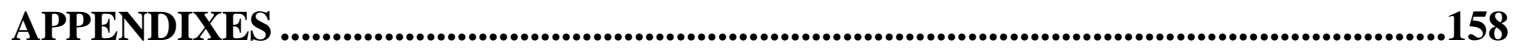

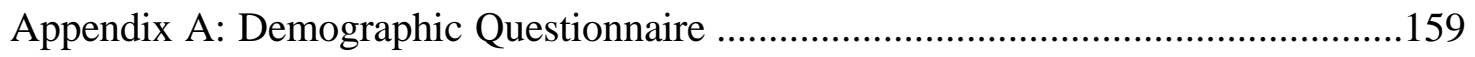

Appendix B: Health Preferences Questionnaire ...................................................161

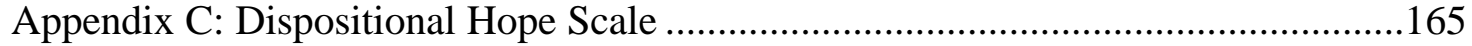

Appendix D: Diabetes Quality of Life Measure ......................................................167 


\section{List of Tables}

Table 3.1: Hypotheses, Measures Used, and Statistical Analyses Employed (p. 66)

Table 4.1: Diabetes Patients' Willingness to Use Treatments for Emotional Difficulties (p. 71)

Table 4.2: Diabetes Patients' Perceived Effectiveness of Treatments for Emotional Difficulties (p. 73)

Table 4.3: Diabetes Patients' Willingness to Seek Help from Various Individuals for Emotional Difficulties (listed from most willing to least willing) (p. 75)

Table 4.4: Mean Differences in Willingness to seek Help from Various Individuals as Compared to Psychologist (p. 76)

Table 4.5: Diabetes Patients' Mean Ratings of Perceived Effectiveness of Various Individuals for Emotional Difficulties (p. 78)

Table 4.6: Mean Differences in Males' Perceived Effectiveness of Various Individuals as Compared to Psychologist (p. 79)

Table 4.7: Mean Differences in Females' Perceived Effectiveness of Various Individuals as Compared to Psychologist (p. 80)

Table 4.8: Step-wise Regression Analysis Predicting Willingness to Seek Help in General After Accounting for Demographic Predictors (p. 83)

Table 4.9: Step-wise Regression Analysis Predicting Willingness to Seek Help from a Psychologist After Accounting for Demographic Variables (p. 85)

Table 4.10: Diabetes Patients' Willingness to Use Treatments for Emotional Difficulties as a Function of Hope Pathways (p. 87) 


\section{Chapter 1: Introduction}

As the field of psychology continues to grow into the $21^{\text {st }}$ century, psychologists are branching out to "nontraditional" settings at increasing rates. It is not uncommon to find psychologists working in business (e.g., Kilburg, 1996; Somerville, 1998), advertising (e.g., Webb, 1999), law (e.g., Ogloff, Tomkins, \& Bersoff, 1996; Tomkins \& Ogloff, 1990), and politics (e.g., Geake, 1995). In addition, the past two decades have seen psychology merge with other health/wellness disciplines-especially in the area of medicine. For example, opportunities now are available for psychologists in the areas of behavioral medicine, cardiology, pediatrics, neurology, surgery, oncology, spinal cord injury units, and genetic counseling (Allan \& Sheidt, 1996; Asken, 1979; Blanchard, 1982; Carpenter, 1989; Cummings, 1992; Dana \& May, 1986; Drotar, 1998; Gabinet \& Friedson, 1980; Masur, 1979; Meyer, DeMaso, \& Koocher, 1996; Sayette \& Mayne, 1990; Shiloh, 1996; Taylor, 1987; Tovian, 1991).

Psychologists are beginning to work in many sectors of health care, including day treatment programs, medical-surgical units, nursing homes, rehabilitation facilities, and comprehensive health maintenance organizations (HMOs) (Biaggio \& Bittner, 1990; DeLeon, 1991; Enright, Resnick, DeLeon, Sciara, \& Tanney, 1990; Enright, Resnick, Ludwigsen, \& DeLeon, 1993; Johnstone et al., 1995; Tulkin \& Frank, 1985; see also Wiggins, 1994). The use of a collaborative practice model between physicians and psychologists is becoming more common due to the combination of medical and psychosocial needs of many patients (Abraham et al., 1991; Biaggio \& Bittner, 1990; Bray \& Rogers, 1995; Doherty \& Baird, 1983; Dym \& Berman, 1986; Enright \& Blue, 1989; Glenn, 1985; Hepworth \& Jackson, 1985; Johnstone et al., 1995; McDaniel, 
Hepworth, \& Doherty, 1992; McDowell, Burgio, Dombrowski, Locher, \& Rodriguez, 1992; Natvig, 1991; Pion, 1991; Prindaville, Sidwell, \& Milner, 1983; Sargent, 1985).

Several reasons have been given for psychologists' shift into the medical setting. First, managed care has pressured psychologists out of private practice and into the public sector. Psychologists have been forced to supplement creatively their income or cease from practicing in the private sector because health insurance companies reimburse mental health treatments with less frequency (Enright et al., 1993). As Johnstone et al. (1995) stated, "The delivery and financing of health care in the United States has changed radically as the control and direction of health care services has moved from practitioners to those who pay for services" (p. 341; see also Frank \& VandenBos, 1994). Furthermore, in an American Psychological Association (APA) presidential address, Wiggins (1994) stated that mental health professionals must branch out to the public sector if psychology is to "survive as a discipline and preserve something to pass on to future generations" (p. 487).

Second, as Katon (1985) notes, more than half of primary care medical visits are due to psychological issues. In other words, many individuals are seeking help from medical personnel regarding psychological issues, such as depression and anxiety. Psychologists are realizing that "the vast majority of patients with mental health disorders are treated solely in the medical sector by non-psychiatrists, most of whom have inadequate training to deal with these problems" (Campbell, McDaniel, \& Seaburn, 1992, p. 196). Moreover, a study of 120 older adults (age 55 and above) who sought help for mental health problems over a two year span found that $101(84.2 \%)$ individuals only sought help from a doctor for their mental health problems, whereas 7 (5.8\%) sought help 
from a mental health clinic and $10(8.3 \%)$ went to both a doctor and a mental health clinic (Phillips \& Murrell, 1994).

Third, the 1990 California Supreme Court decision in the CAPP v. Rank (1989) lawsuit upheld a prior ruling that granted full participation on medical staffs for psychologists (see also Enright, Welch, Newman, \& Perry, 1990). Thus, in the state of California, psychologists may be substituted for psychiatrists for all hospital functions with the exception of prescription of medication. According to Enright and colleagues (1993), this decision along with the landmark Virginia Blues case (Resnick, 1985) supported the notion "that psychologists not only do not represent a "public health hazard' when practicing autonomously in hospitals but also that their presence actually enhances the overall quality of services available to hospital patients" (p. 139).

A fourth reason for the recent movement into the medical field is that psychologists have begun to understand the role psychological factors play in medical diseases. As a result, the fields of social psychology, clinical psychology, biopsychology, developmental psychology, and behavioral medicine have come together to form the field of health psychology (Baum, Gatchel, \& Krantz, 1997). In addition, individuals from other branches of psychology (e.g., counseling psychology) are beginning to work in the area of heath care and health psychology (Altmaier, Johnson, \& Paulsen, 1998; RothRoemer, Robinson Kurpius, \& Carmin, 1998). It has even been suggested that health psychology training models be adopted for counseling rather than clinical psychologists (Wallston, 1993). The APA has also recently recognized the area of clinical health psychology as a distinct field of psychology by approving it as a new specialty area. 
Collectively, health psychologists work from the biopsychosocial model (Engel, 1977) which views biological, psychological, and social factors as interrelated influences on health and illness. Thus, health psychologists take a holistic approach to the onset, course, and treatment of physical illness (e.g., AIDS, cancer, CHD, stroke) by involving all three levels of the biopsychosocial model (Engel, 1980).

\section{Barriers to Psychological and Medical Collaboration}

Although psychologists are beginning to understand the role psychological processes play in disease and illness, not all physicians accept psychologists in the medical setting. In some instances, certain barriers prevent psychologists from working with physicians. McDaniel (1995) identified several barriers to collaboration between physicians and psychologists such as differences in training, theoretical paradigms, language, and working styles, as well as potential turf battles. For example, collaboration may be difficult when the physician works from a traditional biomedical model and the psychologist subscribes to the biopsychosocial model. Likewise, psychologists who lack a basic understanding of medical terminology will have difficulty working along with medical professionals.

In addition, the literature suggests that other potential barriers are the lack of funding for psychological services in medical settings and physicians' stigmas of psychologists and psychology (Haley, Salzburg, \& Barrett, 1993). For example, Haley et al. (1993) found that physicians rated psychologists equal to psychiatrists in assessment of cognitive impairment, assessment of depression, assessment and treatment of substance abuse, and assessment and treatment of aggression; lower than psychiatrists in 
treatment of depression; and lower than nurses in assessment and treatment of noncompliance.

\section{Perception of Psychologists}

Nevertheless, little is known about the public's (i.e., potential clients') perception of psychologists in the medical setting, though it has been suggested that "many medical patients are very hesitant to approach a psychologist for any service" (McDaniel, 1995, p. 118). Thus, different health and wellness professionals may be viewed with varying degrees of skepticism and credibility. This proposed line of research would identify which professionals the public is willing to consult with regarding various illnesses and from whom they are unlikely to seek help. The identification of professions that are connoted negatively may help to identify markers of poor compliance.

\section{Utilization Rates of Mental Health Services}

Research has revealed, though, that when suffering from mental health difficulties, men tend to under-use mental health (Brinson \& Kottler, 1995; Gottesfeld, 1995; Gove, 1984; Greenley \& Mechanic, 1976; Kessler, 1981; Kessler, Brown, \& Broman, 1981; Marcus, Seeman, \& Telesky, 1984; Veroff, Kulka, \& Douran, 1981) and medical services (Leaf \& Bruce, 1987) as compared to women. Thus, the underutilization of mental health services by men may be due to a greater stigmatization of mental health providers and/or services.

The construct of hope, as defined by Snyder, Harris et al. (1991) may also be related to utilization rates and stigmas. Because hope, defined as a "positive motivational state that is based on an interactively derived sense of (a) agency (goaldirected energy), and (b) pathways (planning to meet goals)" (Snyder, Irving, \& Anderson, 1991, p. 287), 
has been hypothesized to be related to client/patient expectancies (Snyder, Michael, \& Cheavens, 1999), it may also prove to be related to individuals' utilization of and stigmas toward mental health services. In other words, if a client has a high level of hope, s/he should have high expectations for mental health services and thus be more willing to utilize such services as compared to an individual with low hope.

\section{Demographics}

Demographic factors, such as race, gender, living in a metropolitan area, age, and level of education, may also contribute to a higher likelihood to seek help. One might expect that individuals who are younger, have a higher degree of education, and are Caucasian would be more receptive and willing to seek out mental health services. Indeed, research has shown that Caucasians, as compared to minorities, are more likely to utilize mental health services (Barker \& Adelman, 1994; Brinson \& Kottler, 1995; Bruhn \& Fuentes, 1977; Gottesfeld, 1995; Lin, 1994; Solberg, Ritsma, Davis, Tata, \& Jolly, 1994; Tata \& Leong, 1994). Additionally, research has shown that women (Bland, Newman, \& Orn, 1997; Leong \& Zachar, 1999; Rickwood \& Braithwaite, 1994), individuals living in large cities (Rabinowitz, Gross, \& Feldman, 1999), younger individuals (Bland et al., 1997), and those with more education (Daly, Power, \& Gondolf, 2001; Ogborne \& DeWitt, 1999) are more likely to seek professional psychological help.

\section{Adherence}

According to Dunbar-Jacob, Burke, and Puczynski (1995), "Patients' failure to adhere to prescribed medical regimens may be one of the most serious problems in health care today" (p. 318). Because adherence is an important issue in medicine, psychology, and health psychology, several researchers have suggested ways to increase compliance. 
For example, Baum et al. (1997) have suggested that practitioners should assess any aspects of the regimen, personality and background of the patient and physician, doctorpatient interaction, comprehension, and disruptiveness that may lead to poor adherence. (Note: The terms adherence and compliance will be used interchangeably, as suggested by Baum et al. [1997], in order to ease the confusion level of the reader; also see "Definition of Terms.")

\section{Treatment Acceptability}

Another way to increase compliance is to assess how acceptable potential clients view potential treatments, or treatment acceptability (TA), and to select the one rated most favorably (O’Brien \& Karsh, 1990). Treatment acceptability, which is commonly defined as "judgments by laypersons, clients, and others of whether treatment procedures are appropriate, fair, and reasonable for the problem or client" (Kazdin, 1981, p. 493), has been shown to: (a) be inversely related to attrition (O'Brien \& Karsh, 1990), (b) directly affect treatment outcome and treatment satisfaction (Cross Calvert \& Johnston, 1990; see also Elliott, 1988; Reimers, Wacker, \& Koeppl, 1987), and (c) be a mediator of negative clinical outcomes, such as treatment termination, noncompliance, and lack of improvement" (Tarnowski \& Simonian, 1992, p. 101).

By selecting treatments based on clients' (positive) pretreatment expectancies, therapists can greatly increase the effectiveness of psychotherapy (Frank, 1978; Kirsch, 1985, 1990; Weinberger \& Eig, 1999). Shapiro (1981) claimed that the effects of psychotherapy could be completely accounted for by clients' pretreatment expectancies. Although this may be an exaggeration, Lambert, Shapiro, and Bergin (1986) claimed that approximately $15 \%$ of the variance in therapy outcome could be accounted for by a 
client's pre-treatment expectancies. Snyder et al. (1999) suggest that this expectancy is related to the client's level of hope.

In addition to medication and surgery, several health psychology interventions have been shown to be effective for a variety of populations, such as relaxation training, stress management, smoking cessation, weight management, and family education (Baum et al., 1997; Parker, 1995; Turk \& Salovey, 1995). Another cognitive-behavioral intervention, exercise prescription, is gaining more empirical support for both psychiatric populations, such as individuals with schizophrenia, depression, anxiety disorders, developmental disabilities, somatoform disorders, and substance abuse disorders (Bosscher, 1993; Craft \& Landers, 1998; Faulkner \& Sparkes, 1999; Hays, 1999; Tkachuk \& Martin, 1999), and chronic disease populations, such as coronary heart disease, hypertension, diabetes, respiratory disease, arthritis, and end-stage renal disease (Martin \& Dubbert, 1987; Minor, 1991; Powell, 1988; Williams, Stephans, McKnight, \& Dodd, 1991). However, no health psychology interve ntions have been evaluated in terms of their acceptability by patients.

Nevertheless, research has reported physicians' ratings of the acceptability of various psychological treatments (e.g., Burgio, Sinnott, Janowsky, \& Hohman, 1992; Haley et al., 1993). For example, Haley et al. (1993) examined physicians' ratings of six psychological services that could be offered to patients and found that neuropsychological testing was viewed as the most valuable service, followed by family therapy, evaluation of depression, individual therapy, group therapy, and personality testing. 
Little is known, however, about clients' perceptions of exercise prescription and/or other potentially efficacious health psychology interventions, such as smoking cessation, stress management, weight management, etc. Nevertheless, compliance rates for exercise programs are approximately 50\% for the first 3 to 6 months (Dishman, 1982, 1988, 1991, 1994; Martin \& Dubbert, 1987; Oldridge, 1982; Ward \& Morgan, 1984), which is similar to other forms of treatment. For example, $40 \%$ of patients comply with physicians’ prescriptions or advice (Becker, 1991; Haynes, Taylor, \& Sackett, 1979). Of clients taking medication for depression, almost one-third stop taking their medication in the first month of treatment and $42 \%$ stop in the first three months of treatment (Lin, Von Korff, Katon, \& Bush, 1995). Adherence rates may be low due to low TA. By determining the treatments that are viewed as acceptable (at a general or individual level), mental health practitioners may be able to predict which treatments will have the best adherence. And as with therapist preference research, TA studies may help identify individuals (e.g., high hope, gender, race, age, etc.) who are likely to comply with what treatments.

\section{Statement of the Problem}

Although some research has examined physicians' perceptions of psychologists and psychological treatments, little research has investigated how the patients themselves view psychologists and psychological interventions. Diabetes patients are of particular interest because of the high prevalence of depression and anxiety in this disease (Lustman, Griffith, Clouse, \& Cryer, 1986). This line of research would help professionals in medical settings target patient education programs. For example, with education, patients may stigmatize psychologists less and be more willing to seek them 
out for services. In fact, several studies have shown that consumer education increases treatment compliance (Kazdin, 1980a; Mudford, 1987; Singh \& Katz, 1985). Dunbar and Agras (1980) found that a lack of knowledge about one's treatment program was a major factor accounting for treatment noncompliance. (For a review of consumer education guidelines for health care professionals, see Meichenbaum \& Turk, 1987.)

Additionally, little research has studied patients' perceptions of various treatments for their illness or disease. When several effective interventions are available for the practitioner, this line of research may help practitioners select a form of treatment that would result in higher compliance rates and identify areas that could be targeted to increase TA.

The majority of related research has focused on the acceptability of treatments rather than a client's willingness to utilize a treatment. Although these constructs may be similar, an individual may still view a treatment as acceptable for someone else and be unwilling to use it or incorporate it into their own life.

Finally, few researchers have investigated the types of clients who will be most and least likely to seek help. Again, obtaining this information would help identify individuals who could be targeted for consumer education programs.

\section{Purpose of Study}

The purpose of this study is to determine: (a) what factors predict an individual's willingness to seek help for emotional issues centered around diabetes, (b) diabetes patients' perceptions of a variety of potential consultants, specifically psychologists, and (c) what health psychology treatments are viewed as most acceptable. Little research has been conducted in this area. According to Brewer, Jeffers, Petitpas, and Van Raalte 
(1994), this type of research is important because psychological interventions can be potentially viewed with skepticism. Not only will the present research potentially provide some initial information as to which interventions patients view as most acceptable, but it may also reveal specific interventions that are viewed negatively by patients.

This information is essential for two reasons. First, if poor adherence rates are not recognized, practitioners will be unable to make reasoned decisions regarding the efficacy of treatment for a given patient (Dunbar-Jacob et al., 1995). Second, only treatments that are viewed as credible and acceptable are likely to be used (see Baum et al., 1997; Ievleva \& Orlick, 1991). Thus, unacceptable treatments will be less likely to be used, resulting in poor adherence and poor outcomes.

The results will also indicate what type of professionals patients are willing to consult with regarding psychological difficulties, as well as potentially reveal any stigmas that patients hold toward certain job titles or professions. This information is crucial because it may show what areas should be addressed with regard to consumer education. In fact, research has shown that education can increase clients' ratings of acceptability and adherence (e.g., Foxx, Bremer, Schultz, Valdez, \& Johndrow, 1996; Jensen, 1997; Jensen, Kennerley, LeJeune-Hall, \& Bacon, 1992; Kazdin, 1980a; Mudford, 1987; Singh \& Katz, 1985; Tingstrom, 1989).

\section{Hypotheses}

In the current study, several hypotheses will be examined.

\section{Willingness to Use Interventions}

First, psychological interventions (counseling, relaxation training, support group) will be rated lower with respect to willingness (i.e., less willing to use) than non- 
psychological interventions (dietary changes, exercise, medication). Second, female participants will rate all interventions higher for willingness to use than male participants. Perceived Effectiveness of Interventions

Third, psychological interventions will be rated lower with respect to perceived effectiveness than non-psychological interventions. Fourth, female participants will rate all interventions higher for perceived effectiveness than male participants. Willingness to Seek Help from Various Individuals

Fifth, psychologists will be rated lower (i.e., less willing to seek out their help) than individuals affiliated with the medical field. Sixth, women will rate all individuals higher than men.

\section{Perceived Effectiveness of Various Individuals}

Seventh, psychologists will be rated lower (i.e., less effective) than individuals affiliated with the medical field. Eighth, women will rate all individuals higher than men. Predicting Willingness to Seek Help

Ninth, several variables (age, gender, mental health experience, hope [pathways], hope [agency], Diabetes Quality of Life Measure [DQOL; Impact], DQOL [Satisfaction]) will predict willingness to seek help, in general. Tenth, the same variables will predict willingness to seek help from a psychologist. In other words, for hypotheses nine and ten, younger participants, females, those with prior mental health experience, individuals with higher pathways hope, individuals with higher agency hope, those who have been highly impacted by their diabetes, and those who are less satisfied with their diabetes will be more likely to seek out help. 


\section{Predicting Willingness to Use Interventions}

Eleventh, participants with high hope pathways scores will be more willing to use all treatments than participants with low pathways scores.

\section{Gender Preferences for Seeking Help}

Twelfth, the majority of participants will prefer to seek out male medical professionals, as compared to female medical professionals, regardless of the participant's gender. Thirteenth, regardless of the participant's gender, participants will prefer to seek out help from a female mental health professional, as compared to male mental health professionals.

\section{Definition of Terms}

Adherence: "the act or quality of doing what one is told or asked to do" (Baum et al., 1997, p. 478). Usually refers to "voluntary action on the part of the patient" and is often used interchangeably with term compliance (p. 249).

Agency: "A cognitive sense of energy for the goal or goals that a person envisions" (Snyder, 1994, p. 535).

Angina (pectoris): "the recurrent chest pain associated with insufficient amounts of oxygen reaching the heart muscle (i.e., ischemia)" (Smith \& Nicassio, 1995, p. 21).

Compliance [with medical regimens]: "willingness or ability to follow recommended treatment" (Baum et al., 1997, p. 480). Usually implies "following the advice or instructions of a health care professional" and is often used interchangeably with term adherence (p. 249). 
Coronary Heart Disease: the incidence of angina pectoris, myocardial infarction, and/or sudden cardiac death, which reflect the underlying condition of coronary artery disease.

Diabetes Mellitus (DM): an endocrine disorder characterized by inadequate pancreatic insulin production and/or insulin ineffectiveness (Pohl, Gonder-Frederick, \& Cox, 1984), which results in hyperglycemia, or abnormally elevated blood glucose (BG) (Aikens \& Wagner, 1998). DM occurs in two major patterns: type 1 (insulin-dependent) and type 2 (non-insulin-dependent).

Exercise Prescription/Exercise Therapy: the recommendation and monitoring of an exercise program to a client made by a physician or mental health professional, usually used in conjunction with another form of "traditional" treatment (e.g., medication, counseling, etc.).

Health Behaviors: "behaviors related to health as in health impairing behaviors or those that improve health" (Baum et al., 1997, p. 482).

Hope: "positive motivational state that is based on an interactively derived sense of (a) agency (goal-directed energy), and (b) pathways (planning to meet goals)" (Snyder, Irving, \& Anderson, 1991, p. 287).

Illness Behaviors: "behaviors that characterize people that are ill" (Baum et al., 1997, p. 482).

Myocardial Infarction: "the actual death of a portion of heart muscle (i.e., myocardium) following prolonged ischemia" (Smith \& Nicassio, 1995, p. 21). Also known as "heart attack." 
Pathways: "A cognitive sense of being able to generate routes to an envisioned goal or goals" (Snyder, 1994, p. 535).

Self-concealment: conceptualized by Kelly and Achter (1995) as "a predisposition to hide distressing and potentially embarrassing personal information" (Cepeda-Benito \& Short, 1998).

Sudden cardiac death: "typically results from a catastrophic disorganization in the rhythm of heart muscle contractions, specifically, ventricular fibrillation" (Smith \& Nicassio, 1995, p. 21).

Therapist (Helper) Preference: a client's preference for an individual to seek help from. Treatment Acceptability: "Judgments by laypersons, clients, and others of whether treatment procedures are appropriate, fair, and reasonable for the problem or client" (Kazdin, 1981, p. 493).

Willingness: Openness to seek help or participate in a specific intervention.

Note: The therapist/helper titles are deliberately left undefined, as the intent is to investigate participants' preconceived perceptions of mental health professionals and the effects of job title. In the present study, the job/helper titles will be: behavioral medicine specialist, counselor, diabetes educator, exercise physiologist, friend/family, health psychologist, minister/pastor, nutritionist, pharmacist, physician/doctor, psychiatrist, and psychologist. 


\section{Chapter 2: Literature Review}

In the following chapter, the public's under-utilization of psychological services and two related issues, hope and the stigmatization of psychology, are discussed. Poor adherence rates for medical and psychological treatment and one potential manner to increase adherence, treatment acceptability, are the n discussed. Finally, two chronic disease populations related to the proposed study are described with regard to incidence and rates of nonadherence to treatments.

\section{Utilization Rates for Psychological Problems}

For years, researchers have attempted to determine reasons for the public's underuse of psychological services (e.g., Deane \& Todd, 1996; Farberman, 1997; McGuire \& Borowy, 1979; Murtsein \& Fontaine, 1993; Reinhold, 1973; Segal, Weiss, \& Sokol, 1965; Stewart, 1996; Webb \& Speer, 1985, 1986; Wood, Jones, \& Benjamin, 1986). Results indicate that unfavorable perceptions of psychotherapy and fears of mental health services are associated with avoidance of psychological services (Leaf \& Bruce, 1987) and unwillingness to seek help (Deane \& Chamberlain, 1994; Deane \& Todd, 1996). Research has also indicated the influence of perceived barriers, health status, gender, minority status, and self-concealment on utilization of mental health services.

\section{Perceived Barriers}

Ironically, previous research indicates that as the need for mental health counseling increases, the amount of perceived barriers to seeking mental health services increases (Lord-Flynn, 1989; Stefl \& Prosperi, 1985). Specifically, Lord-Flynn (1989) found that as the normatively-based need for mental health counseling increased, so did the following perceived barriers: (a) availability, (b) affordability, (c) accessibility, and 
(d) stigma. Moreover, the positive correlation between need and perceived barriers remained after controlling for gender, age, rural versus urban residence, residential distance from a mental health center, education level, frequency of religious practice, annual income, and marital status.

Health Issues/Medical Settings

Little research has investigated predictors of help-seeking in medical settings. Nevertheless, Phillips and Murrell (1994) used a discriminant analysis to differentiate between 120 older adults (55+) who sought mental health help and a comparison group of 120 adults who did not seek help. Results indicated that help-seekers were characterized by: (a) poorer pre-morbid psychological well-being, (b) reporting more physical health problems, (c) reporting a higher level of unpleasant stressful events, and (d) perceiving greater deficits in the amount of social support available to them when needed.

Additionally, 111 of the 120 help-seekers sought mental health services from a medical doctor, and 17 sought help from community mental health centers or clinics. (There was some overlap, due to 10 individuals who received services from both physicians and mental health providers.) Thus, it appears that individuals are more likely to seek assistance for mental health difficulties from medical professionals rather than mental health professionals.

Gender Differences

Studies have found that men are less likely to use mental health services than women (Bland, Newman, \& Orn, 1997; Brinson \& Kottler, 1995; Gottesfeld, 1995; Gove, 1984; Greenley \& Mechanic, 1976; Kessler, 1981; Kessler, Brown, \& Broman, 1981; Leong \& Zachar, 1999; Marcus, Seeman, \& Telesky, 1984; Rickwood \& 
Braithwaite, 1994; Veroff, Kulka, \& Douran, 1981). Women suffering from mental or emotional problems are also more likely to seek help from the general medical sector than men (Leaf \& Bruce, 1987). Moreover, women may be more willing to talk in depth about their problems (Maniar, Curry, Sommers-Flanagan, \& Walsh, 2001). This line of research suggests that men may be more skeptical of psychology, less willing to discuss their emotions, or a combination of the two.

\section{Minority Differences}

Studies have also found that minorities, in general, are less likely to use mental health services than Caucasians (Brinson \& Kottler, 1995; Bruhn \& Fuentes, 1977; Gottesfeld, 1995; Lin, 1994; Solberg, Ritsma, Davis, Tata, \& Jolly, 1994; Tata \& Leong, 1994). However, additional factors may impact help-seeking behavior of minorities. For example, studies have found that Asian-American students' attitudes toward seeking professional help may be influenced by gender, acculturation, social-network orientation, individuation, and previous counseling experience (Gim, Atkinson, \& Whiteley, 1990; Solberg et al., 1994; Tata \& Leong, 1994). In addition, due to historical conflicts with the majority culture, Native American clients may fear or mistrust mental health professionals (Dukepoo, 1980).

\section{Self-Concealment}

The construct of self-concealment, or "the tendency to actively avoid disclosing potentially embarrassing information” (Cepeda-Benito \& Short, 1998, p. 62), may also be related to seeking professional help (Kelly \& Achter, 1995; Cepeda-Benito \& Short, 1998). For example, Cepeda-Benito and Short's (1998) survey of 732 undergraduate 
students found that self-concealment was not only positively associated with distress but also with avoidance of psychological treatment.

The construct of hope may also be related to an individual's willingness to seek help for psychological difficulties.

\section{Hope}

Over the past three decades, three definitions of hope have emerged. These three definitions of hope, as well as implications of hope and how hope differs from other related constructs, are described below.

\section{Definitions of Hope}

Stotland (1969) hypothesized that the core of hope was "an exception greater than zero of achieving a goal" (p. 2). In other words, Stotland believed that hope indicated one's perceived probability of attaining a goal. Moreover, he assumed that in order for hope to be operative, an individual must attribute some minimal level of importance to his or her goal (Snyder, 1995). Once the minimum level of goal importance is achieved, hopefulness is the necessary cognition that is the impetus for action to occur.

Averill, Catlin, and Chon (1990) viewed hope as an emotion governed by cognitive rules. Specifically, when a goal is considered to be important, under some degree of control, has a moderate probability of attainment, and is morally and socially acceptable, hope is appropriate. Averill and colleague's definition of hope was derived from survey research assessing the manner in which people define hope. Although this theory has ecological validity, it is difficult to measure (Snyder, 1995).

Snyder, Harris, and colleagues (1991) built upon Stotland's (1969) belief that hope reflects an expectation of goal attainment. However, Snyder, Harris et al. suggested 
that hope is comprised of two separable, additive cognitive components: agency and pathways. According to Snyder, Harris et al., agency "refers to a sense of successful determination of meeting goals in the past, present, and future," whereas pathways refer to "a sense of being able to generate successful plans to meet goals" (p. 570). Simply put, hope can be defined as "goal-directed determination" (agency) and "planning of ways to meet goals" (pathways) (Snyder, 1994, p. 536).

The present study will use Snyder, Harris, and colleagues' (1991) definition of hope, and from this point forward, unless otherwise stated, "hope" will refer to the construct of hope as defined by Snyder, Harris et al.

\section{Hope and Related Constructs}

Hope can easily be confused with other related constructs, such as optimism. For this reason, the section below describes the similarities and differences between hope and other related constructs.

Optimism. The construct of optimism, or a generalized expectancy that good things will occur (Scheier \& Carver, 1985), has many similarities to hope. First, because both optimism and hope focus on general expectancies, their greatest applicability is to general, ongoing, novel, or multiply-determined behavior (Snyder, Irving, \& Anderson, 1991). On the other hand, neither optimism nor hope has much applicability in explaining behavior involving specific outcome expectancies. Second, hope and optimism are considered stable, dispositional traits (Snyder, Irving, \& Anderson, 1991). (It should be noted, however, that Snyder and colleagues [1996] did develop a state hope scale.) Third, both hope and optimism were suggested in an effort to better understand individual differences in goaldirected behavior (Snyder, Irving, \& Anderson, 1991). 
On the other hand, hope and optimism differ in their explanation of how expectancies predict goal-directed behavior (Snyder, Irving, \& Anderson, 1991). Scheier and Carver (1985) argued that outcome expectancies are the most significant predictors of goaldirected behavior and place little importance on how outcome expectancies are derived. In other words, an optimistic individual's anticipation of success could be based solely on an expectation and have little or no basis in reality. However, hope examines the process between an efficacy expectancy and an outcome expectancy (Snyder, Irving, \& Anderson, 1991).

Self-efficacy. Similar to hope and optimism, Bandura's theory of self-efficacy (1977, 1982, 1986) distinguishes between efficacy and outcome expectancies in an attempt to understand goaldirected behavior. Bandura defines outcome expectancies as beliefs that a specific behavior will produce a specific outcome and efficacy expectancies as the degrees of confidence that one possesses in his or her ability to perform a given behavior that will lead to some desired outcome (Snyder, Irving, \& Anderson, 1991). Unlike hope and optimism, though, self-efficacy theory argues that expectancies based on personal efficacy are the most significant predictors of behavior. Moreover, self-efficacy is situation-specific, whereas hope and optimism can operate at various levels of specificity (Snyder, Irving, \& Anderson, 1991). However, Scheier and Carver (1987) argue that by relying on efficacy rather than outcome expectancy, outcomes that are based on forces beyond an individual's control (e.g., luck, religious faith, etc.) are completely ignored.

Helplessness. Revised attributional models of helplessness also use expectancies to explain behavior (Abramson, Seligman, \& Teasdale, 1978; Miller \& Norman, 1979; 
Roth, 1980; Weiner \& Litman-Adizes, 1980). According to Abramson et al. (1978), the decision to engage in behavior is affected by outcome expectancies which are effected by attributions for good and bad outcomes. In helplessness theory, outcome expectancies are defined in terms of three attributional dimensions: locus of control, stability, and generality (Snyder, Irving, \& Anderson, 1991). Moreover, although attributional models of helplessness rely on outcome expectancies, previous researchers rarely measure or discuss them (Scheier \& Carver, 1987).

Resourcefulness. Rosenbaum (1980) developed an individual differences measure of resourcefulness in order to assess "tendencies to apply self-control methods to the solution of behavioral problems" (Rosenbaum, \& Palmon, 1984, p. 246). Specifically, Rosenbaum's Self-Control Schedule (1980) measures four areas related to an individual's self-regulatory skills: (a) belief in ability to self-regulate cognition and feelings, (b) use of cognition to cope with emotional and physical responses, (c) delaying immediate gratification, and (d) application of problem-solving strategies. Although Rosenbaum and colleagues have not conceptualized helplessness in terms of expectancies, their comments regarding problem-solving and coping strategies is similar to outcome expectancies, and one's belief in his or her ability to self-regulate cognition and feelings is similar to efficacy expectancy (Snyder, Irving, \& Anderson, 1991). However, resourcefulness theory tends to place importance outcome over efficacy expectancies, and resourcefulness includes concepts other than those related to goal-directed behavior (e.g., delayed gratification). Moreover, Rosenbaum and colleagues fail to explain how the components of resourcefulness relate to motivational state. 


\section{Research on Hope}

The construct of hope has been studied in various contexts, such as therapy, expectancies, health-relevant outcomes, and cancer.

Hope and psychotherapy. Research has shown that better therapy outcomes can be predicted for therapists who have hope both in what they must offer to a client in order to initiate change and in their client's ability to change (Snyder, Michael, \& Cheavens, 1999). Specifically, better outcomes can be achieved by therapists who foster the processes of agency and pathways thinking through motivation to help the client, providing a means to do so, and sharing a common goal of improved psychological functioning (Snyder et al., 1999). Additionally, therapists have been advised to monitor their level of stress and potential for burnout (see Pines, 1982; Pines \& Aronson, 1988) in an attempt to avoid projecting their own feelings of hopelessness onto clients (Snyder, 1994).

Hope and expectancies. Expectancy theory, sugge sts that client adherence and improvement is due, in at least some extent, to pre-treatment expectancies of the efficacy and utility of therapy (see Kirsch, 1985, 1990, 1999; Lambert, Shapiro, \& Bergin, 1986; Shapiro, 1981). According to Frank (1973, 1978, 1982), four factors in psychotherapy help to mobilize hope: (a) an emotionally-charged confiding relationship, (b) a healing setting, (c) a rationale (or myth) that explains the client's difficulties and offers a reasonable solution, and (d) a believable treatment for restoring health. Snyder et al. (1999) suggested that expectancies of improvement and effectiveness of particular therapeutic approaches are similar to agency and pathways thinking. 
Hope and health-relevant outcomes. Hope's relationship to health-relevant outcomes has been studied on a number of levels, such as health symptom reporting, objective health status, problem-solving, and the appraisal process related to hope level and goal setting (Snyder, Irving, \& Anderson, 1991). First, many stud ies have reported that the lack or loss of hope is related to the onset of disease (Schmale, 1958), fatal illness (Green, Young, \& Swisher, 1956; Kubler-Ross, 1969; LeShan, 1961), suicide (Beck, Steer, Kovacs, \& Garrison, 1985; Farber, 1968), and depression (Beck, Rush, Shaw, \& Emery, 1979). Moreover, Anderson (1988) found that hope, as measured by the Hope Scale (Snyder, Harris et al., 1991), explained variance in mental illness that could not be explained by life stress, optimism, or locus of control. Second, research has shown that hope plays a facilitative role in objective mental health (Erickson, Post, \& Paige, 1975; Gottschalk, 1974), and it has been suggested that hope plays a role in objective physical health (Snyder, Irving \& Anderson, 1991). Third, individuals with higher hope perceive themselves as being better at problem-solving than individuals with low hope (Gibb, 1990). Fourth, Anderson (1988) found that individuals with high hope, as measured by the Hope Scale, were more likely to view goals in positive and challenging terms as compared to individuals with low levels of hope.

Hope and cancer. Cancer is perceived to be a "hopeless" disease (Snyder, Irving, \& Anderson, 1991). Although research on cancer has focused predominantly on emotional strategies, it has been suggested that hope may also play a crucial role in predicting cancer patients' health and mortality (Snyder, Irving, \& Anderson, 1991). Hope may also play a role in other chronic diseases, such as diabetes. 
Another reason for the under-use of mental health services may be the public's stigmatization of psychology.

\section{Stigmatization of Psychology}

One influence on the public's help-seeking behavior is the stigmatization of psychology and psychologists. In an effort to better understand public perceptions of therapists, researchers have examined clients' perceptions of and preferences for therapists as well as physicians' perceptions of mental health professionals.

\section{Therapist Preference}

Researchers have investigated the effects of several therapist variables on client perceptions of and preferences for therapists and therapy, including the following: attire of therapist (Gass, 1984); fee charged (Bloom, Schroeder, \& Babineau, 1981; Brigham \& Brigham, 1985; Schneider \& Watkins, 1990; Trautt \& Bloom, 1982; Wong, 1994); gender of therapist (Campbell \& Johnson, 1991; Furnham \& Wardley, 1990; Greenberg \& Zeldow, 1980; Wong, 1994); marital status of therapist (Campbell \& Johnson, 1991), office décor (Bloom, Weigel, \& Trautt, 1977), physical attractiveness of therapist (Cash, Begley, McCown, \& Weise, 1975); seating arrangement (Gass, 1984); theoretical orientation/treatment modality (Schneider \& Watkins, 1990; Wong, 1994), and title of therapist (Bass, 1986; Farberman, 1997; Maniar, 2000; Maniar et al., 2001; Maniar, Perna, Newcomer, Roh, \& Stilger, 1999; McGuire \& Borowy, 1979; Murstein \& Fontaine, 1993; Trautt \& Bloom, 1982; Van Raalte, Brewer, Linder, \& DeLange, 1990; Van Raalte, Brewer, Matheson, \& Brewer, 1996; Warner \& Bradley, 1991; Webb \& Speer, 1985, 1986; Wollersheim \& Walsh, 1993). 
Research aimed at evaluating participants' perceptions of various therapists has resulted in two main findings. First, counselors are generally rated more favorably than are psychologists (Murstein \& Fontaine, 1993; Trautt \& Bloom, 1982; Warner \& Bradley, 1991; Wollersheim \& Walsh, 1993). For example, Warner and Bradley (1991) found that undergraduates rated counselors as "more aptly described by the words helpful, caring, friendly, a good listener than were psychologists (p. 140). One explanation for the less favorable views for psychologists is that the public may have less favorable views (i.e., stigmatize) professionals with the "psych" prefix (Maniar et al., 2001; McGuire \& Borowy, 1979). This stigma may be due to society's lack of information about the education, training, and role of psychologists (McGuire \& Borowy, 1979; Warner \& Bradley, 1991; Wollersheim \& Walsh, 1993), or the reluctance may be attributable to the "shrink" connotations associated with the "psych" prefix (Linder, Brewer, Van Raalte, \& DeLange, 1991; Maniar et al., 2001).

In addition to stigmatizing mental health professionals, it also appears that the public minimizes the expertise of psychologists. For example, Janda and England (1998) found that the general public and college faculty members rated the fields of psychology and sociology as making less important contributions to society than natural sciences, such as biology, chemistry, medicine, and physics and that psychologists and sociologists have less expertise in general than individuals in the natural sciences.

The relationship of client variables to therapist preference has also been investigated. First, ethnicity and acculturation of the prospective client may influence what type of therapist they prefer (Kenney, 1994; Ruelas, Atkinson, \& Ramos-Sanchez, 
1998). Specifically, ethnic background and adherence to cultural norms and behaviors predict perceptions of therapist expertise and trustworthiness (Ruelas et al., 1998).

Second, research suggests that the gender of the prospective client may also be related to therapist preference (Greenberg \& Zeldow, 1980). For example, Greenberg and Zeldow (1980) found that females tended to prefer therapists who fit the "masculine stereotypic sex-role (i.e., more confident, controlled, dominating, enduring, orderly, autonomous, and aggressive)," whereas males tended to prefer therapists fitting the "feminine stereotypic sex-role (i.e., more labile, nurturant, affiliatory, changeable, succorant, abasing, and deferent" (p. 474). Nevertheless, whether these differences exist twenty years after Greenberg and Zeldow's study remains to be seen. Indeed, subsequent studies have found mixed results. Pikus and Heavey (1996) found that female clients preferred female therapists, while male clients had no preference, while Stamler, Christiansen, Staley, and Macagno-Shang (1991) found that the gender of the intake counselor tended to impact client's preferences for the gender of their therapist. Additionally, research in the medical field seems to indicate that patients prefer samegender physicians for some health problems but not for others (Delgado et al., 1999).

Third, researchers have also investigated client variables that are related to preference for mental health versus medical professionals (e.g., Zeldow \& Greenberg, 1980). Specifically, Zeldow and Greenberg (1980) found that regardless of gender, liberal college students willingly sought mental health services, stayed in therapy longer, and had few negative attitudes toward physicians in general, whereas conservative college students endorsed positive attitudes toward seeking help from psychologists but were less 
likely to visit a therapist for psychological problems and more likely to seek out the services of a physician for medical problems.

For those individuals who do seek help, adherence to medical and psychological regimens may be one of the largest barriers to improved outcome.

\section{Adherence to Treatments}

Poor adherence to medical and therapeutic regimens contributes to significant costs. For example, $11 \%$ of hospitalizations for the elderly are attributed to noncompliance (Nanada, Fanale, \& Kronholm, 1990), and 10\% of all hospital admissions are due to failure to take prescription medications correctly (American Heart Association [AHA], 1999a). Research also shows that approximately one-third of hospital admissions for insulin-dependent diabetes are due to poor compliance (Fishbein, 1985). Similar statistics have been found for mentally ill patients. For example, the rehospitalization rates for schizophrenics are $27 \%$ for compliant and $73 \%$ for noncompliant patients (Pietzcker, 1985).

On average, $40 \%$ of patients fail to adhere reasonably close to medical treatment regimens (DiMatteo, 1985), and as many as $80 \%$ of patients do not follow their treatment regimen in order to achieve therapeutic benefit (Dunbar-Jacob, Burke, \& Puczynski, 1995). For chronic disease populations, poor adherence to health care regimens contributes to significant cost and mortality (Dunbar-Jacob et al., 1995). Cost-benefit analyses have shown that improving adherence rates are more cost-efficient than the needless re-hospitalizations that result from treatment nonadherence (Stason \& Weinstein, 1977). Moreover, poor adherence may lead to treatment-resistant organisms, which in turn, may lead death (Bloom \& Murray, 1992). 
Research suggests that poor adherence may be more likely among individuals on long-term and more complex treatment regimens (Cluss \& Epstein, 1985; Goodall \& Halford, 1991; Sackett \& Snow, 1979). With respect to DM patients, poor adherence is associated with depression and anxiety, maladaptive personality traits, and poor coping skills (Delameter, Kurtz, Bubb, White, \& Santiago, 1987; Lustman, Frank, \& McGill, 1991).

Likewise, clients who deem a treatment as unacceptable may be less likely to comply with the intended treatment (Kazdin, 1981; O'Brien \& Karsh, 1990). Thus, it is important to assess clients' acceptability for all effective treatments prior to treatment. Then, when possible, therapists can implement the intervention(s) rated as most acceptable by the client. Presumably, those interventions rated the most acceptable will have the highest likelihood of adherence and improved outcome.

\section{Factors Contributing to Adherence}

Dunbar-Jacob et al. (1995) have suggested that three factors influence adherence: patient characteristics, regimen characteristics, and provider and practice characteristics. A fourth factor, treatment acceptability, is also discussed in the subsequent section.

Patient characteristics. Six patient characteristics have been found to affect adherence: (a) whether the patient understands the regimen (i.e., what to do) (e.g., Boyd, Covington, Stanaszck, \& Coussons, 1974; Joyce, Capla, Mason, Reynolds, \& Matthews, 1969); (b) past adherence rates (Desharnais, Bouillon, \& Godin, 1986; Dunbar, 1990; Sherbourne, Hays, Ordway, DiMatteo, \& Kravitz, 1992); (c) self-efficacy expectations (Dersharnais et al., 1986; Ewart, 1989); (d) barriers to implementation of the regimen (Robertson \& Keller, 1992); (e) social support (Bastone \& Kerns, 1995; Belgrave \& 
Lewis, 1994; Duncan \& McAuley, 1993; Schoenberg, 1998); (f) satisfaction with medical care (Nagy \& Wolfe, 1984); and (g) avoidance coping (Sherbourne et al., 1992).

Three additional patient characteristics may influence adherence. First, according to a study by Carney, Freedland, Eisen, Rich, and Jaffe (1995), depression may be one factor that influences medication adherence for coronary artery disease patients. Specifically, Carney et al. (1995) found that non-depressed patients adhered to their regimen at significantly higher rates $(69 \%)$ than depressed patients $(45 \%), p<.02$. Nevertheless, it should be noted that both $69 \%$ and $45 \%$ adherence rates are less than ideal.

Second, the patient's expectancies regarding the treatment, or the degree to which he believes the treatment will be effective, may affect adherence (Kirsch, 1985, 1990, 1999). In other words, the more a patient perceives a treatment to be effective, the more likely he will be to adhere to it.

Third, closely-related to the concept of expectancy is the construct of treatment acceptability (TA), or the degree to which the patient views the treatment as acceptable. Research has shown that clients who deem a treatment as unacceptable may be less likely to comply with intended treatment (Kazdin, 1981; O’Brien \& Karsh, 1990). For a review of TA, please see below.

Regimen characteristics. Four characteristics of a regimen have been found to affect adherence: (a) complexity (Haynes, 1976; O’Brien \& Karsh, 1990), (b) daily frequency (i.e., number of times per day) (Dunbar-Jacob et al., 1995), (c) number of regimens (e.g., medication and exercise rather than medication alone) (Dunbar-Jacob et al., 1995), and (d) duration (Jacobson et al., 1987; Parrish, 1986; Varni \& Babani, 1986). 
Provider and practice characteristics. Initial studies examining the impact of physician characteristics and patient adherence identified positive physician communication skills and attitudes toward the patient (Davis, 1978; Korsch \& Negrete, 1972) and minimization of waiting time (Badgley \& Furnal, 1961; Bierenbaum, Green, Florin, Fleischman, \& Caldwell, 1967) as significant predictors of adherence. Subsequent studies have discovered additional physician attributes and practice styles that influence patients' adherence to treatment. For example, DiMatteo et al. (1993) examined predictors of general adherence and adherence to medication, exercise, and diet recommendations for diabetes, hypertension, and heart disease patients. Results indicated that physician job satisfaction (general), number of patients seen per week (medication), scheduling a follow-up appointment (medication), tendency to answer patients' questions (exercise), number of tests ordered (diet), seriousness of illness (diet), physician specialty (medication, diet), and patient health distress (medication, exercise) predicted patient adherence at two years.

Research has also indicated that the manner in which the prescription is framed may affect adherence to health behaviors (Banks et al., 1995; Block \& Keller, 1995; Detweiler, Bedell, Salovey, Pronin, \& Rothman, 1999; Kalichman \& Coley, 1995; Kalichman, Kelly, Hunter, Murphy, \& Tyler, 1993; Meyerowitz \& Chaiken, 1987; Rothman, 2000; Rothman, Martino, Bedell, Detweiler, \& Salovey, 1999; Rothman \& Salovey, 1997; Sarafino, 1998). Specifically, researchers have investigated whether suggestions/prescriptions should be framed in terms of benefits (gains) or costs (losses). Initial results indicate that: "The relative effectiveness of gain-framed or loss-framed appeals depends, in part, on whether a behavior serves an illness-detecting or a health- 
affirming function" (Rothman \& Salovey, 1997, p. 3). For example, loss-framed messages appear to be more effective for illness-detecting behaviors, such as mammography (Banks et al., 1995), breast cancer self-examination (BSE; Meyerowitz \& Chaiken, 1987), skin cancer self-examination (Block \& Keller, 1995), and HIV testing (Kalichman \& Coley, 1995). On the other hand, according to Rothman and Salovey (1997), gain-framed messages may be more effective for health-affirming, or prevention, behaviors. However, additional research is necessary to examine this hypothesis.

Determining which type of message is more effective, though, may involve more than simply comparing gain-framed and loss- framed messages (Rothman \& Salovey, 1997). Rothman and Salovey (1997) suggest that researchers need to also assess how people decide whether a situation involves a gain or a loss and whether the adoption of the prescribed/recommended behavior is perceived as risky or safe.

\section{Medication}

Most adherence studies in medicine and health psychology have investigated medication regimens. On average, adherence rates for medication are $78 \%$ for acute illnesses with short-term treatment regimens and 54\% for chronic illness with long-term regimens (Cluss \& Epstein, 1985; Sackett \& Snow, 1979). For individuals taking medicine in order to prevent illness, the average adherence rate is $60 \%$ for both short- and long-term regimens.

With regards to specific populations/illnesses, medication adherence rates for hypertension are 64\% (Dunbar-Jacob, Dwyer, \& Dunning, 1991), 40\% to 60\% for rheumatoid arthritis (Belcon, Haynes, \& Tugwell, 1984; Deyo, Inui, \& Sullivan, 1981; Hicks, 1985), and 50\% to 66\% for epilepsy (Leppik, 1991). Of patients suffering from 
chronic obstructive pulmonary disease, more than $50 \%$ discontinued or were missing medication, and more than 50\% took extra medication periodically (Dolce et al., 1991). Research conducted on anti-depressant medication has yielded varying results. One study found medication adherence for individuals suffering from major depression to be $74 \%$ (Engstrom, 1991), whereas another study found that the rates varies from $30 \%$ to $82 \%$ depending on the dosage schedule and duration of therapy (Myers \& Branthwaite, 1992). Diet

Adherence rates for lifestyle changes, such as dietary interventions, appear to be variable and relatively low (Cluss \& Epstein, 1985; Sackett \& Snow, 1979; Sarafino, 1998). Specifically, adherence to dietary regimens for diabetes patients varies from less than $50 \%$ to $86 \%$ (Ary, Toobert, Wilson, \& Glasgow, 1986; Christensen, Terry, Wyatt, Pichert, \& Lorenz, 1983; Glanz, 1980; Webb et al., 1983), 13\% to 76\% for cardiovascular disease patients (Carmody, Fey, Pierce, Connor, \& Matarazzo, 1982; Carmody, Matarazzo, \& Istvan, 1987; Dunbar, 1985; Glanz, 1979, 1980; Kruse, 1991; McCann, Retzlaff, Dowdy, Walden, \& Knopp, 1990; McCann, Retzlaff, Walden, \& Knopp, 1990; Witschi, Singer, Wu-Lee, \& Stare, 1978), and less than 50\% for obesity patients (Glanz, 1980; Sohar \& Sneth, 1973).

Exercise

Although the physiological and psychological benefits of exercise have been welldocumented for chronic illnesses such as CHD, hypertension, diabetes, respiratory disease, arthritis, and end-stage renal disease (Martin \& Dubbert, 1987; Minor, 1991; Powell, 1988; Williams, Stephans, McKnight, \& Dodd, 1991) and mental illnesses such as schizophrenia, depression, anxiety disorders, developmental disabilities, somatoform 
disorders, and substance abuse disorders (Bosscher, 1993; Craft \& Landers, 1998;

Faulkner \& Sparkes, 1999; Hays, 1999; Tkachuk \& Martin, 1999), adherence to exercise programs remains quite low. For example, several studies have found 6-month adherence rates of approximately $50 \%$ for preventive and rehabilitative exercise programs (Dishman, 1982, 1988, 1991, 1994; Martin \& Dubbert, 1987; Oldridge, 1982; Ward \& Morgan, 1984). Moreover, 50\% of patients drop out of exercise programs, altogether, within 6 to 12 months (Emery, Hauck, \& Blumenthal, 1992; Oldridge, 1988; Pollack et al., 1992). Perkins and Epstein (1988) suggest that adherence rates for exercise are lower than other regimens (e.g., medicine) due to greater beha vioral requirements of exercise.

\section{Adherence Rates for CHD Patients}

Specific to CHD patients, only one-third to one-half quit smoking (Perkins \& Epstein, 1988), and in the first three months of treatment, similar to other populations, the dropout rate for exercise programs is approximately 50\% (Carmody, Senner, Malinow, \& Matarazzo, 1980; Dubbert, Rappaport, \& Martin, 1987). Similar trends (i.e., approximately 50\%) appear to exist for medication (Dolce et al., 1991). Dunbar-Jacob et al. (1995) stated that up to $80 \%$ of chronic disease patients do not follow their treatment program to the point necessary for attaining therapeutic benefit. Additionally, a recent study by $\mathrm{Hu}(\mathrm{Haney}, 1999)$ regarding the prevention of heart disease found that completely following physician health advice (i.e., eating sensibly, refraining from smoking, exercising, keeping weight down, and drinking only occasionally) reduced the risk of heart disease by 82 percent. However, only one percent of 84,129 nurses involved in the study actually complied with the advice. 


\section{Adherence Rates for Diabetes Mellitus Patients}

According to Aikens and Wagner (1998), poor adherence to medical regimens is a "major clinical problem" for patients with DM (p. 196). Specifically, noncompliance rates for diet recommendations and insulin administration have been found to range from $58-80 \%$ (Sarafino, 1998). For type 1 patients, $39 \%$ of single and $31 \%$ off multiple hospital admissions have been attributed to poor compliance (Fishbein, 1985). Moreover, for individuals with diabetes, poor adherence is associated with anxiety and depression, maladaptive personality traits (Lustman et al., 1991), and poor coping skills (Delameter et al., 1987).

One way to increase compliance may be to assess how acceptable clients view potential treatments, or treatment acceptability (TA), and select the one rated most favorably. This method of treatment selection is appropriate for chronic disease populations where treatment is not often regimented.

\section{Treatment Acceptability}

The construct of TA evolved from the notion of social validity (Kazdin, 1977; Wolf, 1978), or society's validation of behaviorists' work on at least three levels: (a) whether the specific behavioral goals (of the therapist) are really what society wants, (b) whether consumers consider the treatment procedures acceptable, and (c) whether consumers are satisfied with the results. Wolf (1978), rather sarcastically, noted that mental health professionals sometimes believe they know what is best for their clients, regardless of their clients' perspectives:

They are asking participants in a behavioral treatment program how much they like it. Why, of course they should like it. After all, we are doing it to them for 
their own good aren't we? And even if they don't like it, we know what is best for them. Clearly, if the procedure is effective, it's just not important whether anyone says they like it or not" (p. 206).

This attitude may lead to the development of insensitive professionals who do not ask their clients how acceptable a particular intervention is for them and/or give them choices between various interventions. In some extreme cases, mental health professionals may act as if they do not care how the client feels. For example, Wolf (1978) alluded to this issue by asking the following questions: "Do the ends justify the means? That is, do the participants, caregivers and other consumers consider the treatment acceptable?" (p. 207).

Thus, the construct of TA developed and was defined as "judgments by laypersons, clients, and others of whether treatment procedures are appropriate, fair, and reasonable for the problem or client" (Kazdin, 1981, p. 493). These "judgments of acceptability are likely to embrace evaluation of whether treatment is appropriate for the problem, whether treatment is fair, reasonable, and intrusive, and whether treatment meets with conventional notions about what the treatment should be" (Kazdin, 1980b, p. 259).

Reasons for Studying TA

Two main reasons were initially given for investigating TA. First, several individuals noted the legal and ethical issues associated with certain treatments (e.g., Kazdin, 1981; Witt \& Elliott, 1985). If the courts or other governing bodies determine a treatment is unacceptable, it cannot be considered for treatment (Budd \& Baer, 1976). For example, an Association for the Advancement of Behavior Therapy (AABT) Task Force was created due to the concern of psychological interventions (e.g., time out, punishment 
by overcorrection, and aversive stimulation) that were being used for the treatment of self-injurious behaviors (Favell et al., 1982). Responding to the concerns regarding the acceptability of these treatments (e.g., Kazdin, 1980b; Pickering, Morgan, Houts, \& Rodrigue, 1988), the Task Force made recommendations that attempted to reconcile the criteria of effectiveness with acceptability (see Budd \& Baer, 1976). Additionally, Lennox and Miltenberger (1990) state that TA for mental retardation must consider the intrusiveness of the treatment and refer practitioners to the least restrictiveness doctrine (see Turnbull, Ellis, Boggs, Brooks, \& Biklen, 1981).

Second, as Kazdin (1981) noted, "Treatments that are equal or approximately equal in effectiveness may vary markedly in their acceptability to potential consumers" (p. 494). Thus, if several effective treatments are available to a client, TA research may help the therapist choose treatments that are associated with higher compliance. More importantly, TA research may, on an individual basis, give consumers a "sense of personal control when allowed to select from among effective interventions the one they find most acceptable" (Cross Calvert \& Johnston, 1990, p. 63). Increased treatment compliance may lead to improved treatment outcomes (Kazdin, 1981).

Subsequent research has revealed other reasons for studying TA. Specifically, acceptability of treatments is negatively correlated with attrition and positively correlated with compliance (O’Brien \& Karsh, 1990). TA has also been shown to directly affect treatment outcome and treatment satisfaction (Cross Calvert \& Johnston, 1990; see also Elliott, 1988; Reimers, Wacker, \& Koeppl, 1987). Thus, as Tarnowski and Simonian (1992) state, “...treatment acceptability appears to be implicated in mediating negative clinical outcomes including treatment termination, noncompliance, and lack of 
improvement" (p. 101). Finally, research has shown that empirically validated treatments (EVTs) may be inappropriate, and even potentially harmful, for some minority clients (e.g., Chambless \& Williams, 1995). And, choosing a treatment that is consistent with the minority client's cultural meanings and conceptualization of their concerns is imperative (Rodriguez, 1998). Thus, assessing TA may also help therapists choose a treatment for minority clients—even if the treatment has not been empirically validated. Factors Affecting Acceptability

Witt and Elliott (1985) proposed a model of TA that included three variables hypothesized to directly affect the acceptability of various treatments: (a) treatment use, (b) treatment compliance, and (c) treatment effectiveness. A fourth element, described as client "understanding" of treatment procedures, was later added by Reimers et al. (1987). Three areas of subsequent research have supported this model of acceptability.

Treatment use and complexity. In their review of the literature, O'Brien and Karsh (1990) found that treatment use and compliance appeared to be inversely related to treatment complexity. Thus, complex interventions may require simplification in order to be considered acceptable treatments. Examples of complex interventions are those requiring large amounts of time, skill, and effort (e.g., token economy, multiple medications at various times throughout the day, etc.) (Cross Calvert \& Johnston, 1990). Likewise, clients who deem a treatment as unacceptable may be less likely to comply with the intended treatment (O'Brien \& Karsh, 1990).

Treatment effectiveness. Treatment effectiveness can be a large determinant of acceptability (Clark \& Elliott, 1988; Kazdin, 1984; Tingstrom, McPhail, \& Bolton, 1989). In addition, acceptability can be influenced by the type of effectiveness 
information (Von Brock \& Elliott, 1987). For example, Von Brock and Elliott (1987)

found that research-based treatment effectiveness information (as opposed to consumer satisfaction information) significantly increased acceptability evaluations for mild behavior problems as compared to a no-information condition. However, the type of effectiveness information did not affect acceptability ratings for severe behavior problems. Although treatment effectiveness can increase acceptability, caution must be used when using outcomes to justify interventions. Clearly, in some cases it is unethical for a practitioner to assume that the outcomes of an intervention justify any discomfort the client may feel (see above).

Treatment understanding. Understanding of treatments is an integral aspect of acceptability (Reimers et al., 1987). Unless a client has an understanding of what a proposed treatment includes, s/he may not consider the intervention acceptable. Thus, TA can be increased with consumer education (Foxx, Shultz, Valdez, \& Johndrow, 1996; Jensen, 1997; Jensen, Kennerley, LeJeune-Hall, \& Bacon, 1992; Kazdin, 1980a; Mudford, 1987; Singh \& Katz, 1985; Tingstrom, 1989). For example, Singh and Katz (1985) asked undergraduate students to rate the acceptabilities of four alternative child treatments (differential reinforcement of incompatible behavior, positive practice, time out, and humanistic parenting). After completing the surveys, participants attended 3 onehour, once-weekly lectures on the positive effects and possible adverse side effects of each of the three interventions. (Humanistic modeling parenting was the control condition.) Following the lectures, all differences between the three experimental treatments diminished, and all treatments were rated as more acceptable. Similar results 
have been obtained using videotape education rather than lectures (e.g., Foxx et al., 1996).

Additional factors that may influence TA, such as severity of the problem, type of treatment approach employed, various demographic variables, and variables pertaining to the therapist, have also been examined.

Severity of the problem. Across numerous studies, severity of the problem behavior has been shown to affect ratings of TA (Elliott, Turco, \& Gresham, 1987; Elliott, Witt, Galvin, \& Moe, 1986; Elliott, Witt, Galvin, \& Peterson, 1984; Frentz \& Kelley, 1986; Kazdin, 1980b, Martens, Witt, Elliott, \& Darveaux, 1985; Tarnowski, Kelly, Medlowitz, 1987; Tarnowski, Rasnake, Mulick, \& Kelly, 1989; Turco \& Elliott, 1986; Von Brock \& Elliott, 1987; Witt, Elliott, \& Martens, 1984; Witt \& Martens, 1983; Witt, Martens, \& Elliott, 1984; Witt, Moe, Gutkin, \& Andrews, 1984; Witt \& Robbins, 1985). The initial study that examined the influence of problem severity, conducted by Kazdin (1980b), found that college students rated four treatments (reinforcement of incompatible behaviors, 10-minute time-out from reinforcement, drug treatment, and moderately painful contingent shock) significantly higher for more severe case scenarios than for less severe case scenarios.

Type of treatment employed. Many analogue and clinical studies have demonstrated that positive or reinforcement-based procedures are more acceptable than restrictive or punishment-based procedures (Reimers et al., 1987). Interventions such as corporal punishment, shock, paradoxical interventions (Cross Calvert \& Johnston, 1990), and hypnosis (Maniar et al., 2001) have been rated as unacceptable. 
Cost. Although intuitively logical, no research has investigated the relationship between cost and acceptability. Nevertheless, Reimers et al. (1987) suggested that very costly treatments may be rated as unacceptable, especially when a less costly alternative treatment exists.

Incidence of side effects. Side effects may also influence acceptability ratings (Kazdin, 1981; Reimers et al., 1987). However, only one study (Kazdin, 1981) has investigated the relationship between side effects and acceptability. Specifically, Kazdin (1981) found that treatments with adverse side effects were rated as less acceptable.

Demographic variables. The incidence of multiple demographic variables, such as race (Heffer \& Kelly, 1987), knowledge of behavioral principles (Clark \& Elliott, 1988; Rasnake, Martin, Tarnowski, \& Mulick, 1993), and prior experience with the treatment (Witt \& Martens, 1983; Witt \& Robbins, 1985) have also been shown to affect TA.

Therapist variables. Two therapist variables have also been found to affect clients' TA ratings. First, researchers have found that potential clients' treatment evaluations fluctuate depending on what the treatment is called and how it is described (Witt, Moe et al., 1984; Woolfolk, Woolfolk, \& Wilson, 1977; Woolfolk \& Woolfolk, 1979). For example, in their studies of preservice teachers, Woolfolk et al. (1977) and Woolfolk and Woolfolk (1979) showed a videotape of a teacher reinforcing appropriate behavior. The video was titled "behavior modification" for half of the sample and "humanistic education" for the other half. Participants' ratings of the personal capabilities of the teacher, as well as the effectiveness of the teaching technique, were more positive when the teaching technique was labeled humanistic education. 
Second, rationales for using a treatment have been shown to affect acceptability ratings (Cavell, Frentz, \& Kelley, 1986a, 1986b). For example, Cavell et al. (1986a) examined 120 middle and high school teachers' reactions to paradoxical treatments. One aspect of the study compared TA ratings based on one of four rationales provided for using paradoxical intervention: (a) no rationale, (b) paradoxical rationale (i.e., "this instruction is actually intended to have the opposite effect of what the instruction says"), (c) situation rationale (i.e., "Mike will soon get tired of staying away from school and his friends, and...he will return"), and (d) reverse rationale (i.e., "teenagers will very often respond favorably to this type of 'reverse' psychology”). Although paradoxical treatments were rated as unacceptable, regardless of rationale, TA ratings increased when psychologists' actual intentions were provided and positive effects were provided.

\section{Instruments}

Several TA instruments have been developed to investigate the construct of acceptability. Initially, Kazdin (1980b) developed the Treatment Evaluation Inventory (TEI). The TEI is comprised of 15 items rated on a seven-point Likert-type scale. Individuals rate treatments in six main areas: (a) acceptability, (b) willingness, (c) suitability for individuals having other problems, (d) cruelness/fairness, (e) likely effectiveness, and (f) likeability. An overall acceptability index is also calculated by summing the scores from all 15 items.

Witt and Martens (1983) developed the Intervention Rating Profile (IRP) for judging teachers' acceptabilities of classroom interventions. The results of a factor analysis demonstrated that the IRP was comprised of one primary factor (general acceptability) and four secondary factors (risk, time, effects on children, and teacher 
skill). The IRP was later modified for use with a broader consumer population (e.g., parents, nurses, institutional staff). Of the original 20 items (rated on a six-point Likerttype scale), seven were modified and retained, and eight new items were added. This modified scale was then entitled the IRP-15 (Witt \& Elliott, 1985).

Because of participants dissatisfaction with the length of time required to complete the IRP and its derivatives, Tarnowski and Simonian (1992) developed the Abbreviated Acceptability Rating Profile (AARP) by simplifying the IRP. Likewise, Kelley, Heffer, Gresham, and Elliott (1989) simplified and provided statistical support for a shortened for of the TEI (TEI-SF).

In subsequent years, instruments targeted at more specific populations have been developed. Hunsley (1992) developed the Treatment Acceptability Questionnaire (TAQ) due to the need for an adult-specific acceptability measure, whereas Bourland and Lundervold (1989) developed the Geriatric Treatment Acceptability Survey (GTAS) for use with older populations. The Intervention Perception Questionnaire (IPQ; Brewer, Jeffers, Petitpas, \& Van Raalte, 1994), the Treatment Questionnaire (TQ; Jensen et al., 1992), and the Athlete Preferences Questionnaire (APQ; Maniar et al., 2001) were developed for use with athletes seeking sport psychology interventions.

Finally, in an effort to understand the relationship of acceptability to other variables, several scales were developed based upon modifications of the TEI or IRP. Von Brock and Elliott (1987) added nine items to the IRP in order to assess the relationship of TA to treatment effectiveness. The resulting new scale was named the Behavior Intervention rating Scale (BIRS). And, in an effort to assess the relationship 
among TA, compliance, and problem severity, Reimers and Wacker (1988) modified the TEI to produce the Treatment Acceptability Rating Form (TARF).

Recently, though, there has been some debate as to whether current instruments are accurately measuring the construct of TA (i.e., lack of construct validity). Newer TA instruments may not look at all six of Kazdin's (1980b) factors of TA (discussed previously). For example, some researchers feel that simple endorsement of a treatment constitutes TA rather than assessing individuals' subjective ratings of efficacy and treatment discomfort (see Irvin and Lundervold, 1988; Lundervold, Young, Bourland, \& Jackson, 1991, for review), whereas other investigators have only examined individuals' willingness to use or preferences for participating in treatments (e.g., Brewer et al., 1994; Maniar et al., 1999, 2001). Thus, some disagreement appears to exist regarding which inventories are valid measurements of TA. Moreover, as Spirrison (1992) states, "agreement on what constitutes the treatment acceptability construct must necessarily

precede agreement on how to measure it" (p. 259). Clearly, future research is necessary to determine whether treatment acceptability should be delineated from treatment preference.

\section{Research on Acceptability}

During the 1980s, TA research focused predominantly on interventions for child behavior problems. The initial studies, conducted by Kazdin (1980a, 1980b, 1981), asked college students to rate the acceptability of treatment procedures when presented with scenarios of a normal and mentally retarded child who were demonstrating hyperactive, noncompliant, or aggressive behaviors. Evaluations were conducted using the TEI and Semantic Differential (Osgood, Succi, \& Tannenbaum, 1957). The results indicated that: 
(a) positive treatment procedures were generally more acceptable than negative methods, (b) case severity was a factor of acceptability, (c) nonexclusionary time-outs were rated as more acceptable than exclusionary time-outs, and (d) aversive side effects reduced acceptability ratings.

Following his initial studies with college students, Kazdin extended his research to include ratings of children, parents, and treatment staff (Kazdin, 1984; Kazdin, French, \& Sherick, 1981). Again, using an analogue design, results indicated that: (a) treatments described as having remarkable effects were rated as more acceptable than treatments producing weaker effects, (b) children rated medication as the most acceptable treatment, and (c) parents rated behavioral treatments higher than children. Similar analogue studies further extended Kazdin's research to parents of normal, autistic, and handicapped children (Pickering \& Morgan, 1985), mothers of mentally retarded children (Singh, Watson, \& Winton, 1987), and nurses and hospital staff working with mentally retarded children (Mudford, 1987).

As a result of Kazdin's initial studies, a second domain of acceptability research emerged in the school setting. For example, in a study of preservice teachers, Witt and Martens (1983) found that five factors influenced the acceptability of classroom interventions: (a) suitability of the intervention for a mainstreamed classroom, (b) risk to the child, (c) intervention time (for the teacher), (d) negative side effects on other children, and (e) skill of the teacher. A follow-up study by Witt, Martens, and Elliott (1984) found that behavior severity and type of intervention were additional factors that influenced teachers' TA ratings. In subsequent studies, Epstein, Matson, Repp, and Helsel (1986) examined special education and regular teachers' TA ratings for mentally 
retarded and learning disabled students, and Irvin and Lundervold (1988) evaluated teachers' ratings of acceptability, efficacy, intrusiveness, and restrictiveness for 18 treatments.

Recently, though, acceptability research has been extended to many other areas of psychological treatment. For example, treatments for agoraphobia (Aronson, Craig, Thomason, \& Logue, 1987; Norton, Allen, \& Walker, 1985), depression (Banken \& Wilson, 1992; Hall \& Robertson, 1998; Lundervold \& Lewin, 1990; Rokke, Carter, Rehm, \& Veltrum, 1990; Tarnowski, Simonian, Bekeny, \& Park, 1992), developmental disabilities (Epps, Prescott, \& Horner, 1990), eating disorders (Newton, Hartley, \& Sturmey, 1993; Sturmey, 1992), geriatric behavior problems (Lundervold, Lewin, \& Bourland, 1990; Lundervold et al., 1991), marital therapy (Bornstein et al., 1983; Bornstein et al., 1987; Upton \& Jensen, 1991; Wilson \& Flammang, 1990; Wilson, Flammang, \& Dehle, 1992), mental retardation (Rasnake et al., 1993; Tarnowski et al., 1989), panic disorder (Aronson et al., 1987; Hecker, Fink, \& Fritzler, 1993), paradoxical interventions (Betts \& Remer, 1993; Cavell, Frentz, \& Kelley, 1986a, 1986b; Hunsley, 1993; Hunsley \& Lefebvre, 1991), pediatric behavior problems (Tarnowski et al., 1987), sex offenders (Lundervold \& Young, 1992), sex therapy (Wilson \& Wilson, 1991), and sport psychology (Brewer et al., 1994; Jensen, 1997; Jensen et al., 1992; Maniar et al., 2001) have all been evaluated with regard to acceptability.

For example, Hall and Robertson (1998) asked undergraduates to rate the acceptability of single (i.e., treatment offered by itself) and combined treatments for depression. After reading five descriptions for common approaches for the treatment of depression (cognitive-behavior therapy [CBT], interpersonal therapy [IPT], 
pharmacotherapy + CBT, pharmacotherapy + IPT, and pharamacotherapy + support therapy), participants rated the acceptability of each treatment using five different measures. Similar to previous studies (e.g., Banken \& Wilson, 1992; Bourland \& Lundervold, 1989; Lundervold \& Lewin, 1990; Norton et al., 1985; Rokke et al., 1990; Sturmey, 1992; Tarnowski et al., 1992), results indicated that medication was rated significantly less acceptable than other types of treatment for depression. However, in contrast to these previous studies, all treatments, including psychotherapy + medication (traditionally the least acceptable), were rated in the acceptable and credible range.

The majority of TA studies, though, have used college students and/or hypothetical scenarios. Few studies have used actual clients involved in actual therapy. Moreover, TA research with chronic disease populations has been scant at best. One chronic disease population that psychologists are beginning to work with is diabetes patients (see Bradley, 1994; Camic \& Knight, 1998; Nicassio \& Smith, 1995). Thus, diabetes populations may be better served by TA research.

\section{Diabetes Mellitus}

Diabetes mellitus (DM) is characterized by insufficient pancreatic insulin production and/or insulin ineffectiveness (Expert Committee on the Diagnosis and Classification of Diabetes Mellitus [ECDCDM], 2002; Pohl, Gonder-Frederick, \& Cox, 1984) and occurs in two major types: type 1 (formerly referred to as IDDM, or insulin dependent) and type 2 (formerly referred to as NIDDM, or non insulin dependent).

\section{Incidence}

In the United States, DM prevalence has been estimated at six percent (American Diabetes Association [ADA], 1996; Centers for Disease Control and Prevention [CDC], 
1998) of the population. In 1999, 19.6 million medical office visits in the United States were diabetes-related (National Center for Health Statistics [NCHS], 2001). The direct costs of diabetes in the United States have been estimated at 44.14 billion dollars (Songer, Ettaro, \& EDPP/CDC, 1998). NIDDM accounts for approximately $90 \%$ of people with diabetes (Canadian Diabetes Association [CDA], 1997; Kaplan, Sallis, \& Patterson, 1993) and is more common among Native Americans, African Americans, and individuals of Hispanic decent (Aikens \& Wagner, 1998). The prevalence of NIDDM also increases with age (Aikens \& Wagner, 1998).

Individuals in the Appalachian region of the United States appear to be at greater risk for DM than those who live outside of Appalachia (Tennessee Agriculture Extension Service [TAES], n.d.; West Virginia Bureau for Public Health [WVBPH], 1998). West Virginia, the only state entirely within the Appalachian region, appears to be at particular risk. According to the West Virginia Health People 2010 Initiative (WVBPH, 2001), West Virginia's highest self-reported obesity rate (43\%) in the nation, high sedentary lifestyle $(70 \%)$, highest median age (37.6) in the nation, poor eating habits, low education level, and limited access to health care result in the state's high prevalence of DM-sixth highest in the nation in 1996, according to the CDC (1999).

\section{Treatment}

The treatment regimen for DM most always includes a calorie-limited, balanced, scheduled diet (Aikens \& Wagner, 1998). Diets often include an oral hypoglycemic or insulin-sensitizing agent for type 2 patients, whereas type 1 patients are usually prescribed multiple daily insulin injections (Aikens \& Wagner, 1998). Other treatments, such as subcutaneous insulin pump delivery systems and pancreatic transplantation, are 
also being used for type 1 patients with increased frequency (ADA, 1996). Type 2

patients also are treated often with exercise and oral medication (Macrodimitris \& Endler, 2001).

Psychological treatment. Although psychological treatment is not usually an aspect of DM treatment, psychological referrals are often made for poor diabetes regimen adherence, physiological stress responses exacerbating medical illness, mood and anxiety disorders, and cognitive difficulties (Aikens \& Wagner, 1998). Depression prevalence in DM populations occurs at approximately six times the normally observed rate in the general population (Lustman, Griffith, Clouse, \& Cryer, 1986). Diagnosis, symptomatology, and stringent treatment regimens have been shown to result in increased anxiety and depression for chronic disease patients, such as those suffering from DM (Lustman, 1988; Wells, Golding, \& Burnam, 1988; Wilkinson, 1991).

Several psychological interventions have been shown to be effective with DM patients. Specifically, behavior modification, contingency contracting, and selfmonitoring have demonstrated increased regimen adherence (Masters, Burish Hollon, \& Rimm, 1987; Sarafino, 1998). Helping patients identify and alter environmental cues associated with medication and food intake has also been shown to be effective (Hartwell, Kaplan, \& Wallace, 1986). For DM patients with depression and anxiety, preliminary evidence suggests that cognitive-behavioral therapy (CBT; see Beck et al., 1979 ) is an efficacious treatment (Aikens \& Wagner, 1998). Because as many as $84 \%$ of IDDM patients report that stressful events affect their glucose (Cox et al., 1984), relaxation training is sometimes prescribed for DM patients (Aikens \& Wagner, 1998). However, behavioral stress reduction techniques have demonstrated mixed results with 
DM patients (see Cox \& Gonder-Frederick, 1992; Surwit, Schneider, \& Feinglos, 1992). Aikens and Wagner (1998) also recommend that DM patients should be assessed for eating disorders and cognitive impairment.

Because many patients with DM also suffer from coronary heart disease (Aikens \& Wagner, 1998), the following section on coronary heart disease is also included.

\section{Coronary Heart Disease}

Coronary heart disease, or CHD, (also referred to as coronary artery disease $[\mathrm{CAD}])$ is a general term for the incidence of angina pectoris, myocardial infarction (MI), and/or sudden cardiac death (Smith \& Nicassio, 1995).

\section{Incidence}

Approximately 5 million Americans suffer from CHD (Smith \& Nicassio, 1995). Each year in the United States, 1.5 million individual suffer an initial or recurrent MI, and over 500,000 of these individuals die from the disease (AHA, 1989). The associated costs of lost productivity due to CHD are approximately 30 to 40 billion dollars per year (Smith \& Nicassio, 1995), and the estimated total economic cost (health expenditures and lost productivity) of CHD is 99.8 billion dollars (AHA, 1999b).

\section{Treatment}

Depending on the severity of the disease, treatment for CHD may range from prescribed lifestyle changes (preventative) to medication to surgery.

Lifestyle changes. Because of the association of specific risk factors with future cardiac morbidity and mortality, health care professionals generally prescribe many lifestyle changes for CHD patients (Blumenthal \& Emery, 1988). These lifestyle changes 
typically include the following: smoking cessation; low fat diet; weight loss for overweight patients; and regular exercise.

Medication. Physicians usually prescribe one of three general classes of medication for patients with angina: nitrates, beta-blockers, and calcium channel blockers. Nitrates (e.g., nitroglycerin, isosorbide) increase blood supply to the myocardium by decreasing the amount of necessary work by the left ventricle and by coronary vasodilation and improved collateral flow (Bellg, 1998). Beta-adrenergic blocking agents (e.g., propranolol [Inderal], metoprolol [Lopressor]) block the action of catecholamines on the heart that reduce heart rate and blood pressure, which in turn reduces the amount of oxygen the required by the heart (Bellg, 1998). Beta-blockers are also inotropic (i.e., they reduce myocardial contractility) (Bellg, 1998). Calcium channel blockers (e.g., nifedipine [Procardia], diltiazem [Cardizem]) inhibit coronary vasoconstriction and are also inotropic (Bellg, 1998). Thrombolytic agents, such as streptokinase or tPA (tissue plasminogen activator) may also be prescribed for dissolving clots in the coronary arteries.

Following an MI, patients are sometimes given a thrombolytic (clot-dissolving) agent (e.g., streptokinase [SK], urokinase [UK], tissue plasmogen activator [TPA]) (Bellg, 1998). Primary PTCA or emergency CABG may also be necessary to improve perfusion (see below). Aspirin for reducing clotting mechanisms and stabilizing plaques in the long-term, warfarin (Coumadin) for reducing the chance of clots in the long-term, and heparin for preventing reocclusion in the short-term may also be prescribed (Bellg, 1998). Finally, physicians may opt to prescribe nitrates and beta-blockers for tissue 
recovery and angiotensin-converting enzyme (ACE) inhibitors (e.g., captopril [Capoten], enalapril [Vasotec]) for improved ventricular function (Bellg, 1998).

Surgery. Acute CHD may require surgical treatment, usually accomplished through a coronary artery bypass graft (CABG). In some less severe cases, though, physicians may opt for balloon angioplasty, or Percutaneous Transluminal Coronary Angioplasty (PTCA), which is considered to be a less invasive and stressful treatment (Smith \& Nicassio, 1995). On the other hand, CABG surgery is usually accompanied by "extensive physical trauma" and "is usually experienced by patients and their families as highly stressful" (Smith \& Nicassio, 1995, p. 23). Average costs in 1995 for CABG and PTCA were $\$ 44,820$ and $\$ 20,370$, respectively (AHA, 1999c). A new procedure, transmyocardial laser revascularization (TMLR), is currently being investigated for use with patients having unstable angina (Bellg, 1998).

Psychological treatment. Although traditional treatment for CHD does not include psychological interventions (Smith \& Nicassio, 1995), psychological treatment aimed toward reducing stress and altering related personality characteristics (e.g., Type A) has been shown to reduce recurrent cardiac episodes among CHD patients (Frasure-Smith \& Prince, 1989; Powell \& Thoresen, 1988).

\section{Summary}

In the above chapter, the public's use and under- use of mental health services and how hope and the stigmatization of psychology may influence the public's unwillingness to seek out help from a psychological professional were discussed. Poor adherence rates for medical and psychological treatment and one potential manner to increase adherence, treatment acceptability, were also discussed. 
It was also suggested that one population that may benefit from research that examines the willingness to seek out mental health services as well as use various treatments is individuals with DM. This type of research will provide some initial information as to which interventions patients view as most acceptable, as well as reveal specific interventions that are viewed negatively by patients. Additionally, this area of research will help indicate what type of professionals patients are willing to consult with regarding psychological difficulties, as well as potentially reveal any stigmas that patients hold toward certain job titles or professions. 


\section{Chapter 3: Methods}

\section{Participants}

Participants were 80 diabetes patients from West Virginia University's Physician Office Center and Family Medicine Clinics. Participants ranged from 26 to 87 years of age $(M=59.9, S D=16.9)$. Of all participants, $56(70 \%)$ were female; $72(90 \%)$ were Caucasian and 8 (10\%) were African American; and 56 (70\%) reported having type 2 diabetes, 20 (25\%) had type 1 diabetes, and 4 were unsure of their diabetes type.

Additionally, 48 (60\%) reported having previously seen a mental health professional, and $48(60 \%)$ also reported participating in a diabetes support group. Participants traveled a mean distance of 16.3 miles $(S D=19.3)$ to their clinic, and the average amount of time since participants' diagnosis of DM was 14.2 years $(S D=12.2)$.

\section{Measures}

\section{Demographic Information}

The first page of the questionnaire, entitled "About You," consisted of questions aimed at obtaining a variety of demographic information. Specifically, age, sex, marital status, race, religious affiliation, diabetes type, and distance traveled to the clinic were requested. Additionally, participants were asked if they had ever seen a mental health professional and if they had ever participated in a diabetes support group.

\section{Health Preferences Questionnaire}

The Health Preferences Questionnaire (HPQ) is a modification of the Athlete Preferences Questionnaire (APQ; Maniar, Curry, Sommers-Flanagan, \& Walsh, 2001) and consists of eight questions. Participants are asked to answer the first seven questions with the following scenario in mind: "Patients with diabetes regularly experience 
emotional difficulties (e.g., worries, tension, anxiety, nerves, stress, sadness, etc.). Imagine that you were experiencing diabetes-related emotional difficulties."

The first five questions of the HPQ are answered by circling numbers on a 5-point Likert-type scale anchored by "Never" and "Definitely." The first question asks, "How willing would you be to seek help, in general?" The second question of the HPQ asks, how willing participants are to participate in six interventions: counseling, dietary changes, exercise program, additional medication, relaxation training, and support group. The third question asks how effective the participants think the same six interventions would be. The fourth question asks how willing participants would be to seek help from 13 individuals (presented in alphabetical order): behavioral medicine specialist, counselor, diabetes educator, exercise physiologist, friend/family, health psychologist, minister/pastor, nutritionist, pharmacist, physician/doctor, psychiatrist, and psychologist. The fifth question of the HPQ simply asks how effective participants think the same 13 individuals would be for them.

In essence, the first five questions directly assess a component of treatment acceptability, or two of the six factors of treatment acceptability (acceptability, willingness, suitability for individuals having other problems, cruelness/fairness, likely effectiveness, and likeability) originally measured by Kazdin's TEI (1980b). Rather than asking individuals to rate multiple treatments on each of the six components of TA, several studies (Brewer, Jeffers, Petitpas, \& Van Raalte, 1994; Hall \& Robertson, 1998; Maniar, Perna, Newcomer, Roh, \& Stilger, 1999; Maniar et al., 2001) have simply asked whether they would use an intervention and/or whether they felt the intervention was effective. Several current instruments such as the TAQ or IPQ (see Chapter 2) could also 
be relevant for the present study. Nevertheless, these questionnaires (TAQ and IPQ) are concerned with comparing a small number of interventions (e.g., two or three) and/or using between-groups designs. If the present study were to use these instruments, at least six questions for each of the six treatments, or 36 questions for each participant, would be necessary. Moreover, these instruments would not be able to address the first two items of the HPQ.

The remaining three questions on the HPQ are answered by checking a response. Question six asks participants, "If you did seek help from a medical professional, would you prefer they were male or female?" Participants are asked to check one of the following: male, female, or no preference. Question seven asks the same question as in number six with the exception of "medical professional" being replaced with "psychological professional." The final question asks participants if "anyone has ever mentioned using exercise services to you." If participants check yes for this item, they are asked who mentioned using exercise.

Development of the $H P Q$. The initial version of the HPQ was a modification of the APQ (Maniar et al., 2001). Titles and treatments were generated with the aid of a counseling/health psychologist and an exercise physiologist who had expertise in the area of chronic disease, specifically diabetes. The instrument was pilot tested on a group of individuals $(N=13)$ participating in a diabetes support group (Maniar, 2000). After receiving feedback from the participants, no changes were made to the instrument with the exception of removing smoking cessation as an intervention and replacing it with support group. Smoking cessation was removed because none of the participants smoked 
cigarettes. Moreover, the facilitator of the support group recommended the addition of support group due to the large number of DM patients who are referred to support groups.

\section{Diabetes Quality of Life}

The Diabetes Quality of Life Measure (DQOL) was developed in the early 1980s for use in the Diabetes Control and Complications Trial (DCCT, 1986, 1987, 1988; Jacobson \& DCCT, 1994). The DCCT was a "controlled, randomized clinical trial comparing the efficacy of two alternative treatment regimens on the appearance and development of chronic complications of insulin-dependent diabetes mellitus" (Jacobson \& DCCT, 1994, p. 65). The DQOL was specifically designed to measure the burden of an intensive treatment regimen while maintaining blood glucose levels as close to levels of those without diabetes (Jacobson \& DCCT, 1994). It was hypothesized that intensive treatment would result in a decreased quality of life for DM patients and, in turn, decrease the willingness of patients and health care providers to use intensive treatment. (Jacobson \& DCCT, 1994).

Although the DQOL was first used with IDDM patients, it was purposely cons tructed to be applicable for non-DCCT IDDM patients as well as NIDDM patients (DCCT, 1988; Jacobson \& DCCT, 1994). The DQOL assesses four separate areas: satisfaction with treatment (15 items plus an additional 3 for adolescents), impact of treatment (20 items plus an additional 7 for adolescents), worry about the future effects of diabetes (4 items), and worry about social/vocational issues ( 7 items plus an additional 3 for adolescents). All items solicit a response on a 5-point Likert-type scale, anchored by "Very satisfied" (1) and "Very dissatisfied" (5) for the Satisfaction items and "No impact" (1) and "Always affected" (5) for the Impact items, and "Never worried" (1) and 
"Always worried" (5) for the Worry items. An option for "Does not apply" (0) is also provided. A single, overall well-being item is also included, measured on a 4-point Likert-type scale, anchored by "Excellent" (1) and "Poor" (4).

Scoring. Initially, items were summed, with Impact items 8 and 16 reverse scored, and then divided by the number of items in the respective subscale (DCCT, 1988). The mean scores for each subscale were then interpreted based upon a 5-point scale, where 1 was equivalent to the highest quality of life and 5 with the poorest quality of life. Jacobson and DCCT (1994), though, proposed a new method of scoring the DQOL. All items were reverse scored, with the exception of Impact items 8 and 16, resulting in higher scores equating to higher quality of life. Items in each subscale were then summed into a raw scale score that was then transformed into a 100-point scale, where 0 represented the lowest possible quality of life and 100 represented the highest possible quality of life. The formula (International Resource Center [IRC] for Heath Care Assessment, 1991) is shown below:

New scale $=[($ Raw score - lowest possible score $) /$ Raw score range $] * 100$ The new score is then rounded off to the nearest whole number. Jacobson et al. (1994) also recommended deleting the Worry, Satisfaction, and Impact subscales if more than 2, 3 , and 4 items were missing, respectively.

Reliability. Two studies have found that internal consistency of the scales and the total score were similar in both IDDM and NIDDM populations (DCCT, 1988; Jacobson \& DCCT, 1994). All inter-correlations were found to be significant for adult IDDM populations $(p<.01)$ in at least one study, translating to a minimum correlation of .42 . For NIDDM populations, all but two inter-correlations were found to be significant, 
translating to a minimum correlation of .46 . Non-significant inter-correlations were found for the Social/Vocational Worry and Impact and the Social/Vocational Worry and Diabetes-related Worry.

The test-retest reliability of the DQOL was found to range from .78 to .92 over a one-week span for adult IDDM populations and .86 to .92 for type 1 adolescents (DCCT, 1988). Specifically, test-retest reliability coefficients for type 1 adults retaking the DQOL approximately one week after the initial administration were found to be as follows: .92 (DQOL total), .89 (Satisfaction), .89 (Impact), .80 (Diabetes-related Worry), and .78 (Social/Vocational Worry).

Validity. Construct validity of the DQOL was assessed by examining the relationship of the DQOL to the Symptom Checklist 90-R (SCL-90; Derogatis, Rickels, \& Rock, 1983), the Bradburn Affect Balance Scale (ABS; Bradburn, 1969), and the Psychosocial Adjustment to Illness Scale (PAIS; Derogatis, 1983) (DCCT, 1988). Results indicated that for adult patients, the DQOL total score moderately correlated with the SCL-90 Global Severity Index $(r=-.60)$, ABS $(r=-.57)$, and PAIS subscales ( $r$ s ranging from .34 to .63). Correlations for DQOL subscales were also similar, falling in the range of .30 to .70. Jacobson and DCCT (1994) further assessed the construct validity of the DQOL by examining its relationship to the Medical Outcome Survey (SF36). Significant correlations (i.e., $p<.01, r>.28$ ) were found for DQOL Total, Impact, and Satisfaction with the SF36 subscales (Physical functioning, Social functioning, Role functioning, Pain score, and General health score). The DQOL Diabetes Worry also significantly correlated with the SF36 Role functioning subscale. Moreover, similar correlations were found for type 1 and type 2 patients. 
External validity of the DQOL was assessed by comparing patients with varying severity and numbers of complications in terms of their DQOL score (Jacobson \& DCCT, 1994). Results indicated that increasing severity and number of complications were correlated with lower levels of satisfaction and greater impact of diabetes, even after adjusting for age, marital status, and treatment type. Jacobson and DCCT (1994) also assessed for external validity by using the DQOL to compare type 2 patients who were using three different treatment regimens.

Sensitivity to change. Two studies have examined the DQOL's ability to capture changes in clinical functioning. First, Nathan et al. (1991) found that the DQOL was able to demonstrate improved glycaemic control and lifestyle change by improved scores. A second study found similar results when comparing patients who received an implantable pump to those receiving the usual insulin treatment (Selam, Micossi, Dunn, \& Nathan, 1992).

\section{Dispositional Hope Scale}

Defining hope as "a cognitive set of comprising agency (belief in one's capacity to initiate and sustain actions) and pathways (belief in one's capacity to generate routes) to reach goals" (Snyder et al., 1996, p. 321), Snyder, Harris et al. (1991) developed and validated the Hope Scale as a dispositional self-report measure. The scale is a 12-item self-report instrument with two sub-scales (agency [4 items] and pathways [4 items]) and a total score (agency + pathways). The remaining four items comprise of "filler," or unused, items. All items are rated on a 4 -point scale $(1=$ definitely false, $2=$ mostly false, 3 = mostly true, 4 = definitely true). High scores correspond to high hope, and vice versa. 
Reliability indexes. Reliability was assessed by administering the Dispositional Hope Scale to six separate samples of introductory psychology students and two samples (one inpatient and one outpatient) of individuals in psychological treatment (Snyder, Harris et al., 1991). Cronbach's alphas for all samples ranged as follows: (a) .71 to .76 for the Agency subscale (item remainder coefficients of .40 to .72); (b) .63 to .80 for the Pathways subscale (item remainder coefficients of .36 to .63); and (c) .74 to .84 for the total scale (item remainder coefficients of .23 to .63). The internal reliability was determined to be acceptable based upon criteria set by Nunnally (1978) of .70 to .80 .

The test-retest reliability for the total hope score was found to be .85 over a 3week interval $(N=130$; Anderson, 1988), .73 over an 8 -week period $(N=115$; Harney, 1989), and .76 and .82 (two samples) over a 10-week period $(N=205$, Gibb, $1990 ; N=$ 133, Yoshinobu, 1989).

Factor analysis resulted in a two-factor solution was accepted which accounted for $52 \%$ to $63 \%$ of the variance across college student and psychological treatment samples (Snyder, Harris et al., 1991). Reliabilities between the two subscales (agency and pathways) ranged from .38 to .46 for college students and .46 to .57 for individuals in psychological treatment.

Convergent validity. The Trait Hope Scale was administered along with other conceptually related measures to introductory psychology students and inpatients $(N=$ 241, Gibb, 1990; $N=158$, Holleran \& Snyder, 1990; $N=109$, Irving, Crenshaw, Snyder, Francis, \& Gentry, 1990). The Dispositional Hope Scale correlated .60 and .50 with the Life Orientation Test (LOT; Scheier \& Carver, 1985), a measure of dispositional optimism. Additionally, Dispositional Hope Scale correlated -.62 with the Generalized 
Expectancy for Success Scale (GESS; Fibel \& Hale, 1978), a measure of cross-situational expectancies for attaining goals. The Dispositional Hope Scale also correlated .54 with the Burger-Cooper Life Experiences Survey (Burger \& Cooper, 1979) and -.62 with the Problem Solving Inventory (PSI; Heppner \& Petersen, 1982), where lower scores are indicative of greater perceived problem solving. The Dispositional Hope Scale correlated .58 with the Rosenberg (1965) Self-Esteem Scale, and the scale correlated -.51 with the Hopelessness Scale (Beck, Weissman, Lester, \& Trexler, 1974) and -.41 with the Beck Depression Inventory (BDI; Beck, Ward, Mendelsohn, Mock, \& Erbaugh, 1961). The Dispositional Hope Scale also correlated .30 with the Marlowe-Crowne Social Desirability Scale (Crowne \& Marlowe, 1960) and .28 with the Self-Presentation Scale (Roth, Harris, \& Snyder, 1988; Roth, Snyder, \& Pace, 1986).

The Dispositional Hope Scale correlated with the 10 K-corrected Minnesota Multiphasic Personality Inventory (MMPI; Hathaway \& McKinley, 1951) clinical subscales as follows: Hypochondriasis, $r=-.30$; Depression, $r=-.60$; Hysteria, $r=-.35$; Psychopathic Deviate, $r=-.43$; Masculinity-Femininity, $r=-.13$; Paranoia, $r=-.34$; Psychasthenia, $r=-.52$; Schizophrenia, $r=-.46$; Hypomania, $r=-.08$; and Social Introversion, $r=-.59$. In addition, Trait Hope Scale correlated .63 with the Rotter Incomplete Sentences Blank (ISB; Rotter \& Rafferty, 1950).

Discriminant validity. In order to assess discriminant validity, the Dispositional Hope Scale was also compared to several instruments hypothesized to be unrelated to trait hope (Snyder, Harris et al., 1991). These instruments were as follows: (a) SelfConsciousness Scale (Fenigstein, Sheier, \& Buss, 1975), $r \mathrm{~s}=.06$ (private subscale) and .03 (public subscale); (b) Taylor Manifest Anxiety Scale (TMAS; Taylor, 1953), $r=-.47$; 
(c) State Trait Anxiety Inventory (STAI; Spielberger, Gorsuch, \& Luchene, 1970), $r=$ .58; and (d) Positive and Negative Affect Schedule (PANAS; Watson, Clark, \& Tellegen, 1988), $r=.30$ (positive items), $r=-.18$ (ne gative items).

Multiple regressions were used to assess the reasons for the high correlations on the TMAS and STAI. Results indicated that the Hope Scale uniquely accounted for variance in relation to active coping and planning that was not attributed to positive and negative affect (Snyder, Harris et al., 1991).

Construct validity. Several variables were used to validate the construct of hope: high school and college GPA, number of goals, preferred difficulty of goals, academic goal-setting, goal-attainment appraisals, goal attainment, and life goals appraisals (Snyder, Harris et al., 1991). The results indicated that the Hope Scale appears to measure the intended construct of hope, or agency plus pathways.

\section{Procedures}

Over the course of three months, DM patients waiting in exam rooms in two clinics were asked by a nurse if they would like to voluntarily participate in a study assessing diabetes patients' preferences for treatment. No data on the percentage of patients who agreed to participate was obtained. Informed consent was obtained for all participants, and questionnaires were completed prior to any treatment. Questionnaires consisted of the measures described above, presented in random order. All responses were kept confidential by asking participants to place their questionnaire in provided envelopes. The sealed envelopes that contained questionnaires were then placed in a drop box by the nurse's station. 
All participants were asked if they preferred to be entered in a raffle for a onehour massage or a two-month membership for the Human Performance Lab, a university run exercise facility for individuals with chronic disease. One winner was chosen for each raffle. Winners were notified by mail.

\section{Hypotheses}

In the current study, several hypotheses were examined. Willingness to Use Interventions

First, psychological interventions (counseling, relaxation training, support group) will be rated lower with respect to willingness (i.e., less willing to use) than nonpsychological interventions (dietary changes, exercise, medication). Second, female participants will rate all interventions higher for willingness to use than male participants. Perceived Effectiveness of Interventions

Third, psychological interventions will be rated lower with respect to perceived effectiveness than non-psychological interventions. Fourth, female participants will rate all interventions higher for perceived effectiveness than male participants.

\section{Willingness to Seek Help from Various Individuals}

Fifth, psychologists will be rated lower (i.e., less willing to seek out their help) than individuals affiliated with the medical field. Sixth, women will rate all individuals higher than men.

\section{Perceived Effectiveness of Various Individuals}

Seventh, psychologists will be rated lower (i.e., less effective) than individuals affiliated with the medical field. Eighth, women will rate all individuals higher than men. 


\section{Predicting Willingness to Seek Help}

Ninth, several variables (age, gender, mental health experience, hope [pathways], hope [agency], DQOL [Impact], DQOL [Satisfaction]) will predict willingness to seek help, in general. Tenth, the same variables will predict willingness to seek help from a psychologist. In other words, for hypotheses nine and ten, younger participants, females, those with prior mental health experience, individuals with higher pathways hope, individuals with higher agency hope, those who have been highly impacted by their diabetes, and those who are less satisfied with their diabetes will be more likely to seek out help.

\section{Predicting Willingness to Use Interventions}

Eleventh, participants with high hope pathways scores will be more willing to use all treatments than participants with low pathways scores.

\section{Gender Preferences for Seeking Help}

Twelfth, the majority of participants will prefer to seek out male medical professionals, as compared to female medical professionals, regardless of the participant's gender. Thirteenth, regardless of the participant's gender, participants will prefer to seek out help from a female mental health professional, as compared to male mental health professionals.

\section{Statistical Analyses}

Table 3.1 shows each analysis that was used to analyze each hypothesis. 
Table 3.1

Hypotheses, Measures Used, and Statistical Analyses Employed

\begin{tabular}{|c|c|c|}
\hline Hypothesis & Measures Used & Statistical Analysis \\
\hline $\begin{array}{l}\text { 1. Psychological interventions } \\
\text { (counseling, support group) will be } \\
\text { rated lower with respect to } \\
\text { willingness (i.e., less willing to use) } \\
\text { than non-psychological interventions } \\
\text { (dietary changes, exercise, } \\
\text { medication). }\end{array}$ & HPQ (qn. 2) & $\begin{array}{c}\text { Mixed- model } \\
\text { repeated measures } \\
\text { ANOVA; } \\
\text { Bonferroni-adjusted } t \\
\text { tests }\end{array}$ \\
\hline $\begin{array}{l}\text { 2. Female participants will rate all } \\
\text { interventions higher for willingness } \\
\text { to use than male participants. }\end{array}$ & $\begin{array}{l}\text { About You (qn. 2); } \\
\text { HPQ (qn. 2) }\end{array}$ & $\begin{array}{l}\text { Mixed- model } \\
\text { repeated measures } \\
\text { ANOVA }\end{array}$ \\
\hline $\begin{array}{l}\text { 3. Psychological interventions will } \\
\text { be rated lower with respect to } \\
\text { perceived effectiveness than non- } \\
\text { psychological interventions. }\end{array}$ & HPQ (qn. 3) & $\begin{array}{c}\text { Mixed- model } \\
\text { repeated measures } \\
\text { ANOVA; } \\
\text { Bonferroni-adjusted } t \\
\text { tests }\end{array}$ \\
\hline $\begin{array}{l}\text { 4. Female participants will rate all } \\
\text { interventions higher for perceived } \\
\text { effectiveness than male participants. }\end{array}$ & $\begin{array}{l}\text { About You (qn. 2); } \\
\text { HPQ (qn. 3) }\end{array}$ & $\begin{array}{l}\text { Mixed- model } \\
\text { repeated measures } \\
\text { ANOVA }\end{array}$ \\
\hline $\begin{array}{l}\text { 5. Psychologists will be rated lower } \\
\text { (i.e., less willing to see out their } \\
\text { help) than individuals affiliated with } \\
\text { the medical field. }\end{array}$ & HPQ (qn. 4) & $\begin{array}{c}\text { Mixed-model } \\
\text { repeated measures } \\
\text { ANOVA; } \\
\text { Bonferroni-adjusted } t \\
\text { tests }\end{array}$ \\
\hline $\begin{array}{l}\text { 6. With respect to willingness, } \\
\text { women will rate all individuals } \\
\text { higher than men. }\end{array}$ & $\begin{array}{c}\text { About You (qn. 2); } \\
\text { HPQ (qn. 4) }\end{array}$ & $\begin{array}{l}\text { Mixed- model } \\
\text { repeated measures } \\
\text { ANOVA }\end{array}$ \\
\hline $\begin{array}{l}\text { 7. Psychologists will be rated lower } \\
\text { (i.e., less effective) than individuals } \\
\text { affiliated with the medical field. }\end{array}$ & HPQ (qn. 5) & $\begin{array}{c}\text { Mixed- model } \\
\text { repeated measures } \\
\text { ANOVA; } \\
\text { Bonferroni-adjusted } t \\
\text { tests }\end{array}$ \\
\hline 8. With respect to effectiveness, & About You (qn. 2); & Mixed-model \\
\hline
\end{tabular}


women will rate all individuals

higher than men.

HPQ (qn. 5)

repeated measures

ANOVA

9. Several variables (age, gender, mental health experience, hope [pathways], hope [agency], DQOL [Impact], DQOL [Satisfaction]) will predict willingness to seek help, in general.

10. The same variables will predict willingness to seek help from a psychologist.

About You (qns. 1, 2, 8); Hope Scale; DQOL; HPQ (qn. 1)

Full- model multiple regression; Stepwise multiple regression

About You (qns. 1, 2, 8); Hope Scale;

DQOL; HPQ (qn. 4-L)

Full- model multiple regression; Stepwise multiple regression

11. Participants with high hope pathways scores will be more willing to use all treatments than participants with low pathways scores.

Hope Scale; HPQ (qn. 3)

Median split; Mixed-model repeated measures ANOVA; Bonferroni-adjusted $t$ tests

12. The majority of participants will prefer to seek out male medical professionals, as compared to female medical professionals, regardless of the participant's gender.

13. Regardless of the participant's gender, participants will prefer to seek out help from a female mental About You (qn. 2); HPQ (qn. 6)

Chi-square
About You (qn. 2);
Chi-square HPQ (qn. 7) health professional, as compared to male mental health professionals.

Additionally, as suggested by the American Psychological Association (APA; 2001) and several authors (e.g., Cohen, 1990; Serlin, 1987; Thomas \& Nelson, 1996; Thomas, Salazar, \& Landers, 1991), estimates of effect size (e.g., ?², Cohen's $d$ ) are presented along with $p$ values when appropriate. Moreover, it has recently been suggested that suggested that effect size statistics may be more meaningful when interpreting research than $p$ values (Andersen and Stoové, 1998; Maniar et al., 2001). Finally, with the 
exception of adjusting the alpha level for multiple comparison post hoc tests, an alpha level of .05 was used for all statistical tests. 


\section{Chapter 4: Results}

\section{Effect Size Estimates}

As stated in chapter three, in accordance with the American Psychological Association's Publication Manual (2001), effect size estimates are presented along with $p$ values below. For ANOVA results, $?^{2}$ (eta squared) was calculated, while Cohen's $d$ was used for $t$ tests.

Eta squared is an index of the proportion of the explained variance and can range from 0 to 1 . The index was first developed by Huberty and Smith (1982) and is analogous to other measures that assess the amount of explained variance, such as $R^{2}$ in multiple regression (Pedhazur, 1982). Essentially, ? ${ }^{2}$ represents the proportion of variance in the dependent variable $\left(S S_{\text {TOTAL }}\right)$ that is attributed to the effect $\left(S S_{\text {EFFECT }}\right)$ and is a common effect size estimate for ANOVA, ANCOVA, MANOVA, and MANCOVA. Although, omega squared $\left(?^{2}\right)$ is recommended for repeated measures, this estimate can only be used for equal cell sizes (Tabachnick \& Fidell, 1996). Therefore, the current study used $?^{2}$ for all ANOVAs.

Cohen's $d$, on the other hand, is most often associated with $t$ tests. Cohen (1977), one of the first to propose using effect sizes as a means of determining an estimate of meaningful differences, suggested that a "small" effect corresponded with $d=.10$, a "medium" effect was around $d=.25$, and a "large" effect was over $d=.40$. Subsequent researchers have proposed that a small, moderate, and large effect be set at .20, .50, and .80, respectively (Cohen, 1988; Howell, 1997; Thomas \& Nelson, 1996). 


\section{Treatment and Helper Preference}

Although originally intended as an additional between-subjects variable, diabetes type was dropped because only four male, type 1 patients participated in the study. Additionally, previous mental experience was not used as a between-subjects variable because do differences existed between those who had prior mental health experience and those who had not for willingness to seek help, willingness to counseling and willingness to see a psychologist. Therefore, mixed-model (between-within) repeated measures ANOVAs, rather than MANOVAs, were computed on the list of potential treatments and helpers (within-subjects; computed separately) using gender as the between-subjects comparison. Separate ANOVAs were computed for willingness to use treatments and perceived effectiveness of treatments. When necessary, ANOVAs were corrected for sphericity, using the Greenhouse-Geisser correction.

Similar to the requirement of homogeneity of variance in a standard ANOVA in order to have an accurate estimate of the error variance, repeated measures ANOVAs and MANOVAs require a more complicated assumption known as sphericity. Sphericity "describes a form of the relationship between scores at all levels of the W-S variable" (Weinfurt, 2000, p. 329). (For a detailed explanation of sphericity, see Hertzog, 1994.) Thus, Mauchly's Sphericity Test was first conducted in order to test for sphericity. When this assumption was violated, the Greenhouse-Geisser Epsilon, an adjustment of degrees of freedom used in univariate repeated measures, was used as a correction for sphericity. According to Weinfurt (2000), the Greenhouse-Geisser correction is a more conservative procedure than other estimates, such as the Huyn-Feldt. 
Willingness to Use Treatments

$\mathrm{H}_{1}$ : Psychological interventions (counseling, relaxation training, support group) will be rated lower with respect to willingness (i.e., less willing to use) than non-psychological interventions (dietary changes, exercise, medication).

$\mathrm{H}_{2}$ : Female participants will rate all interventions higher for willingness to use than male participants.

The ANOVA for willingness to use treatments revealed no significant main effects or interactions after correcting for sphericity, thus showing no support for hypotheses one and two. Overall means for treatment willingness are presented in Table 4.1.

Table 4.1

Diabetes Patients' Willingness to Use Treatments for Emotional Difficulties

\begin{tabular}{lcc}
\hline Treatment & Mean Rating & SD \\
\hline Counseling & 4.05 & .61 \\
Dietary changes & 4.37 & .67 \\
Exercise & 4.21 & .70 \\
Medication & 4.37 & .67 \\
Relaxation training & 4.32 & .66 \\
Support group & 4.21 & .84 \\
\hline
\end{tabular}

Note. Ratings were obtained using a 5-point, Likert-type scale, anchored by "Never" (1) and "Definitely" (5). 
Perceived Effectiveness of Treatments

\section{$\mathrm{H}_{3}$ : Psychological interventions will be rated lower with respect to perceived effectiveness than non-psychological interventions. \\ $\mathrm{H}_{4}$ : Female participants will rate all interventions highe $\mathrm{r}$ for perceived effectiveness than male participants.}

The ANOVA for perceived effectiveness of treatments revealed a main effect for treatment, corrected $F(3.287,243.266)=22.922, p=.000, ?^{2}=.236$ and gender, $F(1$, $74)=7.219, p=.009, ?^{2}=.089$, with females rating all treatments an average of .376 points higher than males. The interaction of treatment $\mathrm{X}$ gender was also significant, corrected $F(3.287,243.266)=3.867, p=.008, ?^{2}=.050$. Treatment means for men, women, and overall are presented in Table 4.2.

With respect to hypothesis four, Bonferroni-adjusted post hoc $t$ tests indicated that females rated three treatments significantly higher than males. First, after correcting for unequal variance, medication was rated as more effective by females than males, $t$ (30.6) $=2.943, p=.006, d=.82$. Second, counseling was rated significantly higher by females than males, $t(74)=2.913, p=.005, d=.69$. Third, female participants rated dietary changes as significantly more effective than male participants, $t(74)=2.400, p=.019, d$ $=.55$. No significant differences were found for exercise, relaxation raining, or support group.

Because the interaction was found to be significant, comparisons within treatment ratings were conducted separately for males and females. Bonferroni-adjusted $t$ tests resulted in the following findings. 
Table 4.2

Diabetes Patients' Perceived Effectiveness of Treatments for Emotional Difficulties

\begin{tabular}{lcccc}
\hline Treatment & Men & $S D$ & Women & $S D$ \\
\hline Counseling & 3.17 & 1.09 & 3.85 & .87 \\
Dietary changes & 4.00 & 1.02 & 4.46 & .64 \\
Exercise & 4.67 & .48 & 4.69 & .61 \\
Medication & 3.83 & 1.09 & 4.54 & .64 \\
Relaxation training & 4.17 & .70 & 4.15 & .78 \\
Support group & 3.83 & .92 & 4.23 & .98 \\
\hline
\end{tabular}

Note. Ratings were obtained using a 5-point, Likert-type scale, anchored by "Never" (1) and "Definitely" (5).

For male participants, exercise was rated higher than medication $(p=.016)$, support group $(p=.000)$, and counseling $(p=.000)$; relaxation training was rated higher than medication $(p=.038)$ and counseling $(p=.000)$; dietary changes was rated higher than counseling $(p=.003)$; support group was rated higher than counseling $(p=.000)$; and medication was rated higher than counseling $(p=.004)$. Thus, all treatments were rated as significantly more effective than counseling, and exercise was rated as more effective than a support group.

For female participants, exercise was rated higher than relaxation training ( $p=$ $.002)$ and counseling $(p=.000)$; medication was rated higher than relaxation training $(p=$ $.007)$ and counseling $(p=.000)$; dietary changes were rated higher than relaxation 
training $(p=.010)$ and counseling $(p=.005)$; and support group was rated higher than counseling $(p=.028)$. Thus, all treatments, save relaxation training, were rated as more effective than counseling, and exercise, medication, and dietary changes were rated as more effective than relaxation training. Therefore, for both men and women, support was found for hypothesis three.

\section{Willingness to Seek Help from Various Individuals}

\section{H5: Psychologists will be rated lower (i.e., less willing to seek out their help) than} individuals affiliated with the medical field

\section{H6 $_{6} \quad$ Women will rate all individuals higher than men.}

The ANOVA for willingness to seek help from various individuals revealed a significant main effect for helper, corrected $F(5.083,294.806)=14.999, p=.000, ?^{2}=$ .205. Mean helper ratings are presented in Table 4.3. As shown in Table 4.4, Bonferroniadjusted $t$ tests revealed that participants reported being significantly more likely to seek help from eight professionals (physician/doctor, diabetes educator, exercise physiologist, nutritionist, pharmacist, nurse, friend/family member, and health psychologist) as compared to psychologist, thus supporting hypothesis five. Significant Bonferroni $t$ tests corresponded with Cohen's $d \mathrm{~s} \geq .57$. No main effect emerged for gender, thus showing no support for hypothesis six. 
Table 4.3

Diabetes Patients' Willingness to Seek Help from Various Individuals for Emotional Difficulties (listed from most willing to least willing)

\begin{tabular}{lcc}
\hline Individual/Helper & Mean Rating & $S D$ \\
\hline Physician/Doctor & 4.53 & .60 \\
Diabetes Educator & 4.47 & .68 \\
Exercise Physiologist & 4.21 & .77 \\
Nutritionist & 4.05 & .76 \\
Nurse & 3.94 & .85 \\
Pharmacist & 3.94 & .98 \\
Friend/Family Member & 3.89 & 1.06 \\
Health Psychologist & 3.67 & 1.06 \\
Minister/Pastor & 3.67 & 1.16 \\
Behavioral Medicine Specialist & 3.50 & .87 \\
Counselor/Social Worker & 3.29 & 1.13 \\
Psychiatrist & 3.28 & 1.10 \\
Psychologist & 3.11 & .88 \\
\hline
\end{tabular}

Note. Ratings were obtained using a 5-point, Likert-type scale, anchored by "Never" (1) and "Definitely" (5). 
Table 4.4

Mean Differences in Willingness to seek Help from Various Individuals as Compared to Psychologist

\begin{tabular}{lcc}
\hline Individual/Helper & $M$ Difference & $d$ \\
\hline Physician/Doctor & $1.35^{* * *}$ & 1.55 \\
Diabetes Educator & $1.35^{* * *}$ & 1.20 \\
Nutritionist & $.83^{* * *}$ & 1.01 \\
Exercise Physiologist & $.92^{* * *}$ & .93 \\
Pharmacist & $.83^{* * *}$ & .86 \\
Nurse & $.78^{*}$ & .74 \\
Health Psychologist & $.40^{*}$ & .67 \\
Friend/Family Member & $.80 *$ & .57 \\
Minister/Pastor & .32 & .40 \\
Behavioral Medicine Specialist & .38 & .43 \\
Psychiatrist & .14 & .18 \\
Counselor & .14 & .11 \\
\hline
\end{tabular}

Note. Ratings were obtained using a 5-point, Likert-type scale, anchored by "Never" (1) and "Definitely" (5). $M$ difference obtained using estimated marginal means.

${ }^{*} p<.05 . * * p<.01 . * * * p<.001$. (Bonferroni-adjusted $t$ tests). 


\section{Perceived Effectiveness of Various Individuals}

\section{H$_{7}$ : Psychologists will be rated lower (i.e., less effective) than individuals affiliated with the medical field.}

\section{$\mathrm{H}_{8}$ : Women will rate all individuals higher than men.}

The ANOVA for perceived effectiveness of various individuals revealed a significant main effect for helper, corrected $F(6.355,419.436)=27.988, p=.000, ?^{2}=$ .298 , and a significant interaction for helper $\mathrm{X}$ gender, corrected $F(6.355,419.436)=$ $3.420, p=.002, ?^{2}=049$. Mean ratings for males and females are presented in Table 4.5. No main effect emerged for gender, thus showing no support for hypothesis eight.

Post hoc tests were done separately for men and women. Results of Bonferroniadjusted $t$ tests for men are presented in Table 4.6. Results indicated that four individuals (nutritionist, diabetes educator, exercise physiologist, and health psychologist) were rated significantly higher (i.e., more effective) than psychologist. Because of the relatively small number of men in the current study $(n=24)$, though, effect size estimates are important to consider in addition to $p$ values. For example, physician/doctor, pharmacist, and nurse were rated at leas one-half-point higher than psychologist, with $d$ s at the moderate level $(\geq .54)$. Therefore, with a larger sample size more individuals may have been rated significantly higher than psychologist, and at least three additional titles should be viewed as practically more significant than psychologist.

Post hoc tests for women are presented in Table 4.7. Bonferroni-adjusted $t$ tests revealed that eight professional were rated as more effective than psychologists (physician/doctor, diabetes educator, exercise physiologist, pharmacist, health psychologist, nutritionist, friend/family member, and nurse). Significant $p$ values 
corresponded with $d$ values $\geq .49$. Thus, for both men and women, some support was found for hypothesis seven.

\section{Table 4.5}

Diabetes Patients' Mean Ratings of Perceived Effectiveness of Various Individuals for Emotional Difficulties

\begin{tabular}{|c|c|c|c|c|}
\hline Individual/Helper & Men & $S D$ & Women & $S D$ \\
\hline Behavioral Medicine Specialist & 3.33 & 1.33 & 3.54 & .94 \\
\hline Counselor/Social Worker & 3.17 & 1.09 & 3.08 & 1.01 \\
\hline Diabetes Educator & 4.50 & .51 & 4.64 & .62 \\
\hline Exercise Physiologist & 4.00 & 1.18 & 4.31 & .62 \\
\hline Friend/Family Member & 3.33 & 1.27 & 3.92 & .93 \\
\hline Health Psychologist & 3.67 & .96 & 3.77 & 1.06 \\
\hline Minister/Pastor & 3.17 & 1.49 & 3.77 & 1.06 \\
\hline Nurse & 3.67 & .76 & 3.85 & .96 \\
\hline Nutritionist & 4.50 & .51 & 4.00 & .85 \\
\hline Pharmacist & 4.00 & .83 & 4.00 & .97 \\
\hline Physician/Doctor & 4.33 & .76 & 4.77 & .43 \\
\hline Psychiatrist & 3.17 & 1.24 & 3.31 & 1.34 \\
\hline Psychologist & 3.17 & 1.24 & 3.08 & 1.01 \\
\hline
\end{tabular}

Note. Ratings were obtained using a 5-point, Likert-type scale, anchored by "Never" (1) and "Definitely" (5). 
Table 4.6

Mean Differences in Males' Perceived Effectiveness of Various Individuals as Compared to Psychologist

\begin{tabular}{lcc}
\hline Individual/Helper & M Difference & $d$ \\
\hline Nutritionist & $1.33^{* * *}$ & .75 \\
Diabetes Educator & $1.33^{* *}$ & .68 \\
Health Psychologist & $.50 * *$ & .69 \\
Exercise Physiologist & $.83^{*}$ & .66 \\
Physician/Doctor & 1.17 & .61 \\
Pharmacist & .83 & .55 \\
Nurse & .50 & .54 \\
Behavioral Medicine Specialist & .17 & .24 \\
Friend/Family Member & .17 & .15 \\
Counselor/Social Worker & .00 & .00 \\
Psychiatrist & .00 & .00 \\
Minister/Pastor & & \\
\hline
\end{tabular}

Note. Ratings were obtained using a 5-point, Likert-type scale, anchored by "Never" (1) and "Definitely" (5). $M$ difference obtained using estimated marginal means. $* p<.05 . * * p<.01 . * * * p<.001$. (Bonferroni-adjusted $t$ tests). 
Table 4.7

Mean Differences in Females' Perceived Effectiveness of Various Individuals as

Compared to Psychologist

\begin{tabular}{lcc}
\hline Individual/Helper & M Difference & $d$ \\
\hline Physician/Doctor & $1.64 * * *$ & .94 \\
Diabetes Educator & $1.46^{* * *}$ & .75 \\
Exercise Physiologist & $1.18^{* * *}$ & .67 \\
Pharmacist & $1.00^{* * *}$ & .80 \\
Health Psychologist & $.82 * * *$ & .95 \\
Nutritionist & $.73 * * *$ & .52 \\
Friend/Family Member & $.82 * *$ & .45 \\
Nurse & $.64 *$ & .49 \\
Minister/Pastor & .73 & .47 \\
Behavioral Medicine Specialist & .36 & .41 \\
Psychiatrist & .27 & .27 \\
Counselor/Social Worker & .18 & .19 \\
\hline
\end{tabular}

Note. Ratings were obtained using a 5-point, Likert-type scale, anchored by "Never" (1) and "Definitely" (5). $M$ difference obtained using estimated marginal means.

$*^{*} p<.05 .{ }^{* *} p<.01 .{ }^{* * *} p<.001$. (Bonferroni-adjusted $t$ tests). 


\section{Predicting Willingness to Seek Help}

Seven predictor variables (age, gender, mental health experience, hope [pathways], hope [agency], DQOL [Impact], DQOL [Satisfaction]) were used in two separate multiple regression analyses in an attempt to predict willingness to seek help in general and willingness to seek help from a psychologist.

\section{Willingness to Seek Help in General}

\section{H9: Several variables (age, gender, mental health experience, hope [pathways], hope [agency], DQOL [impact], DQOL [satisfaction]) will predict willingness to seek help, in general.}

Two analyses, a full-model multiple regression and a forced/stepwise multiple regression, were performed to determine the best predictors of general willingness to seek help. Before analyses were conducted, diagnostic checks were first performed on the data to determine the normality of residuals, non-linearity of predictor-criterion relationships, and all influential outliers. Based upon Cook's distance and Centered Leverage values, all cases were retained. Collinearity statistics indicated that for all predictors, tolerance scores were greater than .44. Additionally, with the exception of Hope (pathways), all predictors' VIF scores were less than 1.8. Hope (pathways) had an elevated VIF of 2.262, suggesting shared variance with other predictor. Correlations with other predictors revealed significant correlations between Hope (pathways) and Hope (agency) $(r=.513$, $p=.000)$, DQOL (impact) $(r=.501, p=.000)$, Gender $(r=.481, p=.000)$, Mental Health Experience $(r=.378, p=.001)$, and Age $(r=.335, p=.004)$.

A full-model multiple regression was then performed. By including all seven predictor variables, this model yielded $50.2 \%$ of accounted variability in general 
willingness to seek help. In addition, $R(.709)$ was found to be significant, $F(7,60)=$ $8.647, p=.000$. In order to determine the most influential predictors, a stepwise multiple regression was then performed after accounting for the three demographic predictors (age, gender, mental health experience). The resulting three models are displayed in Table 4.8.

The three demographic predictors accounted for $16.7 \%$ of the variance in general willingness to seek help. Again, $R(.411)$ was found to be significant, $F(3,64)=4.339, p$ $=.008$. Model 2 entered an additional predictor, DQOL (satisfaction), and resulted in a 10.4\% increase in variance accounted for, $p=.004$. Model 3 entered a fifth predictor, DQOL Impact, and resulted in an $18.9 \%$ increase in variance accounted for, $p=.000$. A fourth model not shown in Table 4.8 added a sixth predictor, Hope Pathways, and resulted in a 3.5\% increase in variance accounted for, $p=.043$.

Model 3 was selected as the most parsimonious model, accounting for ample variance. Five variables (Age, Gender, Mental Health Experience, DQOL Satisfaction, and DQOL Impact) predicted general willingness to seek help nearly as well as the entire pool of seven predictors. $\left(R^{2}\right.$ for the stepwise model was .462 , and for the full model, $R^{2}$ $=.502)$. Therefore, some support was found for hypothesis nine. 
Table 4.8

Step-wise Regression Analysis Predicting Willingness to Seek Help in General After Accounting for Demographic Predictors

\begin{tabular}{|c|c|c|c|c|c|}
\hline Step and predictor variables & $B$ & $S E B$ & B & $R^{2}$ & $? R^{2}$ \\
\hline Model 1 & & & & .169 & .169 \\
\hline Age & $.011 * *$ & .004 & .317 & & \\
\hline Gender & .274 & .161 & .208 & & \\
\hline Mental Health Exp. & -.224 & .152 & -.178 & & \\
\hline Model 2 & & & & .273 & .104 \\
\hline Age & .006 & .004 & .195 & & \\
\hline Gender & .323 & .153 & .245 & & \\
\hline Mental Health Exp. & -.219 & .143 & -.174 & & \\
\hline DQOL (satisfaction) & $.012 * *$ & .004 & .345 & & \\
\hline Model 3 & & & & .462 & .189 \\
\hline Age & .002 & .004 & .068 & & \\
\hline Gender & $.454 * * *$ & .136 & .345 & & \\
\hline Mental Health Exp. & -.110 & .126 & -.088 & & \\
\hline DQOL (satisfaction) & $.021 * * *$ & .004 & .587 & & \\
\hline DQOL (impact) & $-.023 * * *$ & .005 & -.508 & & \\
\hline
\end{tabular}

Note. $* * p<.01 . * * * p<.001$. 
Willingness to Seek Help from a Psychologist

\section{$H_{10}$ : Several variables (age, gender, mental health experience, hope [pathways], hope [agency], DQOL [impact], DQOL [satisfaction]) will predict willingness to seek help from a psychologist.}

Two analyses, a full-model multiple regression and a forced/stepwise multiple regression, were also performed to determine the best predictors of willingness to seek help from a psychologist. Before analyses were conducted, diagnostic checks were first performed on the data to determine the normality of residuals, non- linearity of predictorcriterion relationships, and all influential outliers. Based upon Cook's distance and Centered Leverage values, all cases were retained. Collinearity statistics again revealed Hope (Pathways) as potentially inflating variance, with a VIF $=3.096$.

A full-model multiple regression was then performed. By including all seven predictor variables, this model yielded $45.7 \%$ of accounted variability in general willingness to seek help from a psychologist. In addition, $R(.676)$ was found to be significant, $F(7,52)=6.263, p=.000$. In order to determine the most influential predictors, a stepwise multiple regression was then performed after accounting for the three demographic variables (age, gender, mental health experience). The resulting three models are displayed in Table 4.9. The three demographic variables are displayed in Model 1 and accounted for $10.2 \%$ of the variance in willingness to seek help from a psychologist, $F(3,56)=2.118, p=.108$. By adding Hope (agency) in Model 2, an increase of 23.8\% was accounted for, $p=.000$. Model 3 added DQOL (impact) and added an additional $9.3 \%$ of variance accounted for, $p=.004$. 
Table 4.9

Step-wise Regression Analysis Predicting Willingness to Seek Help from a Psychologist After Accounting for Demographic Variables

\begin{tabular}{|c|c|c|c|c|c|}
\hline Step and predictor variables & $B$ & $S E B$ & B & $R^{2}$ & $? R^{2}$ \\
\hline Model 1 & & & & .102 & .102 \\
\hline Age & .016 & .008 & .271 & & \\
\hline Gender & .193 & .305 & .095 & & \\
\hline Mental Health Exp. & .054 & .288 & .027 & & \\
\hline Model 2 & & & & .340 & .238 \\
\hline Age & .005 & .007 & .089 & & \\
\hline Gender & -.125 & .273 & -.061 & & \\
\hline Mental Health Exp. & .006 & .249 & .003 & & \\
\hline Hope (agency) & $.256 * * *$ & .058 & .564 & & \\
\hline Model 3 & & & & .433 & .093 \\
\hline Age & .009 & .007 & .164 & & \\
\hline Gender & -.268 & .260 & -.132 & & \\
\hline Mental Health Exp. & -.008 & .233 & -.004 & & \\
\hline Hope (agency) & $.236 * * *$ & .054 & .519 & & \\
\hline DQOL (impact) & $.022 * *$ & .008 & .320 & & \\
\hline
\end{tabular}

Note. $* * p<.01 . * * * p<.001$.

Model 3 was selected as the most parsimonious model, accounting for ample variance. After accounting for the three demographic variables (age, gender, and mental 
health experience), two variables, Hope (agency) and DQOL Impact, were retained. Model 3 predicted willingness to seek help from a psychologist nearly as well as the entire pool of seven predictors. ( $R^{2}$ for the stepwise model 3 was .433 , and for the full model, $\left.R^{2}=.457\right)$. Therefore, some support was found for hypothesis ten.

Willingness to Use Interventions as a Function of Hope Pathways

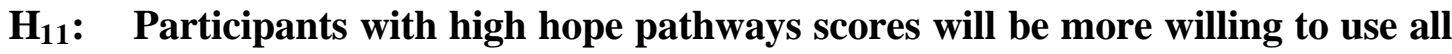 treatments than participants with low pathways scores.}

A median split was performed on the hope pathways scores. The median of the sample was found to be 13 . All participants with hope pathways scores lower than 13 were placed in the "Low" group, while those with scores above 13 were placed in the "High" group. Participants with scores of 13 were not included in the present analysis.

A mixed-model repeated measures ANOVA was then performed using the new pathways categories as the between group comparison and the treatment willingness ratings as the within group comparison. Analysis revealed a main effect for treatment, corrected $F(3.333,193.331)=4.195, p=.005, ?^{2}=.067$ and an interaction between treatment and pathways, corrected $F(7.236,193.331)=4.920, p=.002, ?^{2}=.078$. Post hoc tests, via Bonferroni-adjusted $t$ tests, indicated that for all participants, relaxation training was preferred over exercise $(p=.010)$ and counseling $(p=.001)$, and medication was preferred over counseling $(p=.000)$.

Additionally, participants with higher pathways scores were more willing to use counseling, exercise, and support group than those with lower pathways scores, thus showing some support for hypothesis eleven. Those with lower pathways scores were 
more willing to use medication than those with high pathways scores. See Table 4.10 for statistical values.

Table 4.10

Diabetes Patients' Willingness to Use Treatments for Emotional Difficulties as a Function of Hope Pathways

\begin{tabular}{lcccccc}
\hline Treatment & Low & $S D$ & High & $S D$ & $t$ & \multicolumn{1}{l}{ S/ } \\
\hline Counseling & 4.00 & .51 & 4.29 & .46 & $-2.271^{*}$ & .45 \\
Dietary changes & 4.13 & .61 & 4.43 & .74 & -1.717 & .45 \\
Exercise & 3.88 & .61 & 4.43 & .74 & $-3.132^{*}$ & .79 \\
Medication & 4.63 & .49 & 4.29 & .72 & $2.116^{*}$ & .47 \\
Relaxation training & 4.38 & .49 & 4.57 & .50 & -1.526 & .28 \\
Support group & 4.13 & .79 & 4.57 & .74 & $-2.241^{*}$ & .52 \\
\hline
\end{tabular}

Note. Ratings were obtained using a 5-point, Likert-type scale, anchored by "Never" (1) and "Definitely" (5). Participants were placed in the Low and High groups based upon how they scored relative to the median (13).

$*_{p}<.05$. (Bonferroni-adjusted $t$ tests).

Gender Preferences for Seeking Help

$\mathrm{H}_{12}$ : The majority of participants will prefer to seek out male medical professionals, as compared to female medical professionals, regardless of the participant's gender. 


\section{$\mathrm{H}_{13}$ : Regardless of the participant's gender, participants will prefer to seek out help from a female mental health professional, as compared to male mental health professionals.}

Participants' preferences for the gender of potential medical and psychological professional when seeking help were intended to be analyzed using a chi-square analysis. However, due to minimal numbers in several cells, these analyses could not be conducted. Thus, no evidence for hypotheses twelve and thirteen could be obtained. Nevertheless, when considering the gender of a medical professional when seeking help for emotional difficulties, $71 \%$ of women and $83 \%$ of men reported no preference. Additionally, 14\% of women preferred seeking help from a male medical professional. No men reported preferring to seek help from a male medical professional. Fourteen percent of women and $17 \%$ of men reported preferring to seek help from a female medical professional.

With regard to the gender of mental health professionals, $79 \%$ of women and $100 \%$ of men reported no preference. Fourteen percent of women preferred seeking help from a male mental health professional, while $7 \%$ preferred seeking help from a female mental health professional.

\section{Summary}

The hypothesis that indicated psychological interventions would be rated lower than non-psychological interventions was not supported. The hypothesis that indicated females would rate interventions higher than males was not supported. The hypothesis that proposed that psychological interventions would be rated as less effective than nonpsychological interventions was supported. The hypothesis that indicated that women 
would rate treatments as more effective than men was supported. The hypothesis that stated psychologists would be rated as less willingness to use than medical professionals was supported. The hypothesis that indicated women would be more willing to seek help from all individuals as compared to men was not supported. Support was found for the hypothesis stated psychologists would be rated as less effective than medical professionals. No support was found for the hypothesis that indicated women, as compared to men, would rate all individuals as more effective. Some support was found for the hypotheses that suggested several variables would predict willingness to seek help, in general, and willingness to seek help from a psychologist. The hypothesis that indicated participants with high pathways hope would be more willing to use treatments than individuals with low pathways hope was supported for some interventions. The hypotheses that suggested gender preferences for seeking help could not be assessed. 


\section{Chapter 5: Discussion}

The discussion of the study's results and implications are discussed below.

Discussion of the results relative to each hypothesis is presented first. Following this section, the study's limitations and implications of the findings are discussed.

\section{Discussion of Hypotheses}

\section{Intervention Preferences}

Previous research has suggested that the public tends to stigmatize (Linder, Brewer, Van Raalte, \& DeLange, 1991; Maniar, Curry, Sommers-Flanagan, \& Walsh, 2001; McGuire \& Borowy, 1979) as well as under-utilize (Deane \& Todd, 1996; Farberman, 1997; McGuire \& Borowy, 1979; Murtsein \& Fontaine, 1993; Reinhold, 1973; Segal, Weiss, \& Sokol, 1965; Stewart, 1996; Webb \& Speer, 1985, 1986; Wood, Jones, \& Benjamin, 1986) psychological services. If this trend exists for DM patients, then one might assume that individuals with DM would be reluctant to use psychological interventions as a preventative measure. Moreover, when encountering psychological/emotional difficulties, DM patients would be reluctant to use psychological services as an intervention. For example, they may not want to participate in counseling or a support group. In the present study, patients with DM favorably rated all treatments with regard to willingness to use. Therefore, there was no support for the first hypothesis, which suggested that psychological interventions would be rated the lowest by patients with DM.

Research has also indicated that, when encountering psychological difficulties, men tend to under-utilize medical (Leaf \& Bruce, 1987) and psychological services (Bland, Newman, \& Orn, 1997; Brinson \& Kottler, 1995; Gottesfeld, 1995; Gove, 1984; 
Greenley \& Mechanic, 1976; Kessler, 1981; Kessler, Brown, \& Broman, 1981; Leong \& Zachar, 1999; Marcus, Seeman, \& Telesky, 1984; Rickwood \& Braithwaite, 1994;

Veroff, Kulka, \& Douran, 1981) as compared to women. Therefore, the present study's second hypothesis was that women would be more willing to use all interventions than men. Nevertheless, no support for hypothesis two was found. Rather, men and women were equally willing to use all treatments.

Similar to the rationale discussed above regarding the stigmatization of psychological services, it was hypothesized that psychological treatments would be rated as less effective than other treatments (hypothesis three). In the current study, men rated all interventions (including support group) significantly higher than counseling. Exercise was rated significantly higher than support group. With respect to women, all interventions, with the exception of relaxation training were rated significantly higher than counseling. Therefore, counseling appears to be perceived as less effective than other treatments (e.g., dietary changes, exercise, medication, relaxation training, and support group). Thus, some support for hypothesis three was obtained. It appears that DM patients may be more receptive to a support group than counseling. Finally, because of the under-utilization of psychological services discussed above, it was also hypothesized that women would rate treatments as more effective than men (hypothesis four). Results from the current study demonstrated support for this hypothesis for counseling, medication, and nutritional changes but not for exercise, relaxation training, and support group.

Taken together, the findings suggest that DM patients are willing to use a variety of interventions for emotional difficulties. With respect to perceived effectiveness of 
these interventions, though, counseling seems to be perceived as less effective than other interventions. It may be that patients are entrenched in the medical model, and medical interventions are viewed as the "default" choice. Additionally, counseling, which tends to be effective by empowering patients, may be seen as less viable by patients who prefer or are used to being told what to do. Finally, it may be that this trend is exclusive to diabetes patients in Appalachia.

Nevertheless, counseling was still rated in the "Maybe" to "Probably" effective range. Some differences did emerge for gender as well. Therefore, the poor adherence rates for DM patients mentioned in chapter two do not appear to be related to two (willingness and effectiveness) of Kazdin's (1980b) components of treatment acceptability. It may be that poor adherence rates for DM patients is related to some or all of the other four factors (acceptability, suitability for individuals having other problems, cruelness/fairness, and likeability). Or, adherence for DM patients may be unrelated to treatment acceptability.

\section{Helper Preferences}

The fifth hypothesis stated that DM patients would be more willing to seek out help for emotional difficulties from medical professionals than professionals affiliated with psychology. Support for this hypothesis was found, as participants rated all potential individuals not associated with psychology (physician/doctor, diabetes educator, exercise physiologist, nutritionist, pharmacist, nurse, and friend/family member) higher than psychologist (as well as psychiatrist and counselor). With regard to professionals closely affiliated with both medicine and psychology, health psychologist was rated significantly higher than psychologist, whereas behavioral medicine specialist was not. Results 
corresponded with previous research that found the majority of older adults (84.2\%) sought mental health help exclusively from a physician (Campbell, McDaniel, \& Seaburn, 1992) and research that indicated the public's minimization of psychology's contributions to society as compared to the natural sciences (Janda \& England, 1998). Additionally, Katon (1985) found that over half of all primary care visits are due to psychological reasons. Thus, it seems that society, in general, and DM patients, specifically, tend to go first to a medical professional when encountering psychological difficulties.

No support was found for the sixth hypothesis, which suggested that women would be more willing to seek help from all individuals as compared to men. Thus, it appears that both male and female DM patients are equally willing, or unwilling, to seek help from various individuals when encountering mental health problems.

With regard to perceived effectiveness of potential helpers, for both men and women, medical professionals were rated as significantly more effective than psychologists. Therefore, support was found for hypothesis seven. For men, nutritionists, diabetes educators, exercise physiologists, and health psychologists were perceived as more effective than psychologists. Moreover, with a larger sample size, physicians/doctors, pharmacists, and nurses may have been rated significantly higher than psychologists. For women, all medical professionals were rated significantly higher than psychologists: physicians/doctors, diabetes educators, exercise physiologists, pharmacists, health psychologists, nutritionists, and nurses. Women also preferred friends/family members over psychologists. No support was found for hypothesis eight, which suggested that women would rate all treatments as more effective than men. 
Taken together, the above findings appear to indicate that although psychologists are moving into the medical field (Biaggio \& Bittner, 1990; DeLeon, 1991; Enright, Resnick, DeLeon, Sciara, \& Tanney, 1990; Enright, Resnick, Ludwigsen, \& DeLeon, 1993; Johnstone et al., 1995; Tulkin \& Frank, 1985; see also Wiggins, 1994), they are not perceived as effective helpers by DM patients. Thus, past research that suggests the public's unwillingness to see mental health professionals is due to the stigma of getting mental health treatment, may be accurate. It also appears, though, that this stigma may be related to the public's perception of the ineffectiveness of mental health professionals. Indeed, participants who previously sought mental health treatment were not more willing to seek the help of a psychologist than those with no prior mental health experience. The current study suggests that the unwillingness to seek mental health treatment may be due to perceived ineffectiveness of mental health professionals at treating mental illness, at least when compared to medical professionals. Nevertheless, it appears that diabetes patients are more willing to see a psychologist and perceive them to be more effective when the psychologist is referred to as a "health psychologist" rather than a "psychologist."

\section{Predicting Willingness to Seek Help}

The current study's ninth and tenth hypotheses were that several variables (age, gender, mental health experience, hope [pathways], hope [agency], Diabetes Quality of Life [impact], and Diabetes Quality of Life [satisfaction]) would predict (a) willingness to seek help, in general, and (b) willingness to seek help from a psychologist, respectively. With regard to the former, Diabetes Quality of Life (satisfaction), Diabetes Quality of Life (impact), and gender emerged as the only significant predictors. With 
regard to the latter, after accounting for the three demographic variables, Hope (agency) and Diabetes Quality of Life (impact) emerged as the only significant predictors, accounting for $43.3 \%$ of the variance in willingness to seek help form a psychologist.

In other words, it seems that DM patients with high satisfaction regarding their diabetes treatment, who are highly impacted by their diabetes, and who are female are most willing to seek help for emotional difficulties, in general (i.e., from anyone). With regard to satisfaction, it may be that DM patients, who are dissatisfied with their treatment, may feel more frustrated and/or reluctant to seek out additional help. Additionally, it seems logical that those that feel the most impacted by their diabetes are more likely to seek help as compared to those who are not impacted as greatly. Finally, the greater willingness to seek help by females, as compared to males, corresponds with previous research that has shown that women are more likely to utilize mental health than men (Bland et al., 1997; Leong \& Zachar, 1999; Rickwood \& Braithwaite, 1994).

Additionally, DM patients with high agency hope and low diabetes impact appear to be most willing to seek the help of a psychologist. Perhaps individuals with high agency (i.e., a cognitive sense of energy) feel more hopeful and are therefore more receptive to seeing a psychologist. Unfortunately, research has shown that low hope is associated with depression (Beck, Rush, Shaw, \& Emery, 1979), so those who may truly need to see a psychologist, appear less likely to do so. Moreover, individuals who scored low on diabetes impact may be more willing to see a psychologist because medical professionals may be perceived as the "default" choice when highly impacted. In other words, even though participants were presented with a mental health scenario ("Patients with diabetes regularly experience emotional difficulties [e.g., worries, tension, anxiety, 
nerves, stress, sadness, etc.]. Imagine that you were experiencing diabetes-related emotional difficulties."), it may be that when highly impacted by diabetes, patients are more likely to seek out the assistance of a medical professional. On the other hand, when the diabetes impact is low and psychological symptoms are still existent, a psychologist becomes a more viable option.

Nevertheless, more than half of the variance in both analyses was unaccounted for, suggesting that other factors play a role in determining what types of DM patients will seek help for emotional difficulties. Some of these factors might be rural versus urban residence, residential distance from a mental health center, education level, frequency of religious practice, annual income, and marital status, as Lord-Flynn (1989) suggested.

\section{Predicting Willingness to Use Interventions}

The present study's eleventh hypothesis was that participants with high hope pathways scores would be more willing to use all treatments than participants with low pathways scores. Some support for this hypothesis was found. Individuals with high pathways hope scores rated "psychological" treatments (counseling and support group) and exercise higher than those with low pathways scores. Individuals with low pathways scores rated medication significantly higher than those with high pathways scores. No differences were found for dietary changes or relaxation training. It may be that medication is perceived as the "default" intervention. Individuals with decreased ability to see multiple or alternate solutions to a problem (i.e., low pathways scores) may only rank the default intervention highly. On the other hand, individuals who are able to see 
multiple solutions to a problem may be more apt to select alternatives to medicine as compared to those who are more narrow-minded.

Previous research has also indicated that hope is related to self-efficacy (Snyder, Irving, \& Anderson, 1991). It may also be that those with higher pathways hope had higher self-efficacy, believing that they could make an impact in their symptoms. Those with low hope, and consequently, low self-efficacy, may be more apt to turn to medication because they do not feel they can handle their problems by engaging in some activity (i.e., on their own).

In the current study, patients with high pathways hope were more willing to participate in an exercise program. Because treatment acceptability has been shown to positively correlate with treatment compliance (O’Brien \& Karsh, 1990), hope may be an important measure to assess along with treatment acceptability prior to placing a DM patient on an exercise program. Therefore, if a patient has low hope, it may be advantageous to help the patient increase their pathways hope before making an exercise prescription. This may help increase the already low compliance rates for DM patients and for exercise, in general. Preference for Helper's Gender

The current study was unable to assess for gender preferences of psychological or medical professional helper. Prior research in this area has resulted in mixed results (Delgado et al., 1999; Greenberg \& Zeldow, 1980; Pikus \& Heavey, 1996; Stamler, Christiansen, Staley, \& Macagno-Shang, 1991). 


\section{Study Limitations}

Before making overall discussions and conclusions for the current study, it is important to address some possible limitations. Two main limitations of the current study are generalizability, or external validity, and the nature of the design.

\section{Limitations in External Validity}

The current study used participants from an Appalachian region of the United States. Moreover, most of the participants (70\%) were diagnosed with type 2 diabetes. The majority (90\%) also was Caucasian. Thus, the current study's results may not extend to populations who: (a) do not have diabetes, (b) are not from the Appalachian region of the United States, (c) have some form of diabetes other than type 2, and (d) are not Caucasian.

\section{Limitations in Design}

The current study also had some limitations in the design. First, due to the relatively small sample size $(N=80)$, some predictor variables could not be assessed in multiple regression analyses. Second, because the current study used an analogue design, the results may not be an accurate representation of what participants wo uld have been experiencing had they actually been experiencing emotional difficulties (i.e., rather than asking them to imagine that these symptoms were present). Thus, some ecological validity may have been compromised in the current design. Nevertheless, the present study asked participants to rate acceptability and effectiveness for themselves, whereas a number of previous studies have asked participants to rate acceptability for another, fictitious person. In some instances, prior studies have even used participants who had little or no experience with issue (i.e., non-consumers), assuming they would project their 
feelings and attitudes onto some fictional subject. Third, when answering question on the HPQ, participants may have forgotten that they were to be answering the questions with emotional difficulties in mind. Thus, participants may have been responding to the questions, such as "How effective is..." in general terms rather than in psychological terms.

\section{Overall Discussion and Conclusions}

Results from the current study reveal several implications and areas for future study, such as the following: (a) the collaboration between medicine and psychology, (b) how messages are framed and/or referrals are made to for psychological services, (c) the importance of consumer education, and (d) the need for additional treatment acceptability research in health psychology. Each is discussed below.

\section{Collaboration between Medicine and Psychology}

Because results from the current study indicate a reluctance to seek help for psychological difficulties from mental health professionals, the collaboration between medical and psychological professionals will become important in the treatment of DM patients. McDaniel (1995) outlined three types of collaborative relationships that may exist between physicians and psychologists and potential barriers to that collaboration that are described below.

Types of collaboration. Psychologists and physicians may collaborate in three types of relationships. First, physicians may consult with psychologists regarding psychosocial levels of an illness. According to McDaniel (1995), this type of relationship may be beneficial because "...many medical patients are very hesitant to approach a psychologist for any service. A trusted physician can lower fears, increase motivation for 
change, and pave the way for successful connection between a patient or family and a psychologist" (p. 118). Given the present study's findings, this type of relationship seems to be imperative. Second, a psychologist may consult with a physician regarding clients' disease progress. Thus, a physician can educate the psychologist (and indirectly the patient) about the cause, course, and prognosis of any disease that is present (McDaniel, 1995). Third, psychologists and physicians may work jointly. According to McDaniel, this type of collaboration is the most powerful. Joint sessions can be helpful when psychologists are intimidated by medical aspects of a problem, physicians are intimidated by the psychological or psychosocial aspects of a problem, when the family needs clarification or additional information about the problem, or when the psychological and medical treatment are intertwined (McDaniel, 1995).

Barriers to collaboration. McDaniel (1995) also identified several barriers to collaboration between physicians and psychologists, such as differences in training, theoretical paradigms, language, accessibility, and working styles, as well as potential turf battles and professional competition. Overcoming these barriers through compromise — usually at the expense of the psychologist—is essential to forming a collaborative, holistic approach to health care (McDaniel, 1995). Haley, Salzburg, and Barrett (1993) found that other potential barriers may be the lack of funding for psychological services in medical settings and physicians' stigmas of psychologists and psychology. Finally, Kainz (2002) found that additional barriers from the perspective of physicians were difficulty for patients to see a psychologist quickly, difficulty making appointments, insurance coverage, poor communication, and attitudinal resistance on the part of patients and physicians. 


\section{Message Framing/Making Referrals}

Because it also appears that DM patients are reluctant to seek out the help of a psychological professional on their own volition, psychologists may be dependent upon referrals from medical providers. Therefore, the likelihood of a DM patient seeking psychological help may be related to the nature in which medical professionals make referrals a psychologist and/or how the message is framed regarding the importance of seeking out the services of a mental health professional.

Specifically, prior research has indicated that the manner in which the prescription is framed may affect adherence to health behaviors (Banks et al., 1995; Block \& Keller, 1995; Detweiler, Bedell, Salovey, Pronin, \& Rothman, 1999; Kalichman \& Coley, 1995; Kalichman, Kelly, Hunter, Murphy, \& Tyler, 1993; Meyerowitz \& Chaiken, 1987; Rothman, 2000; Rothman, Martino, Bedell, Detweiler, \& Salovey, 1999; Rothman \& Salovey, 1997; Sarafino, 1998). The conclusions of this line of research seem to indicate that if a patient perceived the referral to a psychologist as serving an illness-detecting function (e.g., to assess for psychological disorders), an increased likelihood of following through with the referral will result if the referral is made in a loss-framed manner (Rothman \& Salovey, 1997). An example of this type of message might be: "If you avoid going to a psychologist, you'll fail to take advantage of early detection and treatment of depression. This could eventually make your diabetes worse and, quite possibly, take years off your life."

On the other hand, if the patient perceives the referral as serving a healthaffirming function, then the probability that the patient will comply with the referral will increase with a gain-framed message (Rothman \& Salovey, 1997). An example of a gain- 
framed message might be: "If you go to see a psychologist, he or she may help you prevent the onset of depression, better manage your diabetes, and, in the long run, increase your life expectancy."

Nevertheless, Rothman and Salovey (1997) caution that determining which type of message is more effective may involve more than simply comparing gain-framed and loss-framed messages. They suggest that it is important for researchers and practitioners to also assess how patients decide whether a situation involves a gain or a loss and whether the adoption of the prescribed/recommended behavior is perceived as risky or safe. Thus, further research in the area of message framing and seeking psychological help is warranted.

\section{Consumer Education}

The current study's results suggest a need to educate the public about the roles of psychologists and the process of counseling. Indeed, past research suggests that consumer education can be a viable and effective may to increase compliance (Kazdin, 1980a; Mudford, 1987; Singh \& Katz, 1985) and treatment acceptability (Foxx, Bremer, Shultz, Valdez, \& Johndrow, 1996; Jensen, 1997; Jensen, Kennerley, LeJeune-Hall, \& Bacon, 1992; Kazdin, 1980a; Mudford, 1987; Singh \& Katz, 1985; Tingstrom, 1989). Three suggested manners of educating consumers are discussed below.

Breaking down barriers. Past research indicated that as one's need for mental health services increases, so do the perceived barriers to seeking that help (Lord-Flynn, 1989; Stefl \& Prosperi, 1985). Similarly, the recent study found that when presented with a mental health scenario, diabetes patients were reluctant to seek out the services of mental health professionals. It may be that the amount of perceived barriers to seeking 
mental health treatment was associated with the scenario. Likewise, individuals with low pathways hope (i.e., inability to see many solutions to a problem) rated psychological interventions lower than individuals with high hope. Because these individuals with low pathways hope were unable to see alternatives to their problems, they may have perceived more barriers to seeking psychological help. Thus, it may important for those in the helping professions to directly address perceived barriers to mental health treatment prior to making a referral. One of these barriers, stigma, is discussed below.

De-stigmatizing psychology and psychological services. Patients who have been diagnosed with DM may have some difficulty adjusting to the diagnosis or label of "diabetes mellitus." If the diagnosis of "depression" or "anxiety" is added to the label of diabetes, it could be overwhelming for a patient to handle everything at once. As Maniar (1998) suggested, because of society's stigmas of psychology, some individuals may fear being seen as "defective," and, thus, be unlikely to seek out the help of a mental health professional (Maniar, 1998). This may be especially true for diabetes patients.

Therefore, psychology must be normalized. The current study's results suggest that one way to achieve this is to add the word "health" to a psychologist's title (i.e., health psychologist). This can also be achieved through education of the public. One way that the American Psychological Association is attempting to do this is through a public education campaign that strives to educate the public about psychologists and mental health care (Farberman, 1997). It may also prove helpful to educate and de-stigmatize psychological services to medical professionals, as it appears that they too are uncertain about the benefits of seeking psychological help (Haley, Salzburg, \& Barrett, 1993). 
For example, previous research by Maniar et al. (2001) has indicated that individuals appear to make the "rational match" between a situation they are encountering and from whom to seek help. In the current study, though, participants' matches for emotional difficulties were medical professionals and not psychologists. For some, then, the rational match may be medical providers or medication. In these cases, it is important that patients are educated regarding the role of psychology and a psychologist. In order to this to occur successfully, though, it may first be necessary that the patient's hope increase, specifically the pathways component.

Finally, future research should assess what exactly diabetes patients find fearful about seeking out mental health services. A focus group and/or qualitative research may help to better understand where stigmas lie. This information is essential in order to educate or de-stigmatize, for it is necessary to know what the stigmas are before we once can address them. Because the current study found favorable attitudes toward diabetes educators, focus groups led by diabetes educators, particularly in Appalachia, may prove beneficial.

Changing expectations: Treatment implications. The need to educate a client about the role and effectiveness of therapy is essential at the outset of counseling. It has been suggested that anywhere from $15 \%$ to $100 \%$ of therapy outcome can be attributed to pre-treatment expectancies (Lambert, Shapiro, \& Bergin, 1986; Shapiro, 1981), and the effectiveness of therapy can be greatly increased by addressing and improving expectations about counseling (Frank, 1978; Kirsch, 1985, 1990; Weinberger \& Eig, 1999). 
According to Harris and Rosenthal (1985), several variables, such as distance, eye contact, the frequency and duration of interaction, smiling, and verbal rewards and punishments, communicate expectancies. Thus, the importance of a positive relationship in the therapeutic process may be related to communicating expectancies (Weinberger \& Eig, 1999). Several researchers have also found that the presentation of a credible treatment rationale facilitates the generation of positive expectancies (Frank, 1982; Nau, Caputo, \& Borkovec, 1974; Shapiro, 1981). Moreover, Kazdin and Krouse (1983) found that rationales that are novel and scientifically based are especially effective.

Messages regarding positive expectancies of therapy can also be presented via video or reading. Researchers have found that a videotape describing therapy and treatment can be effective in conveying more accurate expectancies and reducing symptoms (Deane, Spicer, \& Leathem, 1992; Zwick \& Attkisson, 1985). Additionally, Fennell and Teasdale (1987) asked clients beginning cognitive-behavioral therapy to read a booklet describing the treatment and rationale. Endorsement of the rationale presented in the booklet was not correlated with current or pre-treatment depression, but it did predict rapid, early improvement.

\section{The Need for Additional Treatment Acceptability Research}

Results from the current study also suggest the need for additional research in the area of treatment acceptability and chronic disease populations. Subsequent studies could attempt to replicate the current study's adults with other populations, such as cancer and cardiovascular disease patients. Research that attempts to change or improve patients' attitudes toward psychological services would also be helpful. Finally, treatment acceptability research with all types of populations would assist health care providers is 
choosing the intervention that would have the greatest chance of compliance and outcome. This could be done by matching prospective treatments to patients' preferences.

\section{Summary}

The hypothesis that indicated psychological interventions would be rated lower than non-psychological interventions was not supported. The hypothesis that indicated females would rate interventions higher than males was not supported. The hypothesis that proposed that psychological interventions would be rated as less effective than nonpsychological interventions was supported. The hypothesis that indicated that women would rate treatments as more effective than men was supported. The hypothesis that stated psychologists would be rated as less willingness to use than medical professionals was supported. The hypothesis that indicated women would be more willing to seek help from all individuals as compared to men was not supported. Support was found for the hypothesis stated psychologists would be rated as less effective than medical professionals. No support was found for the hypothesis that indicated women, as compared to men, would rate all individuals as more effective. Some support was found for the hypotheses that suggested several variables would predict willingness to seek help, in general, and willingness to seek help from a psychologist. The hypothesis that indicated participants with high pathways hope would be more willing to use treatments than individuals with low pathways hope was supported for some interventions. The hypotheses that suggested gender preferences for seeking help could not be assessed. Results indicated that DM patients have a stigma about seeking help from psychologists. Nevertheless, additional studies that examine DM patients' stigmas toward 
mental health professionals and mental health treatment are necessary. Research that investigates DM patients' acceptability ratings for various treatments is also warranted. 


\section{References}

Abraham, J. L., Thompson-Heisterman, A. A., Harrington, D. P., Smullen, D. E., Onega, L. L., Droney, E. G., Westerman, P. S., Manning, C. A., \& Lichtenberg, P. A. (1991). Outpatient psychogeriatric nursing services: An integrative model. Archives of Psychiatric Nursing, 5, 151-164.

Abramson, L. Y., Seligman, M. E. P., \& Teasdale, J. D. (1978). Learned helplessness in humans: Critique and reformulation. Journal of Abnormal Psychology, 87, 49-74.

Aikens, J. E., \& Wagner, L. I. (1998). Diabetes Mellitus and other endocrine disorders. In P. Camic \& S. Knight (Eds.), Clinical handbook of health psychology (pp. 191225). Seattle, WA: Hogrefe \& Huber.

Allan, R., \& Sheidt, S. (Eds.). (1996). Heart \& mind: The practice of cardiac psychology. Washington, DC: American Psychological Association.

Altmaier, E. M., Johnson, B. D., \& Paulsen, J. S. (1998). Issues in professional identity. In S. Roth-Roemer, S. E. Robinson Kurpius, \& C. Carmin (Eds.), The emerging role of counseling psychology in health care (pp. 7-29). New York: W. W. Norton.

American Diabetes Association. (1996). Vital Statistics. Alexandria, VA: Author. American Heart Association. (1989). Heart facts. Dallas, TX: Author. American Heart Association. (1999a). Compliance Action Program: Statistics you need to know. Retrieved from http://www.americanheart.org/CAP/prof_statistics2.html American Heart Association. (1999b). Economic cost of cardiovascular diseases. Retrieved from http://www.americanheart.org/statistics/10econom.html 
American Heart Association (1999c). Medical procedures, facilities, and costs. Retrieved from http://www.americanheart.org/statistics/09medicl.html

American Psychological Association (2001). Publication manual of the American Psychological Association (5th ed.). Washington, DC: Author.

Andersen, M. B., \& Stoové, M. A. (1998). The sanctity of $p<.05$ obfuscates good stuff: A comment on Kerr and Gross. Journal of Applied Sport Psychology, 10, 168173.

Anderson, J. R. (1988). The role of hope in appraisal, goal-setting, expectancy, and coping. Doctoral dissertation. University of Kansas, Lawrence, Kansas.

Aronson, T. A., Craig, T. J., Thomason, S., \& Logue, C. (1987). Health care utilization patterns in panic disorder and agoraphobia: A naturalistic study in secondary prevention. Journal of Anxiety Disorders, 1, 283-293.

Ary, D. V., Toobert, D., Wilson, W., \& Glasgow, R. E. (1986). Patient perspectives on factors contributing to nonadherence to diabetes regimen. Diabetes Care, 9, 168172.

Asken, M. J. (1979). Medical psychology: Toward definition, clarification, and organization. Professional Psychology, 10, 66-73.

Averill, J. R., Catlin, G., \& Chon, K. K. (1990). Rules of hope. New York: SpringerVerlag.

Badgley, R. F., \& Furnal, M. A. (1961). Appointment breaking in a pediatric clinic. Yale Journal of Biology and Medicine, 34, 117-123.

Bandura, A. (1977). Self-efficacy: Toward a unifying theory of behavior change. Psychological Review, 84, 191-215. 
Bandura, A. (1982). Self-efficacy mechanism in human agency. American Psychologist, $37,122-147$.

Bandura, A. (1986). Social foundations of thought and action: A social cognitive theory. Englewood Cliffs, NJ: Prentice-Hall.

Banken, D. M., \& Wilson, G. L. (1992). Treatment acceptability of alternative therapies for depression: A comparative analysis. Psychotherapy, 29, 610-619.

Banks, S. M., Salovey, P., Greener, S., Rothman, A. J., Moyer, A., Beauvais, J., \& Epel, E. (1995). The effects of message framing on mammography utilization. Health Psychology, 14, 178-184.

Barker, L. A., \& Adelman, H. S. (1994). Mental health and help-seeking among minority adolescents. Journal of Adolescence, 17, 251-263.

Bass, B. A. (1986). Effects of professional title and degree upon the perceived credibility of a sex therapist. Journal of Sex Education and Therapy, 12, 47-50.

Bastone, E. C., \& Kerns, R. D. (1995). Effects of self-efficacy and perceived social support on recovery-related beha viors after coronary artery bypass graft surgery. Annals of Behavioral Medicine, 17, 324-330.

Baum, A., Gatchel, R. J., \& Krantz, D. S. (1997). An introduction to health psychology (3rd ed.). New York: McGraw-Hill.

Beck, A. T., Rush, A. J., Shaw, B. F., \& Emery, G. (1979). Cognitive therapy of depression. New York: Guilford.

Beck, A. T., Steer, R. A., Kovacs, M., \& Garrison, B. (1985). Hopelessness and eventual suicide: A 10-year prospective study of patients hospitalized with suicidal ideation. American Journal of Psychiatry, 142, 559-563. 
Beck, A. T., Ward, C. H., Mendelsohn, M., Mock, J., \& Erbaugh, J. (1961). An inventory for measuring depression. Archives of General Psychiatry, 4, 53-63.

Beck, A. T., Weissman, A., Lester, D., \& Trexler, L. (1974). The measurement of pessimism: The Hopelessness Scale. Journal of Consulting and Clinical Psychology, 42, 861-865.

Becker, M. H. (1991). In hot pursuit of health promotion: Some admonitions. In S. M. Weiss, J. E. Fielding, \& A. Baum (Eds.), Perspectives in behavioral medicine: Health at work (pp. 178-188). Hillsdale, NJ: Erlbaum.

Belcon, M. C., Haynes, R. B., \& Tugwell, P. (1984). A critical review of compliance studies in rheumatoid arthritis. Arthritis and Rheumatism, 27, 1227-1233.

Belgrave, F. Z., \& Lewis, D. M. (1994). The role of social support in compliance and other health behaviors for African Americans with chronic illnesses. Journal of Health \& Social Policy, 5(3-4), 55-68.

Bellg, A. J. (1998). Clinical cardiac psychology. In P. Camic \& S. Knight (Eds.), Clinical handbook of health psychology (pp. 53-98). Seattle, WA: Hogrefe \& Huber.

Betts, G. R., \& Remer, R. (1993). The impact of paradoxical interventions on the perceptions of the therapist and ratings of treatment acceptability. Professional Psychology: Research and Practice, 24, 164-170.

Biaggio, M. K., \& Bittner, E. (1990). Psychology and optometry: Interaction and collaboration. American Psychologist, 45, 1313-1315.

Bierenbaum, M. L., Green, D. P., Florin, A., Fleischman, A. I., \& Caldwell, A. B. (1967). Modified-fat dietary management of the young male with coronary disease: A five year report. Journal of the American Medical Association, 202, 1119-1123. 
Blanchard, E. B. (1982). Behavioral medicine: Past, present, and future. Journal of Consulting and Clinical Psychology, 50, 795-796.

Bland, R. C., Newman, S. C., \& Orn, H. (1997). Help-seeking for psychiatric disorders. Canadian Journal of Psychiatry, 42, 935-942.

Block, L. G., \& Keller, P. A. (1995). When to accentuate the negative: The effects of perceived efficacy and message framing on intentions to perform a health-related behavior. Journal of Marketing Research, 32, 192-203.

Bloom, B. R., \& Murray, C. J. L. (1992, August 21). Tuberculosis: Commentary on a reemergent killer. Science, 257, 1055-1061.

Bloom, L. J., Schroeder, D. H., \& Babineau, W. (1981). Reputation, training, fee, and androgyny: Their comparative effect son impressions of therapist credibility. Journal of Clinical Psychology, 37, 90-95.

Bloom, L. J., Weigel, R. G., \& Trautt, G. M. (1977). Therapeugenic factors in psychotherapy: Effects of office décor and subject-therapist sex pairing on the perception of credibility. Journal of Consulting and Clinical Psychology, 45, 867873.

Blumenthal, J. A., \& Emery, C. F. (1988). Rehabilitation of patients following myocardial infarction. Journal of Consulting and Clinical Psychology, 56, 374381.

Bornstein, P. H., Ballweg, B. J., Weisser, C. E., Fox, S. G., Kirby, K. L., Andre, J. C., Sturm, C. A., Wilson, G. L., \& McLellarn, R. W. (1983). Treatment acceptability of alternative marital therapies: A comparative analysis. Journal of Marital and Family Therapy, 9, 205-208. 
Bornstein, P. H., Stube, D., Wilson, G. L., Horstman, A. M., Sheets, D. R., Zulauf, J. R., Brier, K. L., \& Cogswell, K. A. (1987). Egalitarian versus traditional behavioral marital therapy: A test of preference. Behavior Therapy, 18, 279-282.

Bosscher, R. J. (1993). Running and mixed physical exercises with depressed psychiatric clients. International Journal of Sport Psychology, 24, 170-184.

Bourland, G., \& Lundervold, D. A. (1989). Acceptability ratings for interventions on problematic behavior of older adults. Journal of Clinical and Experimental Gerontology, 11, 105-114.

Boyd, J. R., Covington, T. R., Stanaszck, W. F., \& Coussons, R. T. (1974). Drug defaulting-Part 1: Determinants of compliance. American Journal of Hospital Pharmacy, 31, 362-364.

Bradburn, N. M. (1969). The structure of psychological well-being. Chicago: Aldine. Bradley, C. (Ed.). (1994). The handbook of psychology and diabetes. Chur, Switzerland: Harwood.

Bray, J. H., \& Rogers, J. C. (1995). Linking psychologists and family physicians for collaborative practice. Professional Psychology: Research and Practice, 26, 132138.

Brewer, B. W., Jeffers, K. E., Petitpas, A. J., \& Van Raalte, J. L. (1994). Perceptions of psychological interventions in the context of sport injury rehabilitation. The Sport Psychologist, 8, 176-188.

Brigham, K. S., \& Brigham, J. C. (1985). The influence of psychotherapy fees on observers' evaluations of therapies and clients. Journal of Social and Clinical Psychology, 3, 224-231. 
Brinson, J. A., \& Kottler, J. A. (1995). Minorities' underutilization of counseling centers' mental health services: A case for outreach and consultation. Journal of Mental Health Counseling, 17, 371-385.

Bruhn, J. G., \& Fuentes, R. G. (1977). Cultural factors affecting utilization of services by Mexican Americans. Psychiatric Annals, 7(12), 20-29.

Budd, K. S., \& Baer, D. M. (1976). Behavior modification and the law: Implications of recent judicial decisions. Journal of Psychiatry and Law, 4, 171-244.

Burger, J. M., \& Cooper, H. M. (1979). The desirability of control. Motivation and Emotion, 3, 381-393.

Burgio, L. D., Sinnott, J., Janosky, J. E., \& Hohman, M. J. (1992). Physicians’ acceptance of behavioral treatments and pharmacotherapy for behavioral disturbance in older adults. The Gerontologist, 32, 546-551.

California Association of Psychology Providers et al. v. Peter Rank et al. (1989). 51 Cal.3d 1, 793 P. 2d 2.

Camic, P., \& Knight, S. (Eds.). (1998). Clinical handbook of health psychology. Seattle: Hogrefe \& Huber.

Campbell, J. L., \& Johnson, M. E. (1991). Marital status and gender similarity in marital therapy. Journal of Counseling and Development, 69, 363-368.

Campbell, T. L., McDaniel, S. H., \& Seaburn, D. (1992). Family systems medicine: New opportunities for psychologists. In T. J. Akamaten (Ed.), Family health psychology (p. 196). New York: Hemisphere.

Canadian Diabetes Association. (1997). Diabetes: What every Canadian needs to know [Brochure]. Toronto, Ontario, Canada: Author. 
Carmody, T. P., Fey, S. G., Pierce, D. K., Connor, W. E., \& Matarazzo, J. D. (1982). Behavioral treatment of hyperlipidemia: Techniques, results, future directions. Journal of Behavioral Medicine, 5, 911-916.

Carmody, T. P., Matarazzo, J. D., \& Istvan, J. A. (1987). Promoting adherence to hearthealthy diets: A review of the literature. Journal of Compliance in Health Care, 2, $105-124$

Carmody, T. P., Senner, J. W., Malinow, M. R., \& Matarazzo, J. D. (1980). Physical exercise and rehabilitation: Long-term dropout rate in cardiac patients. Journal of Behavioral Medicine, 3, 163-168.

Carney, R. M., Freedland, K. E., Eisen, S. A., Rich, M. W., \& Jaffe, A. S. (1995). Major depression and medication adherence in elderly patients with coronary artery disease. Health Psychology, 14, 88-90.

Carpenter, P. (1989). Establishing the role of the pediatric psychologist in a university medical center-based oncology service. Journal of Training and Practice in Professional Psychology, 3, 21-28.

Cash, T. F., Begley, P. J., McCown, D. A., \& Weise, B. C. (1975). When counselors are heard but not seen: Initial impact of physical attractiveness. Journal of Counseling Psychology, 22, 273-279.

Cavell, T. A., Frentz, C. E., \& Kelley, M. L. (1986a). Consumer acceptability of the single case withdrawal design: Penalty for early withdrawal? Behavior Therapy, 17, 82-87. 
Cavell, T. A., Frentz, C. E., \& Kelley, M. L. (1986b). Acceptability of paradoxical interventions: Some nonparadoxical findings. Professional Psychology: Research and Practice, 17, 519-523.

Centers for Disease Control and Prevention. (1998). National diabetes fact sheet: National estimates and general information on diabetes in the United States (rev ed.). Atlanta, GA: U.S. Department of Health and Human Services.

Centers for Disease Control and Prevention. (1999). Statistics: Diabetes surveillance, 1999. Retrieved from http://www.cdc.gov/diabetes/statistics.surv199/chap2/table17.htm

Cepeda-Benito, A., \& Short, P. (1998). Self-concealment, avoidance of psychological services, and perceived likelihood of seeking professional help. Journal of Counseling Psychology, 45, 58-64.

Chambless, D. L., \& Williams, K. E. (1995). A preliminary study of the effects of exposure in vivo for African Americans with agoraphobia. Behavior Therapy, 26, 501-515.

Christensen, N. K., Terry, R. D., Wyatt, S., Pichert, J. W., \& Lorenz, R. A. (1983). Quantitative assessment of dietary adherence in patients with insulin-dependent diabetes mellitus. Diabetes Care, 6, 245-250.

Clark, L., \& Elliott, S. N. (1988). The influence of treatment strength information on knowledgeable teachers' pretreatment evaluation of social skills training methods. Professional School Psychology, 3, 253-269. 
Cluss, P. A., \& Epstein, L. H. (1985). The measurement of medical compliance in the treatment of disease. In P. Karoly (Ed.), Measurement strategies in health psychology. New York: Wiley.

Cohen, J. (1977). Statistical power analysis for the behavioral sciences (Rev. ed.). New York: Academic Press.

Cohen, J. (1988). Statistical power analysis for the behavioral sciences (2nd ed.). New York: Academic Press.

Cohen, J. (1990). Things I have learned (so far). American Psychologist, 45, 1304-1312.

Cox, D. J., \& Gonder-Frederick, L. (1992). Major developments in behavioral diabetes research. Journal of Consulting and Clinical Psychology, 60, 628-638.

Cox, D. J., Taylor, A. G., Nowacek, G., Holley-Wilcox, P., Pohl, S. L., \& Guthrow, E. (1984). The relationship between psychological stress and insulin-dependent diabetic blood glucose control: Preliminary investigations. Health Psychology, 3, $63-75$.

Craft, L. L., \& Landers, D. M. (1998). The effect of exercise on clinical depression resulting from mental illness: A meta-analysis. Journal of Sport \& Exercise Psychology, 20, 339-357.

Cross Calvert, S., \& Johnston, C. (1990). Acceptability of treatments for child behavior problems: Issues and implications for future research. Journal of Child Clinical Psychology, 19, 61-74.

Crowne, D. P., \& Marlowe, D. (1960). A new scale of social desirability independent of psychopathology. Journal of Consulting and Clinical Psychology, 24, 349-354. 
Cummings, J. (1992). Psychologists in the medical-surgical setting: Some reflections. Professional Psychology: Research and Practice, 23, 76-79.

Daly, J. E., Power, T. G., \& Gondolf, E. W. (2001). Predictors of a batterer program. Journal of Interpersonal Violence, 16, 971-991.

Dana, R. H., \& May, W. T. (1986). Health care megatrends and health psychology. Professional Psychology: Research and Practice, 17, 251-255.

Davis, M. S. (1978). Variations in patients' compliance with doctor's advice: An empirical analysis of patterns of communication. American Journal of Public Health, 58, 274-288.

Deane, F. P., \& Chamberlain, K. (1994). Treatment fearfulness and distress as predictors of professional psychological help-seeking. British Journal of Guidance and Counseling, 22, 202-217.

Deane, F. P., Spicer, J., \& Leathem, J. (1992). Effects of videotaped preparatory information on expectancies, anxiety, and psychotherapy outcome. Journal of Consulting and Clinical Psychology, 60, 980-984.

Deane, F. P., \& Todd, D. M. (1996). Attitudes and perceived likelihood of seeking professional help for personal problems or suicidal thinking. Journal of College Student Psychotherapy, 10, 45-59.

Delameter, A. M., Kurtz, S. M., Bubb, J., White, N. H., \& Santiago, J. V. (1987). Stress and coping in relation to metabolic control of adolescents with Type I diabetes. Developmental and Behavioral Pediatrics, 8, 136-140. 
DeLeon, P. H. (1991). Afterword. In J. J. Sweet, R. H. Rozensky, \& S. M. Tovian (Eds.), Handbook of clinical psychology in medical settings (pp. 615-618). New York: Plenum.

Delgado, A., Martinez-Canavate, T., Garcia, V., Frias, J., Rueda, T., \& Morata, J. (1999). Patient preferences and stereotype about the gender of the family physician [Abstract]. Atencion Primaria, 23, 268-274. Abstract from: PubMed: 10341457.

Derogatis, L. R. (1983). The Psychological Adjustment of Illness Scale (PAIS). Journal of Psychosomatic Research, 30, 77-91.

Derogatis, L. R., Rickels, K., \& Rock, A. (1983). The SCL-90-R: Administrations, scoring, and procedures manual II. Baltimore, MD: Clinical Psychometric Research.

Desharnais, R., Bouillon, J., \& Godin, G. (1986). Self-efficacy and outcome expectations as determinants of exercise adherence. Psychological Reports, 59, 1155-1159.

Detweiler, J. B., Bedell, B. T., Salovey, P., Pronin, E., \& Rothman, A. J. (1999). Message framing and sunscreen use: Gain-framed messages motivate beach-goers. Health Psychology, 18, 189-196.

Deyo, R. A., Inui, T. S., \& Sullivan, B. (1981). Noncompliance with arthritis drugs: Magnitude, correlates, and clinical implications. Journal of Rheumatology, 9, 930-936.

Diabetes Control and Complications Trial Group. (1986). Diabetes Control and Complications Trial (DCCT): Design and methodological considerations for the feasibility phase. Diabetes, 35, 530-545. 
Diabetes Control and Complications Trial Research Group. (1987). Diabetes Control and Complications Trial (DCCT): Results of a feasibility study. Diabetes Care, 10, 119.

Diabetes Control and Complications Trial Research Group. (1988). Reliability and validity of a Diabetes Quality of Life Measure for the Diabetes Control and Complications Trial (DCCT). Diabetes Care, 11, 725-732.

DiMatteo, M. R. (1985). Physician-patient communication: Promoting a positive health care setting. In J. C. Rosen \& L. J. Solomon (Eds.), Prevention in health psychology (pp. 328-365). Hanover, NH: University Press of New England.

DiMatteo, M. R., Sherbourne, C. D., Hays, R. D., Ordway, L., Kravitz, R. L., McGlynn, E. A., Kaplan, S., \& Rogers, W. H. (1993). Physicians' characteristics influence patients' adherence to medical treatment: Results from the medical outcomes study. Health Psychology, 12, 93-102.

Dishman, R. K. (1982). Compliance/adherence in health-related exercise. Health Psychology, 1, 237-267.

Dishman, R. K. (1988). Exercise adherence: Its impact on public health. Champaign, IL: Human Kinetics.

Dishman, R. K. (1991). Increasing and maintaining exercise and physical activity. Behavior Therapy, 22, 345-378.

Dishman, R. K. (1994). Advances in exercise adherence. Champaign, IL: Human Kinetics.

Doherty, W. J., \& Baird, M. (1983). Family therapy and family medicine: Towards the primary care of families. New York: Guilford. 
Dolce, J. J., Crisp, C., Manzella, B., Richards, J. M., Hardin, J. M., \& Bailey, W. C. (1991). Medication adherence patterns in chronic obstructive pulmonary disease. Chest, 99, 837-841.

Drotar, D. (1998). Training students for careers in medical settings: A graduate program in pediatric psychology. Professional Psychology: Research and Practice, 29, 402-404.

Dubbert, P. M., Rappaport, N. B., \& Martin, J. E. (1987). Exercise in cardiovascular disease. Behavior Modification, 11, 329-347.

Dukepoo, F. (1980). The elder American Indian. San Diego: Campanile.

Dunbar, J. (1985). Practical aspects of dietary management of hypertension: Compliance. Canadian Journal of Physiologic Pharmacology, 64, 831-835.

Dunbar, J. (1990). Predictors of patient adherence: Patient characteristics. In S. A. Shumaker, E. B. Schron, \& J. K. Ockene (Eds.), The handbook of health behavior change (pp. 348-360). New York: Springer.

Dunbar, J. M., \& Agras, W. S. (1980). Compliance with medical instructions. In J. M. Ferguson \& C. B. Taylor (Eds.), Comprehensive handbook of behavioral medicine (vol. 3). New York: Spectrum.

Dunbar-Jacob, J., Burke, L. E., \& Puczynski, S. (1995). Clinical assessment and management of adherence to medical regimens. In P. M. Nicassio \& T. W. Smith (Eds.), Managing chronic illness: A biopsychosocial perspective (pp. 313-349). Washington, DC: American Psychological Association. 
Dunbar-Jacob, J., Dwyer, K., \& Dunning, E. J. (1991). Compliance with antihypertensive regimens: A review of the research in the 1980's. Annals of Behavioral Medicine, $13,32-39$.

Duncan, T. E., \& McAuley, E. (1993). Social support and efficacy cognitions in exercise adherence: A latent growth curve. Journal of Behavioral Medicine, 16, 199-218.

Dym, B., \& Berman, S. (1986). The primary heath care team: Family physician and family therapist in joint practice. Family Systems Medicine, 4, 9-21.

Elliott, S. N. (1988). Acceptability of behavioral treatments: Review of variables that influence treatment selection. Professional Psychology: Research and Practice, 19, 68-80.

Elliott, S. N., Turco, T. L., \& Gresham, F. M. (1987). Consumers' and clients' pretreatment acceptability ratings of classroom group contingencies. Journal of School Psychology, 25, 145-153.

Elliott, S. N., Witt, J. C., Galvin, G. A., \& Moe, G. L. (1986). Children's involvement in intervention selection: Acceptability of interventions for misbehaving peers. Professional Psychology: Research and Practice, 17, 235-241.

Elliott, S. N., Witt, J. C., Galvin, G. A., \& Peterson, R. (1984). Acceptability of positive and reductive behavior interventions: factors that influence teachers' decisions. Journal of School Psychology, 22, 353-360.

Emery, C. F., Hauck, E. R., \& Blumenthal, J. A. (1992). Exercise adherence or maintenance among older adults: One-year follow-up study. Psychology and Aging, 7, 466-470. 
Engel, G. L. (1977). The need for a new medical model: A challenge to biomedicine. Science, 196, 129-136.

Engel, G. L. (1980). The clinical application of the biopsychosocial model. American Journal of Psychiatry, 137, 535-544.

Engstrom, F. W. (1991). Clinical correlates of antidepressant compliance. In J. A. Cramer \& B. Spilker (Eds.), Patient compliance in medical practice and clinical trials (pp. 187-194). New York: Raven.

Enright, M. F., \& Blue, B. A. (1989). Collaborative treatment of panic disorders by psychologists and family physicians. Psychotherapy in Private Practice, 7, 85-90.

Enright, M. F., Resnick, R. J., DeLeon, P. H., Sciara, A. D., \& Tanney, M. F. (1990). The practice of psychology in hospital settings. American Psychologist, 45, 10591065.

Enright, M. F., Resnick, R. J., Ludwigsen, K. R., \& DeLeon, P. H. (1993). Hospital practice: Psychology's call to action. Professional Psychology: Research and Practice, 24, 135-141.

Enright, M. F., Welch, B. L., Newman, R., Perry, B. M. (1990). The Hospital: Psychology's Challenge in the 1990s. American Psychologist, 45, 1057-1058.

Epps, S., Prescott, A. L., \& Horner, R. H. (1990). Social acceptability of menstrualcare training methods for young women with developmental disabilities. Education and Training in Mental Retardation, 25, 33-44.

Epstein, M. H., Matson, J. L., Repp, A. C., \& Helsel, W. J. (1986). Acceptability of treatment alternatives as a function of teacher status and student level. School Psychology Review, 15, 84-90. 
Erickson, R. C., Post, R., \& Paige, A. (1975). Hope as a psychiatric variable. Journal of Clinical Psychology, 31, 324-329.

Ewart, C. K. (1989). Psychological effects of resistive weight training: Implications for cardiac patients. Medicine and Science in Sports and Exercise, 21, 683-688.

Expert Committee on the Diagnosis and Classification of Diabetes Mellitus. (2002). Report of the Expert Committee on the Diagnosis and Classification of Diabetes Mellitus. Diabetes Care, 25(Suppl. 1), S5-S20.

Farber, M. L. (1968). Theory of suicide. New York: Funk \& Wagnall's.

Farberman, R. K. (1997). Public attitudes about psychologists and mental health care: Research to guide the American Psychological Association Public Education Campaign. Professional Psychology: Research and Practice, 28, 128-136.

Faulkner, G., \& Sparkes, A. (1999). Exercise as therapy for schizophrenia: An ethnographic study. Journal of Sport \& Exercise Psychology, 21, 52-69.

Favell, J. E., Azrin, N. H., Baumeister, A. A., Carr, E. G., Dorsey, M. F., Forehand, R., Foxx, R. M., Lovaas, O. I., Rincover, A., Risley, T. R., Romanczyk, R. G., Russo, D. C., Schroeder, S. R., \& Solnick, J. V. (1982). The treatment of self-injurious behavior. Behavior Therapy, 13, 529-554.

Fenigstein, A., Scheier, M. F., \& Buss, A. H. (1975). Public and private selfconsciousness: Assessment and theory. Journal of Consulting and Clinical Psychology, 43, 522-527.

Fennell, M. J., \& Teasdale, J. D. (1987). Cognitive therapy for depression: Individual differences and the process of change. Cognitive Therapy and Research, 11, 253271. 
Fibel, B., \& Hale, W. D. (1978). The Generalized Expectancy for Success Scale-A new measure. Journal of Consulting and Clinical Psychology, 46, 924-931.

Fishbein, H. A. (1985). Precipitants of hospitalization in insulin-dependent diabetes mellitus (IDDM): A statewide perspective. Diabetes Care, 8(Suppl. 1), 61-64.

Foxx, R. M., Bremer, B. A., Shultz, C., Valdez, J., \& Johndrow, C. (1996). Increasing treatment acceptability through video. Behavioral Interventions, 11, 171-180.

Frank, J. D. (1973). Persuasion and healing. Baltimore: Johns Hopkins University Press.

Frank, J. D. (1978). Expectation and therapeutic outcome: The placebo effect and the role induction of interview. In J. D. Frank, R. Hoen-Saric, S. D. Imber, B. L. Liberman, \& A. R. Stone (Eds.), Effective ingredients in psychotherapy (pp. 134). New York: Brunner/Mazel.

Frank, J. D. (1982). Therapeutic components shared by all psychotherapy. In J. H. Harvey \& M. M. Parks (Eds.), The master lecture series: Vol. 1. Psychotherapy research and behavior change (pp. 5-38). Washington, DC: American Psychological Association.

Frank, R. G., \& VandenBos, G. R. (1994). Health care reform: The 1993-1994 revolution. American Psychologist, 49, 851-854.

Frasure-Smith, N., \& Prince, R. (1989). Long-term follow-up of the Ischemic Heart Disease Life Stress Monitoring Program. Psychosomatic Medicine, 51, 485-513.

Frentz, C., \& Kelley, M. L. (1986). Parents' acceptance of reductive treatment methods: The influence of problem severity and perception of child behavior. Behavior Therapy, $17,75-81$. 
Furnham, A., \& Wardley, Z. (1990). Lay theories of Psychotherapy I: Attitudes to and beliefs about psychotherapy and therapists. Journal of Clinical Psychology, 46, 878-890.

Gabinet, L., \& Friedson, W. (1980). The psychologist as front-line mental health consultant in a general hospital. Professional Psychology, 11, 939-945.

Gass, C. S. (1984). Therapeutic influence as a function of therapist attire and seating arrangement in an initial interview. Journal of Clinical Psychology, 40, 52-57.

Geake, R. R. (1995). Practical tips for getting involved in politics. Professional Psychology: Research and Practice, 26, 463-464.

Gibb, J. (1990). The relationship of hope to problem-solving and coping. Master's thesis. University of Illinois, Champaign, IL.

Gim, R. H., Atkinson, D. R., \& Whiteley, S. (1990). Asian-American acculturation, severity of concerns, and willingness to see a counselor. Journal of Counseling Psychology, 37, 281-285.

Glanz, K. (1979). Dietitians' effectiveness and patient compliance with dietary regimens. Journal of the American Dietetic Association, 75, 631-636.

Glanz, K. (1980). Compliance with dietary regimens: Its magnitude, measurement, and determinants. Preventive Medicine, 9, 787-804.

Glenn, M. L. (1985). Toward collaborative family-oriented health care. Family Systems Medicine, 3, 466-475.

Goodall, T. A., \& Halford, W. K. (1991). Self-management of diabetes mellitus: A critical review. Health Psychology, 10, 1-8. 
Gottesfeld, H. (1995). Community context and the underutilization of mental health services by minority patients. Psychological Reports, 76, 207-210.

Gottschalk, L. A. (1974). A hope scale applicable to verbal samples. Archives of General Psychiatry, 30, 779-785.

Gove, W. (1984). Gender differences in mental and physical illness: The effects of fixed roles and nurturant roles. Social Science and Medicine, 19, 77-91.

Green, W. A., Jr., Young, L., \& Swisher, S. N. (1956). Psychological factors and reticuloendothelial disease: II. Observations on a group of women with lymphomas and leukemia. Psychosomatic Medicine, 18, 284-303.

Greenberg, R. P., \& Zeldow, P. B. (1980). Sex differences for an ideal therapist. Journal of Personality Assessment, 44, 474-478.

Greenley, J. R., \& Mechanic, D. (1976). Social selection in seeking help for psychological problems. Journal of Health and Social Behavior, 17, 249-262.

Haley, W. E., Salzburg, L. F., \& Barrett, J. J. (1993). Psychologists in a geriatric medicine: Results of a national survey. Professional Psychology: Research and Practice, 24, 491-496.

Hall, L. H., \& Robertson, M. H. (1998). Undergraduate ratings of the acceptability of single and combined treatments for depression: A comparative analysis. Professional Psychology: Research and Practice, 29, 269-272.

Haney, D. Q. (1999, November 9). Study: Healthy living almost eliminates heart disease. The Daily Athenaeum, p. 3.

Harney, P. (1989). The Hope Scale: Exploration of construct validity and its influence on health. Master's thesis, University of Kansas, Lawrence, KS. 
Harris, M. J., \& Rosenthal, R. (1985). Mediation of interpersonal expectancy effects: 31 meta-analyses. Psychological Bulletin, 97, 363-386.

Hartwell, S., Kaplan, R., \& Wallace, J. (1986). Comparison of behavioral interventions for control of Type II diabetes. Behavior Therapy, 17, 447-461.

Hathaway, S. R., \& McKinley, J. C. (1951). The MMPI manual. New York: Psychological Corporation.

Haynes, R. B. (1976). A critical review of "determinants" of patient compliance with therapeutic regimens. In D. L. Sackett \& R. B. Haynes (Eds.), Compliance with therapeutic regimens (pp. 26-50). Baltimore: Johns Hopkins University Press.

Haynes, R. B., Taylor, D. W., \& Sackett, D. L. (1979). Compliance in health care. Baltimore: Johns Hopkins University Press.

Hays, K. F. (1999). Working it out: Using exercise in psychotherapy. Washington, DC: American Psychological Association.

Hecker, J. E., Fink, C. M., \& Fritzler, B. K. (1993). Acceptability of panic disorder treatments: A survey of family practice physicians. Journal of Anxiety Disorders, 7, 373-384.

Heffer, R. W., \& Kelly, M. L. (1987). Mothers' acceptance of behavioral interventions for children: The influence of parent race and income. Behavior Therapy, 18, 53163.

Heppner, P. P., \& Petersen, C. H. (1982). The development and implications of a personal problems-solving inventory. Journal of Counseling Psychology, 29, 6675. 
Hepworth, J., \& Jackson, M. (1985). Health care for families: Models of collaboration between family therapists and family physicians. Family Relations, 34, 123-127.

Hertzog, C. (1994). Repeated measures analysis in developmental research: What our ANOVA text didn't tell us. In S. H. Cohen \& H. W. Reese (Eds.), Life-span developmental psychology (pp. 187-122). Hillsdale, NJ: Erlbaum.

Hicks, J. E. (1985). Compliance: A major factor in the successful treatment of rheumatoid disease. Comprehensive Therapy, 11, 31-37.

Holleran, S., \& Snyder, C. R. (1990). Discriminant and convergent validation of the Hope Scale. Unpublished manuscript, University of Kansas, Lawrence.

Howell, D. C. (1997). Statistical methods in psychology (4th ed.). Belmont, CA: Duxbury Press.

Huberty, C. J., \& Smith, J. D. (1982). The study of effects in MANCOVA. Multivariate Behavioral Research, 17, 417-482.

Hunsley, J. (1992). Development of the Treatment Acceptability Questionnaire. Journal of Psychopathology and Behavioral Assessment, 14, 55-64.

Hunsley, J. (1993). Treatment acceptability of symptom prescription techniques. Journal of Counseling Psychology, 40, 139-143.

Hunsley, J., \& Lefebvre, M. (1991). Clinical psychologists' views of the acceptability of paradoxical techniques. Psychotherapy, 28, 580-587.

Ievleva, L., \& Orlick, T. (1991). Mental links to enhanced healing: An exploratory study. The Sport Psychologist, 5, 25-40. 
International Resource Center for Health Care Assessment (1991). How to score the MOS 36-item short-form health survey (SF36). Boston, MA: New England Medical Center Hospitals.

Irvin, L. K., \& Lundervold, D. A. (1988). Social validation of decelerative (punishment) procedures by special educators of severely handicapped students. Research in Developmental Disabilities, 9, 331-350.

Irving, L. M., Crenshaw, W., Snyder, C. R., Francis, P., \& Gentry, G. (1990, May). Hope and its correlates in a psychiatric inpatient setting. Paper presented at the 62nd annual meeting of the Midwestern Psychological Association.

Jacobson, A. M., \& The Diabetes Control and Complications Trial Research Group. (1994). The Diabetes Quality of Life Measure. In C. Bradley (Ed.), Handbook of psychology and diabetes (pp. 65-87). Chur, Switzerland: Harwood.

Jacobson, A. M., Hauser, S. T., Wolfsdorf, J. I., Houlihan, J., Milley, J. E., Herskowitz, R. D., Wertlief, D., \& Watt, E. (1987). Psychologic predictors of compliance in children with recent onset of diabetes mellitus. Journal of Pediatrics, 110, 805811.

Janda, L. H., \& England, K. (1998). Attitudes toward psychology relative to other disciplines. Professional Psychology: Research and Practice, 29, 140-143.

Jensen, B. J. (1997, August). Treatment acceptability of sport psychology interventions: Findings from multiple sports. Poster session presented at the annual meeting of the American Psychological Association, Chicago, IL.

Jensen, B. J., Kennerley, R. J., LeJeune-Hall, A. R., \& Bacon, T. J. (1992, October). Treatment acceptability of sport psychology interventions with golfers. Paper 
presented at the annual meeting of the Association for the Advancement of Applied Sport Psychology, Colorado Springs, CO.

Johnstone, B., Frank, R. G., Belar, C., Berk, S., Bieliauskas, L. A., Bigler, E. D., Caplan, B., Elliott, T. R., Glueckauf, R. L., Kaplan, R. M., Kreutzer, J. S., Mateer, C. A., Patterson, D., Puente, A. E., Richards, J. S., Rosenthal, M., Sherer, M., Shewchuk, R., Siegel, L. J., Sweet, J. J. (1995). Psychology in health care: Future directions. Professional Psychology: Research and Practice, 26, 341-365.

Joyce, C. R. B., Capla, G., Mason, M., Reynolds, E., \& Matthews, J. A. (1969). Quantitative study of doctor-patient communication. Quarterly Journal of Medicine, 38, 183-194.

Kainz, K. (2002). Barriers and enhancements to physician-psychologist collaboration. Professional Psychology: Research and Practice, 33, 169-175.

Kalichman, S. C., \& Coley, B. (1995). Context framing to enhance HIV-antibody-testing messages targeted to African American women. Health Psychology, 14, 247254E.

Kalichman, S. C., Kelly, J. A., Hunter, T. L., Murphy, D. A., \& Tyler, R. (1993). Culturally tailored HIV-AIDS risk-reduction messages targeted to AfricanAmerican urban women: Impact on risk sensitization and risk reduction. Journal of Consulting and Clinical Psychology, 61, 291-295.

Kaplan, R. M., Sallis, J. F., \& Patterson, T. L. (1993). Health and human behavior. New York: McGraw-Hill.

Katon, W. (1985). Somatization in primary care. Journal of Family Practice, 21, 257258. 
Kazdin, A. E. (1977). Assessing the clinical or applied importance of behavior change through social validation. Behavior Modification, 1, 427-452.

Kazdin, A. E. (1980a). Acceptability of time-out from reinforcement procedures for disruptive child behavior. Behavior Therapy, 11, 329-344.

Kazdin, A. E. (1980b). Acceptability of alternative treatments for deviant child behavior. Journal of Applied Behavior Analysis, 13, 259-273.

Kazdin, A. E. (1981). Acceptability of child treatment techniques: The influence of treatment efficacy and adverse side effects. Behavior Therapy, 12, 493-506.

Kazdin, A. E. (1984). Acceptability of aversive procedures and medication as treatment alternatives of deviant child behavior. Journal of Abnormal Child Psychology, 12, 289-302.

Kazdin, A. E., French, N. H., \& Sherick, R. (1981). Acceptability of alternative treatments for children: Evaluations by inpatient children, parents, and staff. Journal of Consulting and Clinical Psychology, 49, 900-907.

Kazdin, A. E., \& Krouse, R. (1983). The impact of variations in treatment rationales and expectancies for therapeutic change. Behavior Therapy, 14, 657-671.

Kelley, M. L., Heffer, R. W., Gresham, F. M., \& Elliott, S. N. (1989). Development of a modified Treatment Evaluation Inventory. Journal of Psychopathology and Behavioral Assessment, 11, 235-247.

Kelly, A. E., \& Achter, J. A. (1995). Self-concealment and attitudes toward counseling in university students. Journal of Counseling Psychology, 42, 40-46.

Kenney, G. E. (1994). Multicultural investigation of counseling expectations and preferences. Journal of College Student Development, 9, 21-39. 
Kessler, R. C. (1981). Reply to Gove and Swafford. Social Forces, 59, 1291-1296.

Kessler, R. C., Brown, R. L., \& Broman, C. L. (1981). Sex differences in psychiatric help-seeking: Evidence from four large scale surveys. Journal of Health and Social Behavior, 22, 49-64.

Kilburg, R. R. (1996). Toward a conceptual understanding and definition of executive coaching. Consulting Psychology Journal: Practice and Research, 48, 134-144.

Kirsch, I. (1985). Response expectancy as a determinant of experience and behavior. American Psychologist, 40, 1189-1202.

Kirsch, I. (1990). Changing expectations: A key to effective psychotherapy. Pacific Grove, CA: Brooks/Cole.

Kirsch, I. (1999). Response expectancy: An introduction. In I. Kirsch (Ed.), How expectancies shape experience (pp. 3-13). Washington, DC: American Psychological Association.

Korsch, B. M., \& Negrete, V. F. (1972). Doctor-patient communication. ScientificAmerican, 227, 66-74.

Kruse, W. H. (1991). Compliance with treatment of hyperlipoproteinemia in medical practice and clinical trials. In J. A. Cramer \& B. Spilker (Eds.), Patient compliance in medical practice and clinical trials (pp. 175-186). New York: Raven.

Kubler-Ross, E. (1969). On death and dying. New York: Macmillan.

Lambert, M. J., Shapiro, D. A., \& Bergin, A. E. (1986). The effectiveness of psychotherapy. In S. L. Garfield \& A. E. Bergin (Eds.), Handbook of psychotherapy and behavior change (3rd ed., pp. 157-211). New York: Wiley. 
Leaf, P. J., \& Bruce, M. L. (1987). Gender differences in the use of mental-health-related services: A re-examination. Journal of Health and Social Behavior, 28, 171-183.

Lennox, D. B., \& Miltenberger, R. G. (1990). On the conceptualization of treatment acceptability. Education and Training in Mental Retardation, 25, 211-224.

Leong, F. T. L., \& Zachar, P. (1999). Gender and opinions about mental illness as predictors of attitudes toward seeking professional psychological help. British Journal of Guidance and Counselling, 27, 123-132.

Leppik, I. E. (1991). Variability of antiepileptic medication concentrations and compliance. In J. A. Cramer \& B. Spilker (Eds.), Patient compliance in medical practice and clinical trials (pp. 349-358). New York: Raven.

LeShan, L. L. (1961). A basic psychological orientation apparently associated with malignant disease. The Psychiatric Quarterly, 35, 314.

Lin, E. H. B., Von Korff, M., Katon, W., \& Bush, T. (1995). The role of the primary care physician in patients' adherence to antidepressant therapy. Medical Care, 33(1), $67-74$

Lin, J. C. H. (1994). How long do Chinese Americans stay in psychotherapy? Journal of Counseling Psychology, 41, 288-291.

Linder, D. E., Brewer, B. W., Van Raalte, J. L., \& DeLange, N. (1991). A negative halo for athletes who consult sport psychologists: Replication and extension. Journal of Sport \& Exercise Psychology, 13, 133-148.

Lord-Flynn, D. J. (1989). Help-seeking for mental health services: The relationship between perceived barriers to service utilization and need for services. Doctoral dissertation. Washington State University, Pullman, Washington. 
Lundervold, D., \& Lewin, L. M. (1990). Older adults' acceptability of pharmacotherapy and behavior therapy for depression: Initial results. The Journal of Applied Gerontology, 9, 211-215.

Lundervold, D., Lewin, L. M., \& Bourland, G. (1990). Older adults' acceptability of treatments for behavior problems. Clinical Gerontologist, 10, 17-28.

Lundervold, D. A., \& Young, L. G. (1992). Treatment acceptability ratings for sexual offenders: Effects of diagnosis and offense. Research in Developmental Disabilities, 13, 229-237.

Lundervold, D., Young, L., Bourland, G., \& Jackson, T. (1991). Psychometric properties of attitudinal measures of behavior treatment in geriatric settings. Behavioral Residential Treatment, 6, 97-106.

Lustman, P. J. (1988). Anxiety disorders in adults with diabetes mellitus. Psychiatric Clinics of North America, 11, 419-432.

Lustman, P. J., Frank, B. L., \& McGill, J. B. (1991). Relationship of personality characteristics to glucose regulation in adults with diabetes. Psychosomatic Medicine, 53, 305-312.

Lustman, P. J., Griffith, L. S., Clouse, R. E., \& Cryer, P. E. (1986). Psychiatric illness in diabetes in diabetes mellitus: Relationship to symptoms and illness control. Journal of Nervous and Mental Disease, 174, 736-742.

Macrodimitris, S. D., \& Endler, N. S. (2001). Coping, control, and adjustment in type 2 diabetes. Health Psychology, 20, 208-216.

Maniar, S. D. (1998). Athlete preferences for sport psychology interventions. Masters thesis. University of Montana, Missoula, Montana. 
Maniar, S. (2000). Diabetes patients' preferences for seeking help for emotional difficulties. Unpublished manuscript.

Maniar, S. D., Curry, L. A., Sommers-Flanagan, J., \& Walsh, J. A. (2001). Studentathlete preferences in seeking help when confronted with sport performance problems. The Sport Psychologist, 15, 205-223.

Maniar, S. D., Perna, F. M., Newcomer, R., Roh, J., \& Stilger, V. (1999, September). Athletic trainers' recognition of psychological distress following athletic injury: Implications for referral. In F. Perna (Chair), Pre-injury screening and post-injury assessment: Interactions between sport psychologists and the sports medicine team. Symposium presented at the 13th annual meeting of the Association for the Advancement of Applied Sport Psychology, Banff, Alberta, Canada.

Marcus, A. C., Seeman, T. E., \& Telesky, C. W. (1984). Teetering on the horns of a dilemma: Professor Gove's latest paper on sex differences in illness behavior. Social Science and Medicine, 19, 84-88.

Martens, B. K., Witt, J. C., Elliott, S. N., \& Darveaux, D. X. (1985). Teacher judgments concerning the acceptability of schoolbased interventions. Professional Psychology: Research and Practice, 16, 191-198.

Martin, J. E., \& Dubbert, P. M. (1987). Exercise promotion. In J. A. Blumenthal \& D. C. McKee (Eds.), Application in behavioral medicine and psychology: A clinician's sourcebook (pp. 371-398). Sarasota, FL: Professional Resource Exchange.

Masters, J. C., Burish, T. G., Hollon, S. D., \& Rimm, D. C. (1987). Behavior therapy: Techniques and empirical findings (3rd ed.). San Diego: Harcourt Brace Jovanovich. 
Masur, F. T. (1979). An update on medical psychology and behavioral medicine. Professional Psychology, 10, 259-268.

McCann, B. S., Retzlaff, B. W., Dowdy, A. A., Walden, C. E., \& Knopp, R. H. (1990). Promoting adherence to low-fat, low cholesterol diets: Review and recommendations. Journal of the American Dietetic Association, 90, 1408-1414.

McCann, B. S., Retzlaff, B. W., Walden, C. E., \& Knopp, R. H. (1990). Dietary intervention for coronary heart disease prevention. In A. S. Shumaker, E. B. Schron, \& J. K. Ockene (Eds.), The handbook of health behavior change (pp. 191-215). New York: Springer.

McDaniel, S. H. (1995). Collaboration between psychologists and family physicians: Implementing the biopsychosocial model. Professional Psychology: Research and Practice, 26, 117-122.

McDaniel, S. H., Hepworth, J., \& Doherty, W. J. (1992). Medical family therapy. New York: Basic Books.

McDowell, J., Burgio, K. L., Dombrowski, M., Locher, J. L., \& Rodriguez, E. (1992). An interdisciplinary approach to the assessment and behavioral treatment of urinary incontinence in geriatric outpatients. Journal of the American Geriatric Society, 40, 370-374.

McGuire, J. M., \& Borowy, T. D. (1979). Attitudes toward mental health professionals. Professional Psychology, 10, 74-79.

Meichenbaum, D., \& Turk, D. C. (1987). Facilitating treatment adherence: A practitioner's guidebook. New York: Plenum. 
Meyer, E. C., DeMaso, D. R., \& Koocher, G. P. (1996). Mental health consultation in the pediatric intensive care unit. Professional Psychology: Research and Practice, 27, 130-136.

Meyerowitz, B. E., \& Chaiken, S. (1987). The effect of message framing on breast selfexamination attitudes, intentions, and behavior. Journal of Personality and Social Psychology, 52, 500-510.

Miller, I. H., \& Norman, W. H. (1979). Learned helplessness in humans: A review and attribution theory model. Psychological Bulletin, 86, 93-118.

Minor, M. M. (1991). Physical activity and management of arthritis. Annals of Behavioral Medicine, 13, 117-124.

Mudford, O. C. (1987). Acceptability of a visual screening procedure for reducing stereotypy in mentally retarded children: Evaluation by New Zealand institutional staff. Behavior Change, 4, 4-13.

Murstein, B. I., \& Fontaine, P. A. (1993). The public's image about psychologists and other mental health professionals. American Psychologist, 48, 839-845.

Myers, E. D., \& Branthwaite, A. (1992). Out-patient compliance with antidepressant medication. British Journal of Psychiatry, 160, 83-86.

Nagy, V. T., \& Wolfe, G. R. (1984). Cognitive predictors of compliance in chronic disease patients. Medical Care, 22, 912-921.

Nanada, Col., Fanale, J. E., \& Kronholm, P. (1990). The role of medication noncompliance and adverse drug reactions in hospitalizations of the elderly. Archives of Internal Medicine, 150, 841-845. 
Nathan, D. M., Fogel, H., Norman, D., Russell, P. S., Tolkoff-Rubin, N., Delmonico, F. L., Auchinloss, H., Camuso, J., \& Cosimi, A. B. (1991). Long-term metabolic and quality of life results with pancreatic/renal transplantation in insulin-dependent diabetes mellitus. Transplantation, 52(1), 85-91.

National Center for Health Statistics. (2001). Fast stats A to Z: Diabetes. Retrieved from http://www.cdc.gov/nchs/fastats/diabetes.htm

Nau, D. S., Caputo, L. A., \& Borkovec, T. D. (1974). The relationship between credibility of therapy and simulated therapy effects. Journal of Behavior Therapy and Experimental Psychiatry, 5, 129-134.

Natvig, D. (1991). The role of the interdisciplinary team in using psychotropic drugs. Journal of Psychosocial Nursing and Mental Health Services, 29, 3-8.

Newton, T., Hartley, P., \& Sturmey, P. (1993). Treatment evaluation for eating disorders by clients with eating disorders. Behavioural and Cognitive Psychotherapy, 21, 371-374.

Nicassio, P. M., \& Smith, T. W. (Eds.). (1995). Managing chronic illness: A biopsychosocial perspective. Washington, DC: American Psychological Association.

Norton, G. R., Allen, G. E., \& Walker, J. R. (1985). Predicting treatment preferences for agoraphobia. Behaviour Research and Therapy, 23, 699-701.

Nunnaly, J. C. (1978). Psychometric theory (2nd ed.). New York: McGraw-Hill.

O’Brien, S., \& Karsh, K. G. (1990). Treatment acceptability: Consumer, therapist, and society. In A. C. Repp \& N. N. Singh (Eds.), Nonaversive and aversive 
interventions for persons with developmental disabilities (pp. 503-516).

Sycamore, IL: Sycamore.

Ogborne, A. C., \& DeWitt, D. J. (1999). Lifetime use of professional and community services for help with drinking: Results from a Canadian population survey. Journal of Studies on Alcohol, 60, 867-872.

Ogloff, J. R. P., Tomkins, A. J., \& Bersoff, D. N. (1996). Education and training in psychology and law/criminal justice: Historical foundations, present structures, and future developments. Criminal Justice \& Behavior, 23, 200-235.

Oldridge, N. B. (1982). Compliance with intervention and rehabilitation exercise programs: A review. Preventive Medicine, 11, 56-70.

Oldridge, N. B. (1988). Cardiac rehabilitation exercise programme: Compliance and compliance-enhancing strategies. Sports Medicine, 6, 42-55.

Osgood, C. E., Succi, G. J., \& Tannenbaum, P. H. (1957). Measurement of meaning. Urbana, IL: University of Illinois.

Parker, J. C. (1995). Stress management. In P. M. Nicassio \& T. W. Smith (Eds.), Managing chronic illness: A biopsychosocial perspective (pp. 285-312). Washington, DC: American Psychological Association.

Parrish, J. M. (1986). Parent compliance with medical and behavioral recommendations. In N. A. Krasnegor, J. D. Arasteh, \& M. F. Cataldo (Eds.), Child health behavior: A behavioral pediatrics perspective. New York: Wiley.

Pedhazur, E. J. (1982). Multiple regression in behavioral research (2nd ed.). Fort Worth, TX: Rinehart \& Winston. 
Perkins, K. A., \& Epstein, L. H. (1988). In R. K. Dishman (Ed.), Exercise adherence: Its impact on public health (pp. 399-416). Champaign, IL: Human Kinetics.

Phillips, M. A., \& Murrell, S. A. (1994). Impact of psychological and physical health, stressful events, and social support on subsequent mental health help seeking among older adults. Journal of Consulting and Clinical Psychology, 62, 270-275.

Pickering, D., \& Morgan, S. B. (1985). Parental ratings of treatments of self-injurious behavior. Journal of Autism and Developmental Disorders, 15, 303-314.

Pickering, D., Morgan, S. B., Houts, A. C., \& Rodrigue, J. R. (1988). Acceptability of treatments for self-abuse: Do risk-benefit information and being a parent make a difference? Journal of Clinical Child Psychology, 17, 209-216.

Pietzcker, W. G. (1985). One-year outcome of schizophrenia patients-The interaction of chronicity and neuroleptic treatment. Pharmacopsychiatry, 18, 235-239.

Pikus, C. F., \& Heavey, C. L. (1996). Client preferences for therapist gender. Journal of College Student Psychotherapy, 10(4), 35-43.

Pines, A. (1982). Helpers' motivation and the burnout syndrome. In T. A. Wills (Ed.), Basic processes in helping relationships (pp. 453-475). San Diego: Academic Press.

Pines, A., \& Aronson, E. (1988). Career burnout: Causes and cues (2nd ed.). New York: Free Press.

Pion, G. M. (1991). A rational human resources agenda for psychology: The need for a broader perspective. Professional Psychology: Research and Practice, 22, 449455. 
Pohl, S. L., Gonder-Frederick, L., \& Cox, D. J. (1984). Area review: Diabetes mellitus. Behavioral Medicine Update, 6, 3-7.

Pollack, M. L., Carroll, J. F., Graves, J. E., Leggett, S. H., Braith, R. W., Limacher, M., \& Hagberg, J. M. (1992). Injuries and adherence to walk/jog and resistance training in the elderly. Medicine and Science in Sports and Exercise, 23, 11941200.

Powell, K. E. (1988). Habitual exercise and public health: An epidemiological view. In R. K. Dishman (Ed.), Exercise adherence: Its impact on public health (pp. 15-39). Champaign, IL: Human Kinetics.

Powell, L. H., \& Thoresen, C. E. (1988). Effects of Type A behavioral counseling and severity of prior acute myocardial infarction on survival. American Journal of Cardiology, 62, 1159-1163.

Prindaville, G. M., Sidwell, L. H., \& Milner, D. E. (1983). Integrating primary health care and mental health services: A successful rural linkage. Public Health Reports, 98, 67-72.

Rabinowitz, J., Gross, R., \& Feldman, D. (1999). Correlates of a perceived need for mental health assistance and differences between those who do and do not seek help. Social Psychiatry and Psychiatric Epidemiology, 34, 141-146.

Rasnake, L. K., Martin, J., Tarnowski, J., \& Mulick, J. A. (1993). Acceptability of behavioral treatments: Influence of knowledge of behavioral principles. Mental Retardation, 31, 247-251. 
Reimers, T. M., \& Wacker, D. P. (1988). Parents' ratings of acceptability of behavioral treatment recommendations made in an outpatient clinic: A preliminary analysis of the influence of treatment effectiveness. Behavioral Disorders, 14, 7-15.

Reimers, T. M., Wacker, D. P., \& Koeppl, G. (1987). Acceptability of behavioral interventions: A review of the literature. School Psychology Review, 16, 212-227.

Reinhold, J. E. (1973). Users and nonusers of college and psychiatric services. Journal of American College Health, 21, 201-208.

Resnick, R. J. (1985). A case against the Blues: The Virginia challenge. American Psychologist, 39, 988-995.

Rickwood, D. J., \& Braithwaite, V. A. (1994). Social-psychological factors affecting help-seeking for emotional problems. Social Science and Medicine, 39, 563-572.

Robertson, D., \& Keller, C. (1992). Relationship among health beliefs, self-efficacy, and exercise adherence in patients with coronary artery disease. Heart and Lung, 21, $56-63$.

Rodriguez, E. R. (1998). Addressing the needs of diverse racial/ethnic populations. . In S. Roth-Roemer, S. E. Robinson Kurpius, \& C. Carmin (Eds.), The emerging role of counseling psychology in health care (pp. 356-393). New York: W. W. Norton.

Rokke, P. D., Carter, A. S., Rehm, L. P., \& Veltrum, L. G. (1990). Comparative credibility of current treatments fro depression. Psychotherapy, 27, 235-242.

Rosenbaum, M. (1980). A schedule for assessing self-control behaviors: Preliminary findings. Behavior Therapy, 11, 109-121.

Rosenbaum, M., \& Palmon, N. (1984). Helplessness and resourcefulness in coping with epilepsy. Journal of Consulting and Clinical Psychology, 52, 244-253. 
Rosenberg, M. (1965). Society and adolescent self-image. Princeton, NJ: Princeton University Press.

Roth, D. L., Harris, R. L., \& Snyder, C. R. (1988). An individualdifferences measure of attributive and repudiative tactics of favorable self-presentation. Journal of Social and Clinical Psychology, 6, 159-170.

Roth, D. L., Snyder, C. R., \& Pace, D. L. (1986). Dimensions of favorable selfpresentation. Journal of Personality and Social Psychology, 51, 867-874.

Roth, S. (1980). A revised model of learned helplessness in humans. Journal of Personality, 48, 103-133.

Roth-Roemer, S., Robinson Kurpius, S. E., \& Carmin, C. (1998). Counseling psychology in health care: An introduction. In S. Roth-Roemer, S. E. Robinson Kurpius, \& C. Carmin (Eds.), The emerging role of counseling psychology in health care (pp. 14). New York: W. W. Norton.

Rothman, A. J. (2000, September). Shaping perceptions to promote healthy behavior: A social psychological approach to health communication. Invited address presented to NIOSH/CDC "See the Light" Series, Morgantown, WV.

Rothman, A. J., Martino, S. C., Bedell, B. T., Detweiler, J. B., \& Salovey, P. (1999). The systematic influence of gain- and loss-framed message s on interest in and use of different types of health behavior. Personality and Social Psychology Bulletin, 25, 1355-1369.

Rothman, A. J., \& Salovey, P. (1997). Shaping perceptions to motivate healthy behavior: The role of message framing. Psychological Bulletin, 121, 3-19. 
Rotter, J. B., \& Rafferty, J. E. (1950). The manual for the Rotter Incomplete Sentences Blank. New York: Psychological Corporation.

Ruelas, S. R., Atkinson, D. R., \& Ramos-Sanchez, L. (1998). Counselor helping model, participant ethnicity and acculturation level, and perceived counselor credibility. Journal of Counseling Psychology, 45, 98-103.

Sackett, D. L., \& Snow, J. C. (1979). The magnitude of compliance and noncompliance. In R. B. Haynes, D. W. Taylor, \& D. L. Sackett (Eds.), Compliance in health care. Baltimore: Johns Hopkins University Press.

Sarafino, E. P. (1998). Health psychology: Biopsychosocial interactions (3rd ed.). New York: Wiley.

Sargent, J. (1985). Physician-family therapist collaboration: Children with medical problems. Family Systems Medicine, 3, 454-465.

Sayette, M. A., \& Mayne, T. J. (1990). Survey of clinical and research trends in clinical psychology. American Psychologist, 45, 1263-1266.

Scheier, M. F., \& Carver, C. S. (1985). Optimism, coping, and health: Assessment and implications of generalized outcome expectancies. Health Psychology, 4, 219247.

Scheier, M. F., \& Carver, C. S. (1987). Dispositional optimism and physical well-being: The influence of generalized outcome expectancies on health. Journal of Personality, 55, 169-210.

Schmale, A. H. (1958). Relationship of separation and depression to disease. Psychosomatic Medicine, 20, 259-277. 
Schneider, L. J., \& Watkins, E., Jr. (1990). Perceptions of therapists as a function of professional fees and treatment modalities. Journal of Clinical Psychology, 46, 923-927.

Schoenberg, N. E. (1998). The relationship between perceptions of social support and adherence to dietary recommendations among African-American elders with hypertension. International Journal of Aging \& Human Development, 47, 279297.

Segal, B. E., Weiss, R. J., \& Sokol, R. (1965). Emotional adjustment, social organization, and psychiatric treatment rates. American Sociological Review, 30, 548-556.

Selam, J. L., Micossi, P., Dunn, F. L., \& Nathan, D. M. (1992). Clinical trial of programmeable implantable insulin pump for Type I diabetes. Diabetes Care, 15, 877-884.

Serlin, R. C. (1987). Hypothesis testing, theory building, and the philosophy of science. Journal of Counseling Psychology, 34, 365-371.

Shapiro, D. A. (1981). Comparative credibility of treatment rationales: Three tests of expectancy theory. British Journal of Psychiatric Research, 21, 111-122.

Sherbourne, C. D., Hays, R. D., Ordway, L., DiMatteo, M. R., \& Kravitz, R. L. (1992). Antecedents of adherence to medical recommendations: Results from the medical outcomes study. Journal of Behavioral Medicine, 15, 447-468.

Shiloh, S. (1996). Genetic counseling: A developing area of interest for psychologists. Professional Psychology: Research and Practice, 27, 475-486.

Singh, N. N., \& Katz, R. C. (1985). On the modification of acceptability ratings for alternative child treatment. Behavior Modification, 9, 375-386. 
Singh, N. N., Watson, J. E., \& Winton, A. S. (1987). Parents' acceptability ratings of alternative treatments for use with mentally retarded children. Behavior Modification, 11, 17-26.

Smith, T. W., \& Nicassio, P. M. (1995). Psychological practice: Clinical application of the biopsychosocial model. In P. M. Nicassio \& T. W. Smith (Eds.), Managing chronic illness: A biopsychosocial perspective (pp. 1-31). Washington, DC: American Psychological Association.

Snyder, C. R. (1994). Hope and optimism. In V. S. Ramachandran (Ed.), Encyclopedia of human behavior (vol. 2, pp. 535-542). San Diego: Academic Press.

Snyder, C. R. (1995). Conceptualizing, measuring, and nurturing hope. Journal of Counseling and Development, 73, 355-360.

Snyder, C. R., Harris, C., Anderson, J. R., Holleran, S. A., Irving, L. M., Sigmon, S. T., Yoshinobu, L., Gibb, J., Langelle, C., \& Harney, P. (1991). The will and the ways: Development and validation of an individual-differences measure of hope. Journal of Personality and Social Psychology, 60, 570-585.

Snyder, C. R., Irving, L. M., \& Anderson, J. R. (1991). Hope and health. In C. R. Snyder \& D. R. Forsyth (Eds.), Handbook of social and clinical psychology: The health perspective (pp. 285-305). Elmsford, NY: Pergamon.

Snyder, C. R., Michael, S. T., \& Cheavens, J. S. (1999). Hope as a psychotherapeutic foundation of common factors, placebos, and expectancies. In M. A. Huble, B. Duncan, \& S. Miller (Eds.), Heart and soul of change (pp. 179-200). Washington, DC: American Psychological Association. 
Snyder, C. R., Sympson, S. C., Ybasco, F. C., Borders, T. F., Babyak, M. A., \& Higgins, R. L. (1996). Development and validation of the State Hope Scale. Journal of Personality and Social Psychology, 2, 321-335.

Sohar, E., \& Sneth, E. (1973). Follow-up of obese patients: 14 years after a successful reducing diet. American Journal of Clinical Nutrition, 26, 845-848.

Solberg, V. S., Ritsma, S., Davis, B. J., Tata, S. P., \& Jolly, A. (1994). Asian-American students' severity of problems and unwillingness to seek help from university counseling centers: Role of previous counseling experience, gender, and ethnicity. Journal of Counseling Psychology, 41, 275-279.

Somerville, K. (1998). Where is the business of business psychology headed?. Consulting Psychology Journal: Practice and Research, 50, 237-241.

Songer, T. J., Ettaro, L., \& Economics of Diabetes Project Panel/Centers for Disease Control and Prevention. (1998). Publications and products: Studies on the cost of diabetes. Retrieved from http://www.cdc.gov/diabetes/pubs/costs/appendices.htm

Spielberger, C. D., Gorsuch, R. L., \& Luchene, R. E. (1970). The State-Trait Anxiety Inventory. Palo Alto, CA: Consulting Psychologists Press.

Spirrison, C. L. (1992). Measurement and meaning: The treatment acceptability construct and comments on Lundervold et al. (1991). Behavioral Residential Treatment, 7, 259-264.

Stamler, V. L., Christiansen, M. D., Staley, K. H., \& Macagno-Shang, L. (1991). Client preferences for counselor gender. Psychology of Women Quarterly, 15, 317-321.

Stason, W. B., \& Weinstein, M. C. (1977). Allocation of resources to manage hypertension. New England Journal of Medicine, 296, 732-739. 
Stefl, M., \& Prosperi, D. (1985). Barriers to mental health utilization. Community Mental Health Journal, 21, 167-1178.

Stewart, D. W. (1996). Predicting counseling service utilization patterns with the MMPI2 College Maladjustment Scale. Canadian Journal of Counseling, 30, 211-216.

Stotland, E. (1969). The psychology of hope. San Francisco: Jossey-Bass.

Sturmey, P. (1992). Treatment acceptability for anorexia nervosa: Effects of treatment type, problem severity and treatment outcome. Behavioural Psychotherapy, 20, 91-93.

Surwit, R. S., Schneider, M. S., \& Feinglos, M. N. (1992). Stress and diabetes mellitus. Diabetes Care, 15, 1413-1422.

Tabachnick, B. G., \& Fidell, L. S. (1996). Using multivariate statistics (3rd ed.). New York: HarperCollins.

Tarnowski, K. J., Kelly, P. A., \& Mendlowitz, D. R. (1987). Acceptability of behavioral pediatric interventions. Journal of Consulting and Clinical Psychology, 55, 435436.

Tarnowski, K. J., Rasnake, L. K., Mulick, J. A., \& Kelly, P. A. (1989). Acceptability of behavioral treatments for self-injurious behavior. American Journal of Mental Retardation, 93, 575-580.

Tarnowski, K. J., \& Simonian, S. J. (1992). Assessing treatment acceptance: The Abbreviated Acceptability Rating Profile. Journal of Behavior Therapy and Experimental Psychiatry, 23, 101-106.

Tarnowski, K. J., Simonian, S. J., Bekeny, P., \& Park, A. (1992). Acceptability of interventions for childhood depression. Behavior Modification, 16, 103-117. 
Tata, S. P., \& Leong, F. T. L. (1994). Individualism-collectivism, social- network orientation, and acculturation as predictors of attitudes toward seeking professional psychological help among Chinese Americans. Journal of Counseling Psychology, 41, 280-287.

Taylor, J. A. (1953). A personality scale of manifest anxiety. Journal of Abnormal and Social Psychology, 48, 285-290.

Taylor, S. E. (1987). The progress and prospects of health psychology: Tasks of a maturing discipline. Health Psychology, 6, 73-89.

Tennessee Agriculture Extension Service. (n.d.). Healthy living: A self-care program for persons with diabetes and their caregivers. Retrieved January 17, 2002, from http://www.utextension.utk.edu/health/hldiabetes/default.htm

Thomas, J. R., \& Nelson, J. K. (1996). Research methods in physical activity (3rd ed.). Champaign, IL: Human Kinetics.

Thomas, J. R., Salazar, W., \& Landers, D. M. (1991). What is missing at $p<.05$ ? Effect size. Research Quarterly for Exercise and Sport, 62, 344-348.

Tingstrom, D. H. (1989). Increasing acceptability of alternative behavioral interventions through education. Psychology in the Schools, 26, 188-194.

Tingstrom, D. H., McPhail, R. L., \& Bolton, A. B. (1989). The influence of reported effectiveness and age of target child. Journal of Psychology, 123, 133-140.

Tkachuk, G. A., \& Martin, G. L. (1999). Exercise therapy for patients with psychiatric disorders: Research and clinical implications. Professional Psychology: Research and Practice, 30, 275-282. 
Tomkins, A. J., \& Ogloff, J. R. (1990). Training and career options in psychology and law. Behavioral Science \& the Law, 8, 205-216.

Tovian, S. (1991). Integration of clinical psychology into adult and pediatric oncology programs. In J. Sweet, R. Rozensky, \& S. Tovian (Eds.), Handbook of clinical psychology in medical settings (pp. 331-352). New York: Plenum.

Trautt, G. M., \& Bloom, L. J. (1982). Therapeugenic factors in psychotherapy: The effects of fee and title on credibility and attraction. Journal of Clinical Psychology, 38, 274-279.

Tulkin, S. R., \& Frank, G. W. (1985). The changing role of psychologists in health maintenance organizations. American Psychologist, 40, 1125-1130.

Turco, T. L., \& Elliott, S. N. (1986). Children's acceptability judgments of teacherinitiated interventions. Journal of School Psychology, 24, 277-283.

Turk, D. C., \& Salovey, P. (1995). Cognitive-behavioral treatment of illness behavior. In P. M. Nicassio \& T. W. Smith (Eds.), Managing chronic illness: A biopsychosocial perspective (pp. 245-284). Washington, DC: American Psychological Association.

Turnbull, H. R., Ellis, J., Boggs, E., Brooks, P., \& Biklen, D. (1981). The least restrictive alternative: Principles and practices. Washington, DC: American Association for Mental Deficiency.

Upton, L. R., \& Jensen, B. J. (1991). The acceptability of behavioral treatments for marital problems: A comparison of behavioral exchange and communication skills training procedures. Behavior Modification, 15, 51-63. 
Van Raalte, J. L., Brewer, B. W., Linder, D. E., \& DeLange, N. (1990). Perceptions of sport-oriented professionals: A multidimensional scaling analysis. The Sport Psychologist, 4, 228-234.

Van Raalte, J. L., Brewer, D. D., Matheson, H., \& Brewer, B. W. (1996). British athletes' perceptions of sport and mental health practitioners. Journal of Applied Sport Psychology, 8, 102-108.

Varni, J. W., \& Babani, L. (1986). Long-term adherence to health care regimens in pediatric chronic disorders. In N. A. Krasnegor, J. D. Arasteh, \& M. F. Cataldo (Eds.), Child health behavior: A behavioral pediatrics perspective. New York: Wiley.

Veroff, J., Kulka, R., \& Douran, E. (1981). Mental health in America. New York: Basic Books.

Von Brock, M. B., \& Elliott, S. N. (1987). Influence of treatment effectiveness information on the acceptability of classroom interventions. Journal of School Psychology, 25, 131-144.

Wallston, K. A. (1993). Health psychology in the USA. In S. Maes, H. Leventhal, \& M. Johnston (Eds.), International review of health psychology (vol. 2, pp. 215-228). New York: Wiley.

Ward, A., \& Morgan, W. (1984). Adherence patterns of healthy men and women enrolled in an adult exercise program. Journal of Cardiac Rehabilitation, 4, 143-152.

Warner, D. L., \& Bradley, J. R. (1991). Undergraduate psychology students' views of counselors, psychiatrists, and psychologists: A challenge to academic psychologists. Professional Psychology: Research and Practice, 22, 138-140. 
Watson, D., Clark, L. A., \& Tellegen, A. (1988). Development and validation of brief measures of positive and negative affect: The PANAS scales. Journal of Personality and Social Psychology, 54, 1063-1070.

Webb, A. R., \& Speer, J. R. (1985). The public image of psychologists. American Psychologist, 40, 1063-1064.

Webb, A. R., \& Speer, J. R. (1986). Prototype of a profession: Psychology's public image. Professional Psychology: Research and Practice, 17, 5-9.

Webb, K. L., Dobson, A. J., O’Connell, D. L., Tupling, H. E., Harris, G. W., Moxon, J. A., Sulway, M. J., Leeder, S. R. (1983). Dietary compliance among insulindependent diabetics. Journal of Chronic Disease, 37, 633-643.

Webb, R. C. (1999). Psychology of the consumer and its development: An introduction. New York: Kluwer/Plenum.

Weinberger, J., \& Eig, A. (1999). Expectancies: The ignored factor in psychotherapy. In I. Kirsch (Ed.), How expectancies shape experience (pp. 357-382). Washington, DC: American Psychological Association.

Weiner, B., \& Litman-Adizes, T. (1980). An attributional, expectancy-value analysis of learned helplessness and depression. In J. Garber \& M. E. P. Seligman (Eds.), Human helplessness: Theory and applications (pp. 35-57). New York: Academic Press.

Weinfurt, K. P. (2000). Repeated measures analyses: ANOVA, MANOVA, and HLM. In L. G. Grimm \& P. R. Yarnold (Eds.), Reading and understanding more multivariate statistics (pp. 317-361). Washington, DC: American Psychological Association. 
Wells, K. B., Golding, J. M., \& Burnam, M. A. (1988). Psychiatric disorder in a sample of the general population with and without chronic medical conditions. American Journal of Psychiatry, 145, 976-981.

West Virginia Bureau for Public Health. (1998). Behavioral risk factor survey, 1997. Charleston, WV: West Virginia Department of Health and Human Services.

West Virginia Bureau for Public Health. (2001). West Virginia Healthy People 2010 objectives. Retrieved from http://www.wvdhhr.org/bph/hp2010/objective/5.htm

Wiggins, J. G. (1994). Would you want you child to be a psychologist? American Psychologist, 49, 485-492.

Wilkinson, G. (1991). Psychological problems and psychiatric disorders in diabetes mellitus. In J. Pickup \& G. Williams (Eds.), Textbook of diabetes (vol. 2, pp. 784791). London: Blackwell Scientific Publications.

Williams, A., Stephans, R., McKnight, T., \& Dodd, S. (1991). Factors affecting adherence of end-stage renal disease patients to an exercise programme. British Journal of Sports Medicine, 25, 89-93.

Wilson, G. L., \& Flammang, M. R. (1990). Treatment acceptability of alternative formats of behavioral marital therapy. Scandinavian Journal of Behaviour Therapy, 19, 87-99.

Wilson, G. L., Flammang, M. R., \& Dehle, C. M. (1992). Therapeutic formats in the resolution of relationship dysfunction: An acceptability investigation. Journal of Sex and Marital Therapy, 18, 20-33. 
Wilson, G. L., \& Wilson, L. J. (1991). Treatment acceptability of alternative sex therapies: A comparative analysis. Journal of Sex and Marital Therapy, 17, 3544.

Witschi, J. C., Singer, M., Wu-Lee, M., \& Stare, F. S. (1978). Family cooperation and effectiveness in a cholesterol-lowering diet. Journal of the American Dietetic Association, 72, 384-389.

Witt, J. C., \& Elliott, S. N. (1985). Acceptability of classroom management strategies. In T. R. Kratochwill (Ed.), Advances in school psychology (vol. 4, pp. 251-288). Hillsdale, NJ: Erlbaum.

Witt, J. C., Elliott, S. N., \& Martens, B. K. (1984). Acceptability of behavioral interventions used in classrooms: The influence of amount of teacher time, severity of behavior problems, and type of intervention. Behavior Disorders, 9, 95-104.

Witt, J. C., \& Martens, B. K. (1983). Assessing the acceptability of behavioral interventions used in the classrooms. Psychology in the Schools, 20, 510-517.

Witt, J. C., Martens, B. K., \& Elliott, S. N. (1984). Factors affecting teachers' judgments of the acceptability of behavioral interventions: Time involvement, behavior problem severity, and type of intervention. Behavior Therapy, 15, 204-209.

Witt, J. C., Moe, G., Gutkin, T. B., \& Andrews, L. (1984). The effect of saying the same thing in different ways: The problem of language and jargon in school-based consultation. Journal of School Psychology, 22, 361-367. 
Witt, J. C., \& Robbins, J. R. (1985). Acceptability of reductive interventions for the control of inappropriate child behavior. Journal of Abnormal Child Psychology, 13, 59-67.

Wolf, M. M. (1978). Social validity: The case for subjective measurement of how applied behavior analysis is finding its heart. Journal of Applied Behavior Analysis, 11, 203-214.

Wollersheim, D. M., \& Walsh, J. A. (1993). Clinical psychologists: Professionals without a role? Professional Psychology: Research and Practice, 24, 171-175.

Wong, J. L. (1994). Lay theories of psychotherapy and perceptions of therapists: A replication and extension of Furnham and Wardley. Journal of Clinical Psychology, 50, 624-632.

Wood, W., Jones, M., \& Benjamin, L. T., Jr. (1986). Surveying psychology's public image. American Psychologist, 41, 947-953.

Woolfolk, A. E., Woolfolk, R. C., \& Wilson, G. T. (1977). A rose by any other name...: Labeling bias and attitudes toward behavior modification. Journal of Consulting and Clinical Psychology, 45, 184-191.

Woolfolk, R. C., \& Woolfolk, A. E. (1979). Modifying the effect of the behavior modification label. Behavior Therapy, 10, 575-578.

Yoshinobu, L. R. (1989). Construct validation of the hope scale: Agency and pathways components. Masters thesis. University of Kansas, Lawrence, Kansas.

Zeldow, P. B., \& Greenberg, R. P. (1980). Who goes where: Sex-role differences in psychological and medical help-seeking. Journal of Personality Assessment, 44, 433-435. 
Zwick, R., \& Attkisson, C. C. (1985). Effectiveness of a client pretherapy orientation videotape. Journal of Counseling Psychology, 32, 514-524. 


\section{APPENDIXES}

Appendix A: Demographic Questionnaire Appendix B: Health Preferences Questionnaire Appendix C: Dispositional Hope Scale

Appendix D: Diabetes Quality of Life Measure 
Appendix A: Demographic Questionnaire 


\section{About You...}

1.) Age:

2.) Gender: Female Male

3.) Marital status: Single (never married)

Separated or Divorced

Married

Widowed

4.) Race:

5.) Religious affiliation:

6.) Diabetes Type: type 1 type 2

7.) Years since diabetes diagnosis: months years

8.) Have you ever seen a mental health professional (e.g., counselor, social worker, psychologist, psychiatrist)? Yes No

9.) Have you ever participated in a diabetes support group?

- Yes

10.) How far do you travel to this clinic? miles

11.) I live in (city) 
Appendix B: Health Preferences Questionnaire 
Health Preferences Questionnaire

Directions Answer questions 1 through 7 with this in mind:

Patients with diabetes regularly experience emotional difficulties (e.g., worries, tension, anxiety, nerves, stress, sadness, etc.). Imagine that you were experiencing diabetes-related emotional difficulties.

For questions 1 through 5, please circle one number for each item. For example, if you felt that it was "MAYBE" likely that you would do something, you would circle "3."

EXAMPLE

NEVER PROBABLY NOT MAYBE

PROBABLY

DEFINITELY

$\begin{array}{lllll}1 & 2 & 3 & 4 & 5\end{array}$

1. How willing would you be to seek help, in general?

$\begin{array}{ccccc}\text { NEVER } & \text { PROBABLY NOT } & \text { MAYBE } & \text { PROBABLY } & \text { DEFINITELY } \\ 1 & 2 & 3 & 4 & 5\end{array}$

2. How willing would you be to:

NEVER PROBABLY NOT MAYBE PROBABLY DEFINITELY

a. Participate in counseling?

1

b. Incorporate dietary changes?

1

3

4

5

c. Participate in an exercise program?

12

3

4

5

d. Take additional medication?

1

2

3

4

5

e. Participate in relaxation training?

1

3

4

5

f. Participate in a support group? 
3. How effective do you think the following interventions would be?
a. Counseling
12
3
4
5
b. Dietary changes
1
2
3
4
5
c. Exercise program
d. Medication
1
2
3
4
5
e. Relaxation training
f. Support group
1

2
3
4
5
2
3
4
5
2
3
4
5

4. How willing would you be to seek help from the following individuals?
a. Behavioral Medicine
Specialist
a. Behavioral Medicine
Specialist
b. Counselor/ Social Worker

2
3
4
5
c. Diabetes Educator

2
3
4
5
d. Exercise Physiologist
2
3
4
5
e. Friend/Family Member 1
2

3
4
5
f. Health Psychologist

2
3
4
5
g. Minister/Pastor
2
3
4
5
h. Nurse
2
3
4
5
i. Nutritionist
2
3
4
5
j. Pharmacist
2
3
4
5
k. Physician/Doctor
1. Psychiatrist

1
2
2
3
4
5
m. Psychologist (general) 1
2
3
4
5
5 NEVER PROBABLY NOT MAYBE PROBABLY

DEFINITELY 
5. How effective do you think the following individuals would be for you?
a. Behavioral Medicine Specialist NEVER PROBABLY NOT MAYBE
PROBABLY
b. Counselor/
2
3
4
5
Social Worker
c. Diabetes Educator 1
2
3
4
5
d. Exercise Physiologist 1
2
3
4
5
e. Friend/Family Member 1
2
3
4
5
f. Health Psychologist 1
2
3
4
5
g. Minister/Pastor
2
3
4
5
h. Nurse
2
3
4
5
i. Nutritionist
2
3
4
5
j. Pharmacist
2
3
4
5
k. Physician/Doctor
1. Psychiatrist
12
m. Psychologist (general) 1
2

$3 \quad 4 \quad 5$

DEFINITELY

6. If you did seek help from a medical professional, would you prefer that they were male or female? (check one)

Male Female No Preference

7. If you did seek help from a psychological professional, would you prefer that they were male or female? (check one) Male Female No Preference

8. Has anyone ever mentioned using exercise psychology services to you?

No Yes

If yes, who: 
Appendix C: Dispositional Hope Scale 
The Futures Scale

Directions: Read each item carefully. Using the scale shown below, please select the number that best describes YOU, and put the number in the blank provided.

$1=$ Definitely False $\quad 2=$ Mostly False $\quad 3=$ Mostly True $\quad 4=$ Definitely True

_ 1. I can think of many ways to get out of a jam.

2. I energetically pursue my goals.

3. I feel tired most of the time.

4. There are lots of ways around any problem.

5. I am easily downed in an argument.

6. I can think of many ways to get the things in life that are most important to me.

7. I worry about my health.

8. Even when others get discouraged, I know I can find a way to solve the problem.

9. My past experiences have prepared me well for the future.

10. I've been pretty successful in life.

11. I usually find myself worrying about something.

12. I meet the goals that I set for myself. 
Appendix D: Diabetes Quality of Life Measure 


\section{Please circle the appropriate response.}

SATISFACTION:

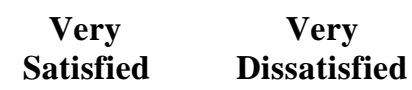

1. How satisfied are you with the amount of time it takes to $\begin{array}{lllll}1 & 2 & 3 & 4 & 5\end{array}$ manage your diabetes?

2. How satisfied are you with the amount of time you spend $\begin{array}{llllll}1 & 2 & 3 & 4 & 5\end{array}$ getting check-ups?

3. How satisfied are you with the time it takes do determine $\begin{array}{llllll}1 & 2 & 3 & 4 & 5\end{array}$ your sugar level?

4. How satisfied are you with your current treatment?

$\begin{array}{lllll}1 & 2 & 3 & 4 & 5\end{array}$

5. How satisfied are you with the flexibility you have in $\begin{array}{lllll}1 & 2 & 3 & 4 & 5\end{array}$ your diet?

6. How satisfied are you with the burden your diabetes is $\begin{array}{lllll}1 & 2 & 3 & 4 & 5\end{array}$ placing on your family?

7. How satisfied are you with your knowledge about your $\quad \begin{array}{llllll}1 & 2 & 3 & 4 & 5\end{array}$ diabetes?

8. How satisfied are you with your sleep? $\quad 1 \quad 2 \quad 3 \quad 4 \quad 5$

9. How satisfied are you with your social relationships and $\begin{array}{llllll}1 & 2 & 3 & 4 & 5\end{array}$ friendships?

10. How satisfied are you with your sex life? $\quad \begin{array}{lllll}1 & 2 & 3 & 4 & 5\end{array}$

11. How satisfied are you with your work, school, and $\quad \begin{array}{lllll}1 & 2 & 3 & 4 & 5\end{array}$ household activities?

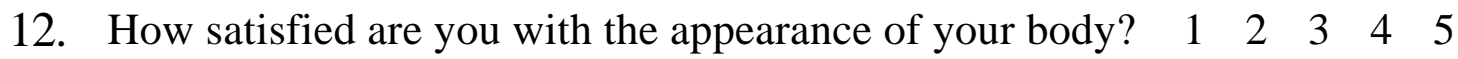

13. How satisfied are you with the time you spend $\quad \begin{array}{lllll}1 & 2 & 3 & 4 & 5\end{array}$ exercising?

14. How satisfied are you with your leisure time? $\quad \begin{array}{lllll}1 & 2 & 3 & 4 & 5\end{array}$

15. How satisfied are you with life in general? $\quad \begin{array}{lllll}1 & 2 & 3 & 4 & 5\end{array}$ 
IMPACT:

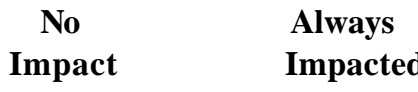

1. How often do you feel pain associated with the treatment of $\quad \begin{array}{lllll}1 & 2 & 3 & 4 & 5\end{array}$ your diabetes?

2. How often are you embarrassed by having to deal with your $\begin{array}{llllll}1 & 2 & 3 & 4 & 5\end{array}$ diabetes in public?

3. How often do you have low blood sugar?

$\begin{array}{lllll}1 & 2 & 3 & 4 & 5\end{array}$

4. How often do you feel physically ill?

$\begin{array}{lllll}1 & 2 & 3 & 4 & 5\end{array}$

5. How often does you diabetes interfere with your social

$\begin{array}{lllll}1 & 2 & 3 & 4 & 5\end{array}$ relationships and friendships?

6. How often do you have a bad night's sleep?

$\begin{array}{lllll}1 & 2 & 3 & 4 & 5\end{array}$

7. How often do you find your diabetes limiting your social

$\begin{array}{lllll}1 & 2 & 3 & 4 & 5\end{array}$ relationships and friendships?

8. How often do you feel good about yourself?

9. How often do you feel restricted by your diet?

$\begin{array}{lllll}1 & 2 & 3 & 4 & 5\end{array}$

10. How often does your diabetes interfere with your sex life?

$\begin{array}{lllll}1 & 2 & 3 & 4 & 5\end{array}$

11. How often does your diabetes keep you from driving a car or using a machine (e.g., a typewriter)?

12. How often does your diabetes interfere with exercising?

$\begin{array}{lllll}1 & 2 & 3 & 4 & 5\end{array}$

13. How often do you miss work, school, or household duties

$\begin{array}{lllll}1 & 2 & 3 & 4 & 5\end{array}$ because of your diabetes?

14. How often do you find yourself explaining what it means to $\begin{array}{llllll}1 & 2 & 3 & 4 & 5\end{array}$ have diabetes?

15. How often do you find that your diabetes interrupts your leisure-time activities?

16. How often do you tell others about your diabetes?

$\begin{array}{lllll}1 & 2 & 3 & 4 & 5\end{array}$

17. How often are you teased because you have diabetes?

$\begin{array}{lllll}1 & 2 & 3 & 4 & 5\end{array}$

18. How often do you feel that because of your diabetes you go to $\begin{array}{llllll}1 & 2 & 3 & 4 & 5\end{array}$ the bathroom more than others? 
19. How often do you find that you eat something you

$\begin{array}{lllll}1 & 2 & 3 & 4 & 5\end{array}$ shouldn't rather tell someone that you have diabetes?

20. How often do you hide from others the fact that you are $\begin{array}{llllll}1 & 2 & 3 & 4 & 5\end{array}$ having an insulin reaction?

\section{WORRY:}

Social/Vocational:

\section{Never} Worried
Always Worried

1. How often do you worry about whether you will get $\quad \begin{array}{llllll}1 & 2 & 3 & 4 & 5\end{array}$ married?

2. How often do you worry about whether you will have $\begin{array}{lllll}1 & 2 & 3 & 4 & 5\end{array}$ children?

3. How often do you worry about whether you will not get $\begin{array}{lllll}1 & 2 & 3 & 4 & 5\end{array}$ a job?

4. How often do you worry about whether you will be $\quad \begin{array}{llllll}1 & 2 & 3 & 4 & 5\end{array}$ denied insurance?

5. How often do you worry about whether you will be able $\quad \begin{array}{lllll}1 & 2 & 3 & 4 & 5\end{array}$ to complete your education?

6. How often do you worry about whether you will miss $\quad \begin{array}{llllll}1 & 2 & 3 & 4 & 5\end{array}$ work?

7. How often do you worry about whether you will be able $\begin{array}{lllll}1 & 2 & 3 & 4 & 5\end{array}$ to take a vacation or trip?

\section{Diabetes Related:}

1. How often do you worry about whether you will pass $\quad \begin{array}{lllll}1 & 2 & 3 & 4 & 5\end{array}$ out?

2. How often do you worry that your body looks different $\begin{array}{llllll}1 & 2 & 3 & 4 & 5\end{array}$ because you have diabetes?

3. How often do you worry that you will get complications $\begin{array}{llllll}1 & 2 & 3 & 4 & 5\end{array}$ from your diabetes?

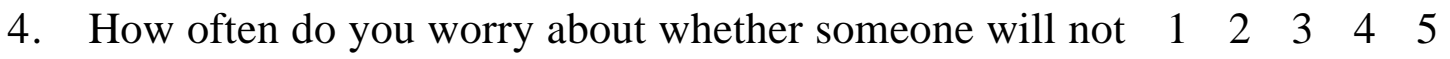
go out with you because you have diabetes? 